Review

\title{
Isomers of Terpyridine as Ligands in Coordination Polymers and Networks Containing Zinc(II) and Cadmium(II)
}

\author{
Catherine E. Housecroft $*$ (D) and Edwin C. Constable \\ Department of Chemistry, University of Basel, BPR 1096, Mattenstrasse 24a, CH-4058 Basel, Switzerland; \\ edwin.constable@unibas.ch \\ * Correspondence: catherine.housecroft@unibas.ch
}

check for updates

Citation: Housecroft, C.E.

Constable, E.C. Isomers of

Terpyridine as Ligands in

Coordination Polymers and

Networks Containing Zinc(II) and

Cadmium(II). Molecules 2021, 26, 3110

https://doi.org/10.3390/

molecules 26113110

Academic Editors: Marina Fonari and Rodica Olar

Received: 1 May 2021

Accepted: 18 May 2021

Published: 23 May 2021

Publisher's Note: MDPI stays neutral with regard to jurisdictional claims in published maps and institutional affiliations.

Copyright: (c) 2021 by the authors. Licensee MDPI, Basel, Switzerland. This article is an open access article distributed under the terms and conditions of the Creative Commons Attribution (CC BY) license (https:// creativecommons.org/licenses/by/ $4.0 /)$.
Abstract: The use of divergent $4,2^{\prime}: 6^{\prime}, 4^{\prime \prime}$ - and $3,2^{\prime}: 6^{\prime}, 3^{\prime \prime}$-terpyridine ligands as linkers and/or nodes in extended coordination assemblies has gained in popularity over the last decade. However, there is also a range of coordination polymers which feature $2,2^{\prime}: 6^{\prime}, 2^{\prime \prime}$-terpyridine metal-binding domains. Of the remaining 45 isomers of terpyridine, few have been utilized in extended coordination arrays. Here, we provide an overview of coordination polymers and networks containing isomers of terpyridine and either zinc(II) and cadmium(II). Although the motivation for investigations of many of these systems is their luminescent behavior, we have chosen to focus mainly on structural details, and we assess to what extent assemblies are reproducible. We also consider cases where there is structural evidence for competitive product formation. A point that emerges is the lack of systematic investigations.

Keywords: 2,2' $: 6^{\prime}, 2^{\prime \prime}$-terpyridine; $3,2^{\prime}: 6^{\prime}, 3^{\prime \prime}$-terpyridine; $4,2^{\prime}: 6^{\prime}, 4^{\prime \prime}$-terpyridine; coordination polymer; coordination network; zinc(II); cadmium(II)

\section{Introduction}

The archetypal terpyridine (tpy) is $2,2^{\prime}: 6^{\prime}, 2^{\prime \prime}$-tpy (Scheme 1 ) which, as undergraduates learn, prefers a terdentate, bis-chelating mode of coordination to a metal ion. A conformational change from s-trans,s-trans to s-cis,s-cis accompanies metal binding (Scheme 1), and mononuclear complexes containing $\left\{\mathrm{M}\left(2,2^{\prime}: 6^{\prime}, 2^{\prime \prime} \text {-tpy }\right)_{2}\right\}$ (Scheme 1$)$ or $\left\{\mathrm{M}\left(2,2^{\prime}: 6^{\prime}, 2^{\prime \prime}\right.\right.$-tpy) $\left.\mathrm{X}_{n}\right\}$ domains are ubiquitous [1-4]. Two points are often missed in discussions of terpyridine coordination chemistry. The first is that metal coordination compounds in which $2,2^{\prime}: 6^{\prime}, 2^{\prime \prime}$-tpy ligands exhibit hypodentate modes are well represented [5]. The second is that, while $2,2^{\prime}: 6^{\prime}, 2^{\prime \prime}$-tpy is indeed the most studied isomer of terpyridine, another 47 isomers can be drawn (Figure S1 in the Supporting Material). In terms of synthesis, some are certainly far more accessible than others. For example, the Kröhnke [6] and one-pot Hanan [7] strategies allow straightforward routes to symmetrical (with respect to the equivalence of the outer pyridine rings) compounds including $3,2^{\prime}: 6^{\prime}, 3^{\prime \prime}$-tpy and 4,2':6', $4^{\prime \prime}$-tpy (Scheme 2), albeit with occasional examples where cyclic products are favored [8]. These synthetic routes also permit functionalization of the tpy unit, in particular, at the $4^{\prime}$-position in $2,2^{\prime}: 6^{\prime}, 2^{\prime \prime}$-tpy, $3,2^{\prime}: 6^{\prime}, 3^{\prime \prime}$-tpy and $4,2^{\prime}: 6^{\prime}, 4^{\prime \prime}$-tpy as illustrated in Scheme 3 for the introduction of an aryl group.

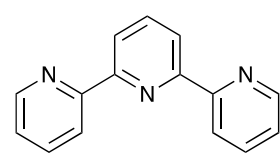

$2,2^{\prime}: 6^{\prime}, 2^{\prime \prime}-$ tpy trans, trans-conformation

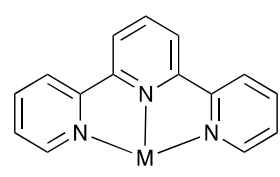

Coordinated 2,2':6',2"-tpy cis, cis-conformation

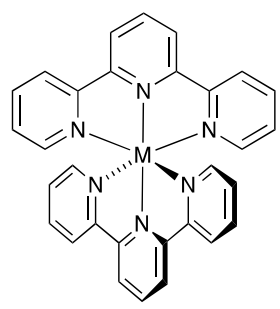

Scheme 1. Structure of $2,2^{\prime}: 6^{\prime}, 2^{\prime \prime}$-terpyridine in the free ligand (left) and in a bis-chelate mode, and a typical $\left\{\mathrm{M}\left(2,2^{\prime}: 6^{\prime}, 2^{\prime \prime} \text {-tpy }\right)_{2}\right\}$ domain containing an octahedral metal center. 


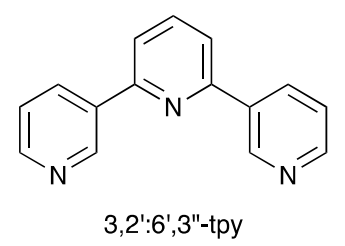<smiles>c1cc(-c2ccncc2)nc(-c2ccncc2)c1</smiles>

Scheme 2. The structures of $3,2^{\prime}: 6^{\prime}, 3^{\prime \prime}$-terpyridine and $4,2^{\prime}: 6^{\prime}, 4^{\prime \prime}$-terpyridine.<smiles>[X]c1ccc(C(=O)c2ccc(C(C)=O)cc2)cc1</smiles>

Scheme 3. Use of the Hanan one-pot strategy [7] to synthesize a $4^{\prime}$-functionalized $4,2^{\prime}: 6^{\prime}, 4^{\prime \prime}$-tpy. The method can be adapted by using 2-acetylpyridine or 3-acetylpyridine precursors to prepare derivatives of $2,2^{\prime}: 6^{\prime}, 2^{\prime \prime}$-tpy or $3,2^{\prime}: 6^{\prime}, 3^{\prime \prime}$-tpy.

This review concerns coordination polymers and networks, and the latter are conveniently considered in terms of combinations of organic linkers and metal nodes, organic nodes and metal linkers, or organic nodes and metal nodes. The coordination geometries of the metal centers, combined with the vectorial properties of the ligand donor sites, are key starting points in the design of an assembly. Inspection of Figure S1 quickly leads to the conclusion that (organic synthetic aspects aside), the choice of an isomer of terpyridine is fundamental to selecting building blocks suitable for a polymeric rather than a discrete molecular assembly. For example, 2,2':6, $3^{\prime \prime}$-tpy (Figure S1) offers a bidentate, chelating site and a remote monodentate site that direct the assembly of a metallomacrocycle rather than a coordination polymer in the reaction of cadmium(II) acetate with ligand 1 (Figure 1) in $\mathrm{MeOH}$ to give $\left[\mathrm{Cd}_{2}(\mathbf{1})_{2}(\mathrm{MeOH})_{2}\left(\mathrm{O}_{2} \mathrm{CMe}\right)_{2}\right]^{2+}$ (Figure 1a) [9]. Some isomers of tpy are conformationally flexible, and this is illustrated in Scheme 4 for 3,2': $6^{\prime}, 3^{\prime \prime}$-tpy for which three planar limiting conformations exist. The ligand conformation can be switched in the solid-state structure by introducing different substituents [10], and this impacts the structures of coordination polymers containing such ligands [11-13]. Note that while conformations $\mathbf{A}$ and $\mathbf{B}$ in Scheme 4 are divergent, conformation $\mathbf{C}$ is convergent and often leads to discrete molecular complexes, for example, the dizinc(II) macrocycle [14] shown in Figure 1b.

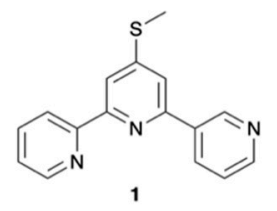

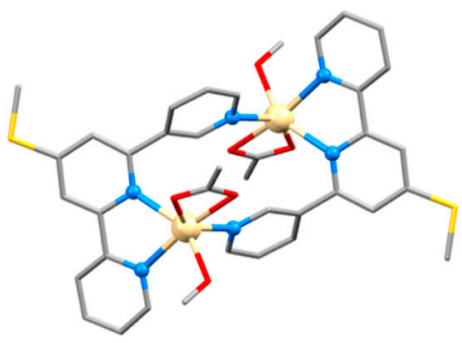

(a)

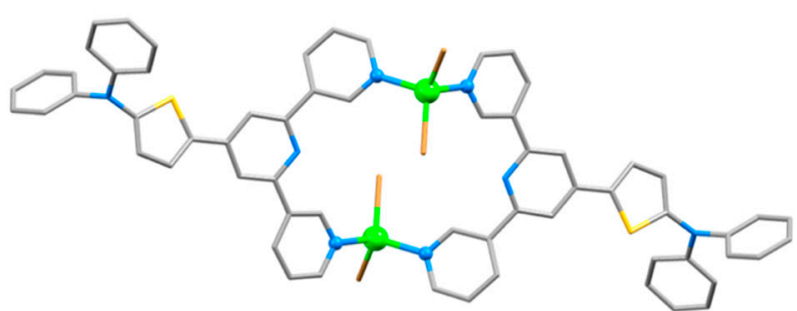

(b)

Figure 1. (a) The structure of ligand 1 (a derivative of $2,2^{\prime}: 6^{\prime}, 3^{\prime \prime}$-tpy) and the metallocycle $\left[\mathrm{Cd}_{2}(\mathbf{1})_{2}(\mathrm{MeOH})_{2}\left(\mathrm{O}_{2} \mathrm{CMe}\right)_{2}\right]^{2+}$, structurally characterized as the $\left[\mathrm{PF}_{6}\right]^{-}$salt (CSD refcode REFFEN). (b) An example of a $4^{\prime}$-functionalized 3,2':6, $3^{\prime \prime}$-tpy in

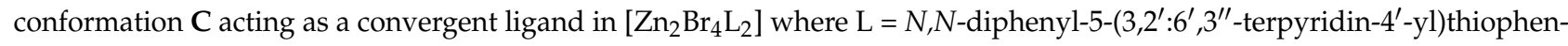
2-amine (CSD refcode ELANIQ). 


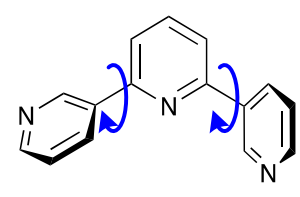<smiles></smiles><smiles></smiles>

Scheme 4. Some isomers of tpy are conformationally flexible, for example, rotation about the inter-ring $\mathrm{C}-\mathrm{C}$ bonds in $3,2^{\prime}: 6^{\prime}, 3^{\prime \prime}$-tpy leads to three planar conformers.

In this review, we focus on coordination polymers and networks that contain zinc(II) and cadmium(II) in combination with isomers of terpyridine. A comprehensive survey of compounds that have been structurally characterized is presented and the content is based upon searches of the Cambridge Structural Database (CSD) [15] made using CSD version 2020.3.1 [16] and ConQuest version 2020.3.1 [16]. We have chosen to exclude detailed discussion of assemblies including co-ligands which function as building blocks. However, we note that co-ligands are one means of extending the dimensionalities of assemblies. We also draw attention to cases where a potential co-ligand added to the reaction mixture (usually under solvothermal conditions) appears to act as a template rather than being incorporated into the coordination assembly. The review is organized according to terpyridine isomer, and the functional groups that the ligand carries, and whether the latter are coordinatively innocent or not. Structural diagrams in this review have been drawn using Mercury 2020.3.1 [17] with coordinates retrieved from the CSD.

\section{2. $2,2^{\prime}: 6^{\prime}, 2^{\prime \prime}$-Terpyridine}

The propensity for $2,2^{\prime}: 6^{\prime}, 2^{\prime \prime}$-tpy to form chelates and thereby function as a monotopic ligand means that the introduction of a coordinatively non-innocent substituent into the $2,2^{\prime}: 6^{\prime}, 2^{\prime \prime}$-tpy unit is typically required to transform an $\left\{\mathrm{M}\left(2,2^{\prime}: 6^{\prime}, 2^{\prime \prime} \text {-tpy }\right)_{2}\right\}$ or $\left\{\mathrm{M}\left(2,2^{\prime}: 6^{\prime}, 2^{\prime \prime}-\right.\right.$ tpy) $\mathrm{X}_{n}$ \} unit into a building block within an extended assembly. There are no examples in the CSD (v. 2020.3.1) [16] of coordination polymers or networks containing $\left\{\mathrm{Zn}\left(2,2^{\prime}: 6^{\prime}, 2^{\prime \prime}\right.\right.$ tpy $\left.)_{2}\right\}$ or $\left\{\mathrm{Cd}\left(2,2^{\prime}: 6^{\prime}, 2^{\prime \prime} \text {-tpy }\right)_{2}\right\}$ units, and the assemblies described in the following sections incorporate $\left\{\mathrm{M}\left(2,2^{\prime}: 6^{\prime}, 2^{\prime \prime}\right.\right.$-tpy $\left.) \mathrm{X}_{n}\right\}$ domains.

\subsection{Assemblies with $\left\{M\left(4^{\prime}-\right.\right.$ pyridinyl-2, $2^{\prime}: 6^{\prime}, 2^{\prime \prime}$-tpy $\left.) X_{n}\right\}(M=Z n, C d)$ Building Blocks}

The incorporation of a $4^{\prime}$-pyridinyl substituent, in particular, $4^{\prime}$-pyridin- 4 -yl, into $2,2^{\prime}: 6^{\prime}, 2^{\prime \prime}$-tpy is frequently employed to transform the ligand into a divergent metal-binding domain. The $1 \mathrm{D}$-coordination polymer $\left[\mathrm{Zn}\left(4^{\prime}-(4-\mathrm{py}) \mathrm{tpy}\right)\left(\mathrm{ONO}_{2}\right)_{2}\right]_{n}$ (Figure 2a) (4'-(4py)tpy $=4^{\prime}$-pyridin-4-yl-2,2': $6^{\prime}, 2^{\prime \prime}$-terpyridine) assembles under solvothermal conditions from $\mathrm{Zn}\left(\mathrm{NO}_{3}\right)_{2} \cdot 6 \mathrm{H}_{2} \mathrm{O}$ and $4^{\prime}$-(4-py)tpy [18]. The chain is linear as a consequence of the octahedral $\mathrm{Zn}(\mathrm{II})$ centers with trans-nitrato ligands (Figure 2a). This contrasts with the zigzag cationic chain found in $\left[\left\{\mathrm{Zn}\left(4^{\prime}-(4-p y) t p y\right)(\mathrm{OAc})\right\}_{n}\right]\left[\mathrm{PF}_{6}\right]_{n}$, in which the $\mathrm{Zn}(\mathrm{II})$ centers are 5-coordinate (Figure 2b) [19].

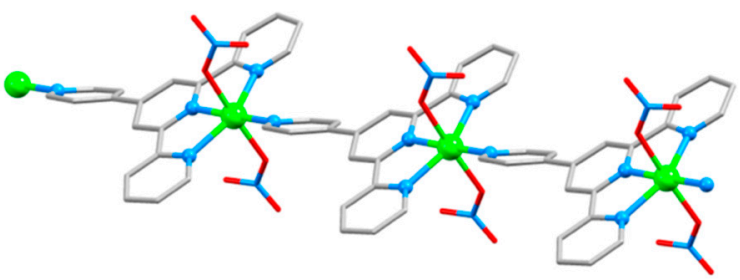

(a)

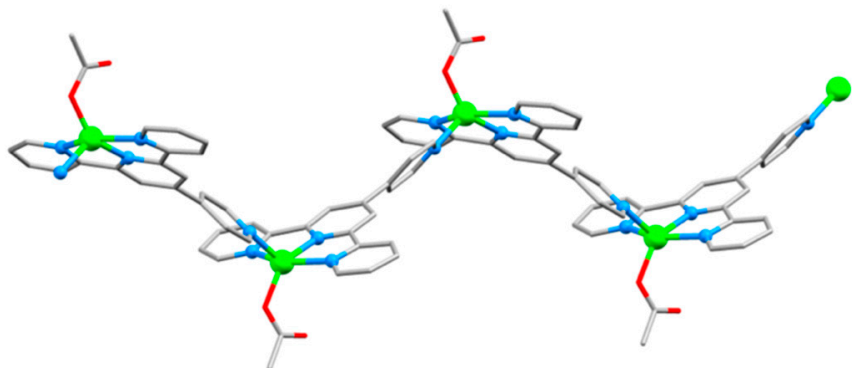

(b)

Figure 2. Parts of the 1D-coordination polymer chains in (a) $\left[\mathrm{Zn}\left(4^{\prime}-(4-p y) \operatorname{tpy}\right)\left(\mathrm{NO}_{3}\right)_{2}\right]_{n}(\mathrm{CSD}$ refcode UPUFOB) and (b) $\left[\left\{\mathrm{Zn}\left(4^{\prime}-(4-\mathrm{py}) \text { tpy }\right)(\mathrm{OAc})\right\}_{n}\right]^{n+}$, isolated as the $\left[\mathrm{PF}_{6}\right]^{-}$salt (refcode WUJREA). 
The vectorial properties of the $\mathrm{M}\left(4^{\prime}\right.$-pyridinyl-2, $2^{\prime}: 6^{\prime}, 2^{\prime \prime}$-tpy) unit can be altered by the movement from a pyridin-4-yl to pyridin-3-yl or pyridin-2-yl substituent. Crystal growth by layering an $\mathrm{MeOH}$ solution of $\mathrm{CdCl}_{2} \cdot \mathrm{H}_{2} \mathrm{O}$ over a THF solution of $4^{\prime}$-pyridin3 -yl-2, $2^{\prime}: 6^{\prime}, 2^{\prime \prime}$-tpy $\left(4^{\prime}\right.$-(3-py)tpy) under ambient conditions resulted in the assembly of $\left[\mathrm{Cd}_{2} \mathrm{Cl}_{4}\left(4^{\prime} \text {-(3-py)tpy)(MeOH) }\right]_{n}\right.$ in which the heterocyclic ligands are linked by tetranuclear 4 -connecting nodes (Figure $3 \mathrm{a}$ ). The structure propagates into a 2D-sheet with a wavelike profile (Figure $3 \mathrm{~b}$ ). In contrast, when thiocyanate replaces chloride ion, a 1D-chain assembles with ditopic ligands interconnected through trinuclear $\left\{\mathrm{Cd}_{3}(\mu-\mathrm{NCS})_{4}\right\}$ units (Figure 3c). Face-to-face $\pi$-interactions between pairs of ligands arranged in a head-to-tail fashion are key packing interactions in both structures shown in Figure 3 [20]. Related assemblies incorporating $\left[1,1^{\prime}\right.$-biphenyl]-2,2'-dicarboxylate as a co-ligand have also been reported [21].

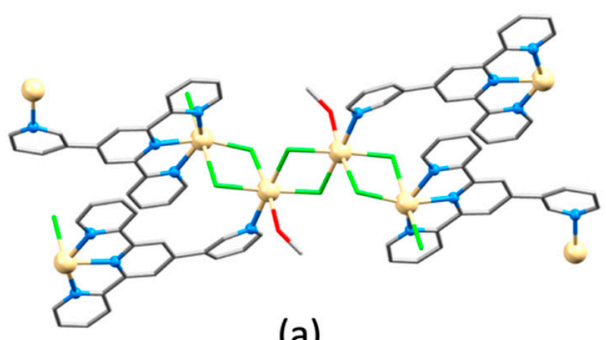

(a)

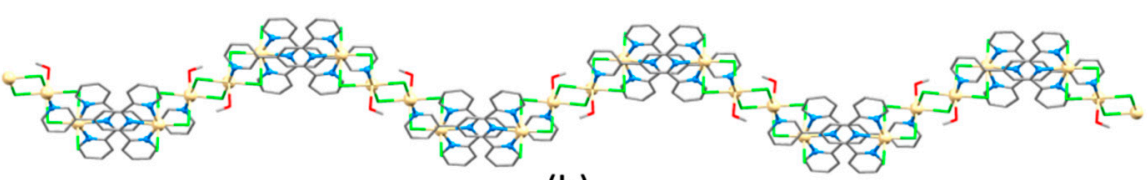

(b)

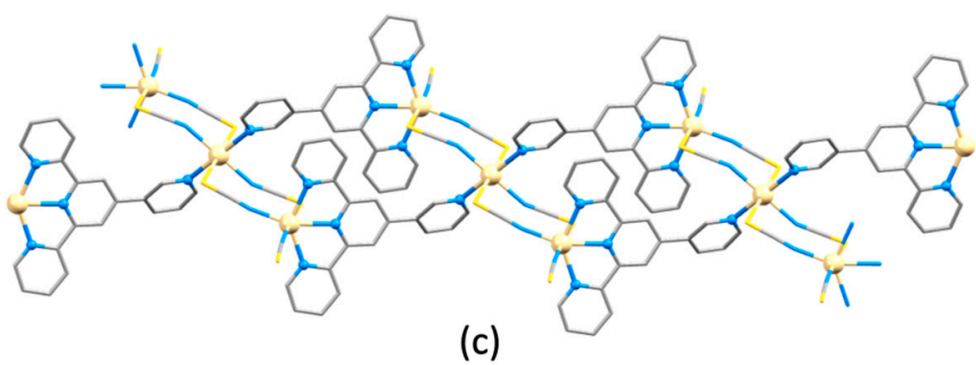

Figure 3. The structure of $\left[\mathrm{Cd}_{2} \mathrm{Cl}_{4}\left(4^{\prime}-(3-\mathrm{py}) \mathrm{tpy}\right)(\mathrm{MeOH})\right]_{n}$ (CSD refcode RIXDOS): (a) ligands are connected by tetracadmium 4-connecting nodes, and (b) 2D-sheets assemble with a wave-like profile. (c) Part of the 1D-chain in $\left[\mathrm{Cd}_{3} \mathrm{SCN}\right)_{6}\left(4^{\prime}-(3-\right.$ py)tpy) $\left.{ }_{2}\right]_{n} \cdot 2 n$ THF (refcode RIXDIM).

\subsection{Assemblies with $\left\{C d\left(4^{\prime}-(4-(5-t e t r a z o l a t o) p h e n y l)-2,2^{\prime}: 6^{\prime}, 2^{\prime \prime}\right.\right.$-tpy) $\left.X_{n}\right\}$ Building Blocks}

Several cadmium(II)-containing coordination polymers featuring the conjugate bases of $4^{\prime}$-(4-(tetrazol-5-yl)phenyl)-2, $2^{\prime}: 6^{\prime}, 2^{\prime \prime}$-terpyridine, $\mathrm{H} 2$, and $4^{\prime}$-( $4^{\prime}$-(tetrazol-5-yl)-[1, $1^{\prime}$ biphenyl]-4-yl)-2,2': $6^{\prime}, 2^{\prime \prime}$-terpyridine, $\mathrm{H} 3$, have been described, four as communications to the CSD [22-25]. [CdCl(2) $]_{n} \cdot n \mathrm{H}_{2} \mathrm{O}$ and $\left.[\mathrm{CdBr}(2)]_{n} \cdot n \mathrm{H}_{2} \mathrm{O}\right]$ are isostructural $[22,23]$ and form 1D-chains (Figure $4 \mathrm{a}$ ) with $\pi$-interactions between the phenylene ring of one ligand and one outer pyridine ring of the adjacent ligand (centroid ... centroid $=3.84 \AA$ ). The corresponding iodido-derivative has a similar structure [24]. As Figure 4a shows, only one $\mathrm{N}$-donor of the tetrazole is coordinated and ligand $\mathbf{2}^{-}$is ditopic, with each $\mathrm{Cd}(\mathrm{II})$ center being 5-coordinate. In contrast, $3^{-}$acts as a tritopic ligand in $\left[\mathrm{Cd}\left(\mathrm{O}_{2} \mathrm{CH}\right)(3)\right]_{n} \cdot 2 n \mathrm{H}_{2} \mathrm{O}$ and the $\mathrm{Cd}(\mathrm{II})$ is 7 -coordinate (the formate ion is bidentate, Figure $4 \mathrm{~b}$ ) $[25,26]$. The structure propagates into a corrugated 2D-sheet and the sheets pack together as shown in Figure 4c,d. Terpyridine $\mathrm{H} 3$ was designed to possess intra-ligand charge-transfer (ICT) properties to facilitate singlet-triplet inter-system crossing. $\left[\mathrm{Cd}\left(\mathrm{O}_{2} \mathrm{CH}\right)(3)\right]_{n} \cdot 3 n \mathrm{H}_{2} \mathrm{O}[26]$ loses water while retaining the coordination network structure, and the process is fully reversible with a concomitant color change from yellow to orange. This remarkable material exhibits a long persistent luminescence in the dehydrated state, and this is suppressed when water re-enters the lattice. The incorporation of the triazole unit is key to these noteworthy photophysical properties, as is also demonstrated in $\left[\mathrm{Cd}(2)_{2}\right]_{n} \cdot 6.5 n \mathrm{H}_{2} \mathrm{O}$, which exhibits a white-light emission when excited over a range of wavelengths $(286-386 \mathrm{~nm})$. The $\left[\mathrm{Cd}(2)_{2}\right]_{n}$ polymer consists of a double-stranded $1 \mathrm{D}$ chain with the $\mathrm{Cd}(\mathrm{II})$ center in a distorted tetrahedral environment; each $2,2^{\prime}: 6^{\prime}, 2^{\prime \prime}$-tpy and each triazole unit coordinates to a $\mathrm{Cd}(\mathrm{II})$ center through only one $\mathrm{N}$-donor [27]. 


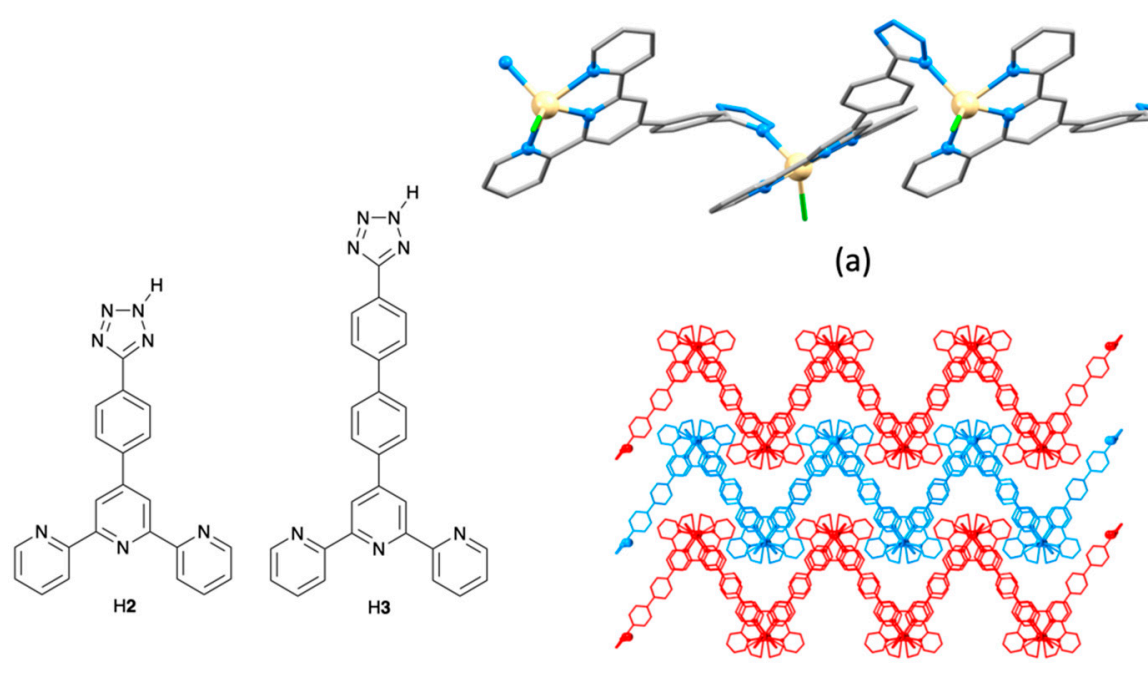

(c)

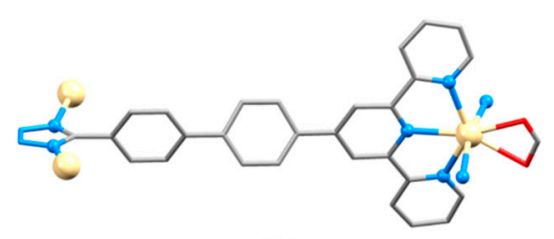

(b)

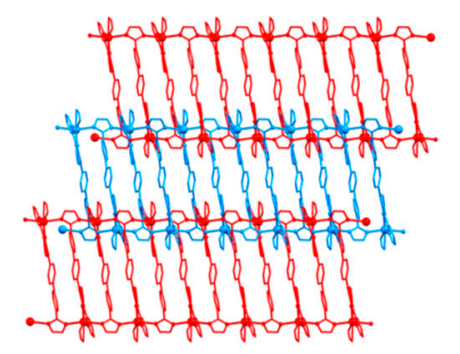

(d)

Figure 4. The structures of $\mathrm{H} 2$ and $\mathrm{H} 3$, and of coordination polymers containing their conjugate bases. (a) Part of the 1D-chain in $[\mathrm{CdCl}(2)]_{n} \cdot n \mathrm{H}_{2} \mathrm{O}$ (CSD refcode QIVRAR). (b) The building block in $\left[\mathrm{Cd}\left(\mathrm{O}_{2} \mathrm{CH}\right)(3)\right]_{n} \cdot 2 n \mathrm{H}_{2} \mathrm{O}$ (refcode PUCBUN). Packing of corrugated 2D-sheets in $\left[\mathrm{Cd}\left(\mathrm{O}_{2} \mathrm{CH}\right)(3)\right]_{n} \cdot 2 n \mathrm{H}_{2} \mathrm{O}$ viewed (c) down the $c$-axis and (d) down the $c$-axis, with adjacent layers colored red and blue.

\subsection{Assemblies Containing Zn(II) and 2,2':6', $2^{\prime \prime}$-tpy Ligands Functionalized with Carboxylate Donors}

Scheme 5 presents the structures of $2,2^{\prime}: 6^{\prime}, 2^{\prime \prime}$-tpy ligands bearing carboxylic acid functionalities that have been combined with zinc(II) or cadmium(II) in structurally characterized assemblies. In this section, we focus on zinc(II)-containing coordination polymers. Although the conjugate base of $\mathrm{H4}$ (Scheme 5) is regularly observed to interconnect $\mathrm{Zn}$ (II) centers into 1D-chains, the choice of zinc(II) salt and the reaction conditions are critical to the detailed assembly. Under hydrothermal conditions at $\mathrm{pH} 11.0, \mathrm{Zn}(\mathrm{OAc})_{2} \cdot 2 \mathrm{H}_{2} \mathrm{O}$ reacts with $\mathrm{H} 4$ to give $\left[\mathrm{Zn}(4)_{2}\right]_{n} \cdot 0.5 n \mathrm{H}_{2} \mathrm{O}$. The structure is a $1 \mathrm{D}$-chain and contains 5 -coordinate $\mathrm{Zn}$ (II) centers. As Figure 5a shows, there are two crystallographically independent ligands, one monodentate, binding only through the $\mathrm{CO}_{2}{ }^{-}$unit and one utilizing both a chelating $2,2^{\prime}: 6^{\prime}, 2^{\prime \prime}$-tpy and monodentate carboxylate to connect two $\mathrm{Zn}$ (II) centers [28]. The structure contrasts with the double-chain exhibited by $\left[\mathrm{Cd}(4)_{2}\right]_{n} \cdot n \mathrm{H}_{2} \mathrm{O}$ (see Section 2.4). Zinc(II) acetate reacted with $\mathrm{H} 4$ under solvothermal conditions in DMF to produce [ $\left[\mathrm{Zn}_{2}(\mu-\right.$ $\left.\left.\mathrm{OAc})_{2}\right\} \mathrm{Zn}(\mathrm{OAc})_{2}(4)_{2}\right]_{n} \cdot n \mathrm{H}_{2} \mathrm{O}$ (Figure 5b) [29]. The structure of the 1D-chain is related to that in $\left[\mathrm{Zn}(4)_{2}\right]_{n} \cdot 0.5 n \mathrm{H}_{2} \mathrm{O}$ in that only one of two crystallographically independent $4^{-}$ligands supports the backbone of the chain. However, the propensity for acetato ligands to be involved in the assembly of dinuclear zinc units makes the two chains in Figure $5 \mathrm{a}, \mathrm{b}$ distinct from one another. Moreover, each pendant $2,2^{\prime}: 6^{\prime}, 2^{\prime \prime}$-tpy domain in $\left[\left\{\mathrm{Zn}_{2}(\mu-\mathrm{OAc})_{2}\right\} \mathrm{Zn}(\mathrm{OAc})_{2}(4)_{2}\right]_{n} \cdot n \mathrm{H}_{2} \mathrm{O}$ binds a $\mathrm{Zn}(\mathrm{OAc})_{2}$ unit (Figure $\left.5 \mathrm{~b}\right)$, in contrast to the non-coordinated $2,2^{\prime}: 6^{\prime}, 2^{\prime \prime}$-tpy units in $\left[\mathrm{Zn}(4)_{2}\right]_{n} \cdot 0.5 n \mathrm{H}_{2} \mathrm{O}$. Combining zinc(II) acetate with $\mathrm{H} 4$ under solvothermal conditions $\left(\mathrm{H}_{2} \mathrm{O} / \mathrm{MeCN}\right.$ concentrated $\left.\mathrm{HCl}, 160{ }^{\circ} \mathrm{C}\right)$ led to the assembly depicted in Figure 5c. Chlorido ligands are incorporated at the expense of acetato units and a simple 1D-chain forms in $\left[\mathrm{Zn}_{2} \mathrm{Cl}_{2}(4)_{2}\right]_{n} \cdot 0.5 n \mathrm{H}_{2} \mathrm{O}$. Although Figure $5 c$ illustrates alternating 5- and 6-coordinate $\mathrm{Zn}$ (II) centers, the difference is described by the authors as 'subtle'; the $\mathrm{Zn}-\mathrm{O}$ distances are 2.047(4) and 2.468(5) $\AA$ for the bidentate $\mathrm{CO}_{2}{ }^{-}$, and 1.947(4) and 3.408(4) $\AA$ for the monodentate $\mathrm{CO}_{2}{ }^{-}$. An interesting feature of this structure is that adjacent chains interact through efficient face-to-face $\pi$-stacking of arene rings, and Hong and coworkers [30] describe the final assembly as a ' $2 \mathrm{D}+2 \mathrm{D} \rightarrow 3 \mathrm{D}$ inclined polycatenated coordination polymer' with the interchain $\pi$-stacking underpinning the higher dimensionality description. In the same work, Hong and coworkers showed that a change from zinc(II) acetate to nitrate and reaction with $\mathrm{H} 4$ under the same conditions (solvothermal in $\mathrm{H}_{2} \mathrm{O} / \mathrm{MeCN}$ with concentrated $\mathrm{HCl}$ at $160{ }^{\circ} \mathrm{C}$ ) leads to the 
formation of $\left[\mathrm{Zn}(4)_{2}\right]_{n} \cdot 2.5 n \mathrm{H}_{2} \mathrm{O}$. This comprises a $1 \mathrm{D}$-chain analogous to that shown in Figure 5a. However, in $\left[\mathrm{Zn}(4)_{2}\right]_{n} \cdot 2.5 n \mathrm{H}_{2} \mathrm{O}$ (which crystallizes in the triclinic $P-1$ space group, refcode GEYTIP), the pendant $2,2^{\prime}: 6^{\prime}, 2^{\prime \prime}$-tpy unit was presented with a cis,cis conformation [30] rather than the trans, trans conformation found in $\left[\mathrm{Zn}(4)_{2}\right]_{n} \cdot 0.5 n \mathrm{H}_{2} \mathrm{O}$ (space group C2/c) [28]. The latter is more usual for a non-coordinated $2,2^{\prime}: 6^{\prime}, 2^{\prime \prime}$-tpy, and the atypical conformation in $\left[\mathrm{Zn}(4)_{2}\right]_{n} \cdot 2.5 n \mathrm{H}_{2} \mathrm{O}$ is not discussed by the authors. Finally in this series, a communication to the CSD [31] provides the structure of $[\mathrm{ZnCl}(4)]_{n} \cdot\left[\mathrm{ZnCl}\left(\mathrm{OH}_{2}\right)(4)\right]_{n}$. Two different 1D-coordination polymers are present in the lattice. The first comprises single $\left[\mathrm{ZnCl}\left(\mathrm{OH}_{2}\right)(4)\right]_{n}$ chains in which each 6-coordinate $\mathrm{Zn}(\mathrm{II})$ center is bound by chelating $2,2^{\prime}: 6^{\prime}, 2^{\prime \prime}$-tpy, bidentate $\mathrm{CO}_{2}{ }^{-}$and an aqua ligand. The backbone of the bridging ligand $4^{-}$ is markedly bowed (Figure $5 \mathrm{~d}$ ). The second polymer $[\mathrm{ZnCl}(4)]_{n}$ differs from the first in having no coordinated $\mathrm{H}_{2} \mathrm{O}$ and in possessing a double-stranded chain (Figure 5e). The $\mathrm{Zn}-\mathrm{O}$ bond lengths within the carboxylate chelate ring are 2.226(5) and 2.399(3) $\AA$, while the $\mathrm{Zn}-\mathrm{O}$ distance between the two strands is 2.573(4) $\AA$. Figure $5 \mathrm{f}$ illustrates the role of $\pi$-stacking within the double-stranded chain, and between the two different chains in $[\mathrm{ZnCl}(4)]_{n} \cdot\left[\mathrm{ZnCl}\left(\mathrm{OH}_{2}\right)(4)\right]_{n}$.

Compounds $\mathrm{H} 5$ and $\mathrm{H} 6$ (see Section 2.4) are related to $\mathrm{H} 4$ by the introduction of $\mathrm{OCH}_{2}$ and $\mathrm{OC}_{6} \mathrm{H}_{4}$ spacers, respectively (Scheme 5). The reaction of $\mathrm{ZnCl}_{2}$ with $\mathrm{H} 5$ under hydrothermal conditions produced the $1 \mathrm{D}$-coordination polymer $[\mathrm{ZnCl}(5)]_{n} \cdot 0.5 n \mathrm{H}_{2} \mathrm{O}[32]$. Structurally, this is similar to $\left[\mathrm{Zn}_{2} \mathrm{Cl}_{2}(4)_{2}\right]_{n} \cdot 0.5 n \mathrm{H}_{2} \mathrm{O}$ (Figure $5 \mathrm{c}$ ), but differs in having one crystallographically independent $\{\mathrm{ZnCl}(\mathrm{tpy})\}$ unit (Figure 6a). The lattice $\mathrm{H}_{2} \mathrm{O}$ molecules are involved in $\mathrm{C}-\mathrm{H}$... O hydrogen bonds and link the polymer chains into a 2D-sheet. $\mathrm{Hu}$ and coworkers extended this investigation to include the co-ligands terephthalic acid, fumaric acid, succinic acid and adipic acid [32]. Although coordination assemblies between Cd(II) and H7 (Scheme 5) have been reported (see Section 2.4), no coordination polymers with $\mathrm{Zn}$ (II) have been structurally characterized. Both dicarboxylic acids $\mathrm{H}_{2} 8$ and $\mathrm{H}_{2} 9$ form extended structures with $\mathrm{Zn}(\mathrm{II})$. Under solvothermal conditions (DMF $/ \mathrm{H}_{2} \mathrm{O}, 160{ }^{\circ} \mathrm{C}$ ), $\mathrm{ZnSO}_{4} \cdot 6 \mathrm{H}_{2} \mathrm{O}$ and $\mathrm{H}_{2} 8$ combine to give $[\mathrm{Zn}(8)]_{n}$ (Figure $6 \mathrm{~b}$ ). The presence of the two $\mathrm{CO}_{2}{ }^{-}$ groups per ligand facilitates the assembly of a double-stranded chain [33]. This may be compared to the double-stranded chain found in $[\mathrm{ZnCl}(4)]_{n} \cdot\left[\mathrm{ZnCl}\left(\mathrm{OH}_{2}\right)(4)\right]_{n}$ (Figure $5 \mathrm{e}$ ), but the additional carboxylate groups lead to distinct differences in the dinuclear building blocks in the 1D-chain. Polymer $[\mathrm{Zn}(8)]_{n}$ was used as a sensor for $\mathrm{Cr}^{3+}$ ions through enhancement of fluorescence. $\mathrm{H}_{2} 9$ reacts with zinc(II) nitrate under solvothermal conditions $\left(\mathrm{MeCN} / \mathrm{H}_{2} \mathrm{O}, 12{ }^{\circ} \mathrm{C}\right)$ to give single crystals of $[\mathrm{Zn}(9)]_{n} \cdot n \mathrm{H}_{2} \mathrm{O}$ which possesses a $2 \mathrm{D}$ network (Figure 6c). Each $\mathrm{Zn}$ (II) center is 5-coordinate and each $\mathbf{9}^{2-}$ ligand is tritopic through the use of a chelating tpy unit and two monodentate carboxylates. The assembly is, therefore, a $\left\{6^{3}\right\}$ net. When the reaction is carried out in N-methyl-2-pyrrolidone (NMP) and methanol at $95^{\circ} \mathrm{C}$, the assembly switches to a 3D-net (Figure 6d) with a ths topology. Although ligand $\mathbf{9}^{2-}$ again acts as a 3 -connecting node in $[\mathrm{Zn}(9)]_{n} \cdot 2 n \mathrm{MeOH} \cdot n \mathrm{NMP}$; the difference in the $[\mathrm{Zn}(9)]_{n}$ structure found for the two solvates arises from a change in directionality of the $\mathrm{O}-\mathrm{Zn}$ vectors (Figure 6e). It is interesting to note that the change in topology is associated with a change from the monoclinic $P 2{ }_{1} / n$ space group to the orthorhombic Fdd2 space group. [Zn(9) $]_{n} \cdot 2 n \mathrm{MeOH} \cdot n \mathrm{NMP}$ exhibits a high capture capacity for $\mathrm{CO}_{2}$ with an unusual multistep gas-adsorption process [34]. 
<smiles>O=C(O)c1ccc(-c2cc(-c3ccccn3)nc(-c3ccccn3)c2)cc1</smiles>

$\mathrm{H} 4$<smiles>O=C(O)c1ccc(-c2cc(-c3ccccn3)nc(-c3ccccn3)c2)cc1C(=O)O</smiles>

$\mathrm{H}_{2} 8$<smiles>O=C(O)COc1ccc(-c2cc(-c3ccccn3)nc(-c3ccccn3)c2)cc1</smiles>

H5<smiles>O=C(O)c1cc(C(=O)O)cc(-c2cc(-c3ccccn3)nc(-c3ccccn3)c2)c1</smiles>

$\mathrm{H}_{2} 9$<smiles>O=C(O)c1ccc(Oc2ccc(-c3cc(-c4ccccn4)nc(-c4ccccn4)c3)cc2)cc1</smiles>

H6<smiles>[R]c1cc(-c2cc(C(=O)O)ccn2)nc(-c2cc(C(=O)O)ccn2)c1</smiles>

$\mathrm{H}_{2} 10 \mathrm{R}=$ phenyl

$\mathrm{H}_{2} 11 \mathrm{R}=$ furan-2-yl<smiles>O=C(O)c1cccc(-c2cc(-c3ccccn3)nc(-c3ccccn3)c2)c1</smiles>

$\mathrm{H} 7$<smiles>O=C(O)c1ccnc(-c2cc(C(=O)O)cc(-c3cc(C(=O)O)ccn3)n2)c1</smiles>

Scheme 5. Carboxylic acid-functionalized 2,2' $: 6^{\prime}, 2^{\prime \prime}$-tpy ligands.

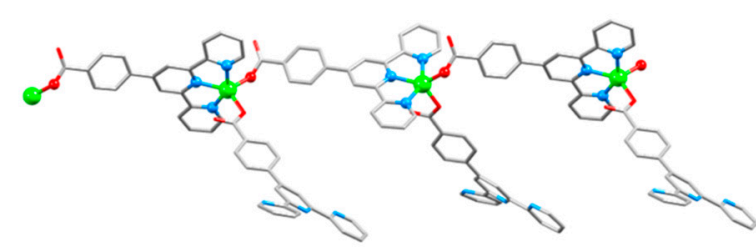

(a)

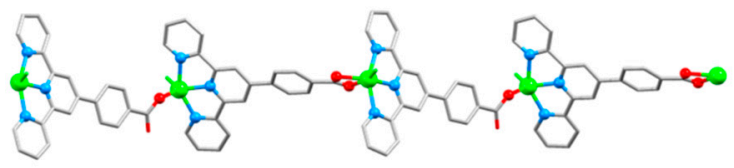

(c)

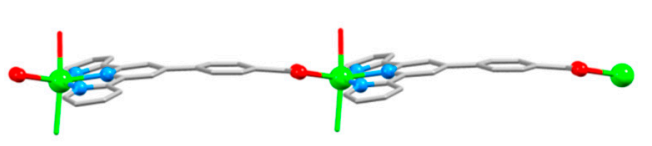

(d)

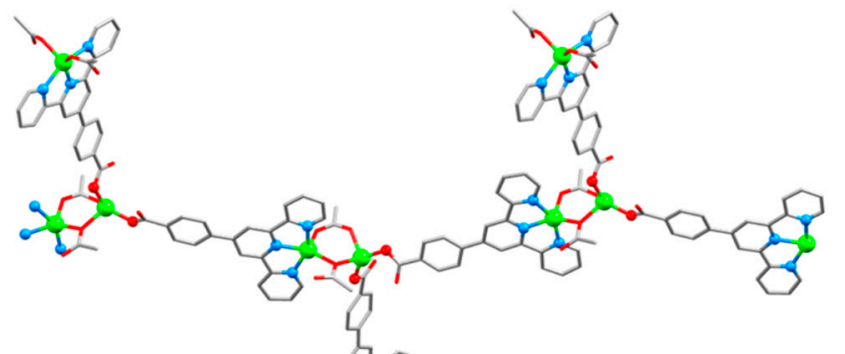

(b)

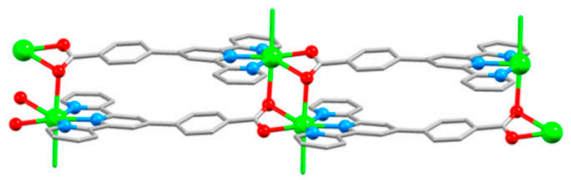

(e)

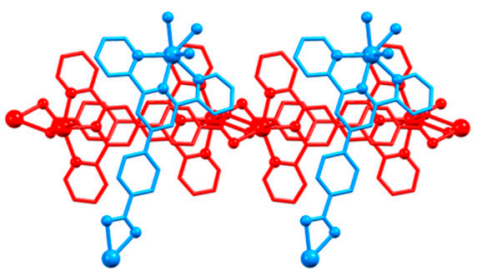

(f)

Figure 5. Parts of the $1 \mathrm{D}$-coordination polymer chains in (a) $\left[\mathrm{Zn}(4)_{2}\right]_{n} \cdot 0.5 n \mathrm{H}_{2} \mathrm{O}\left(\mathrm{CSD}\right.$ refcode CEJBAW), (b) [\{Zn ${ }_{2}(\mu-$ $\left.\left.\mathrm{OAc})_{2}\right\} \mathrm{Zn}(\mathrm{OAc})_{2}(4)_{2}\right]_{n} \cdot n \mathrm{H}_{2} \mathrm{O}$ (recode DUBWUV), and (c) $\left[\mathrm{Zn}_{2} \mathrm{Cl}_{2}(4)_{2}\right]_{n} \cdot 0.5 n \mathrm{H}_{2} \mathrm{O}$ (refcode GEYSOU). The structure of $[\mathrm{ZnCl}(4)]_{n} \cdot\left[\mathrm{ZnCl}\left(\mathrm{OH}_{2}\right)(4)\right]_{n}$ (refcode NUCBAR) contains both (d) single $\left[\mathrm{ZnCl}\left(\mathrm{OH}_{2}\right)(4)\right]_{n}$ 1D-polymers, and (e) doublestranded $[\mathrm{ZnCl}(4)]_{n}$ polymers; (f) $\pi$-stacking within the double-stranded chain (red) and between the two different chains (red and blue) is the dominant packing interaction in $[\mathrm{ZnCl}(4)]_{n} \cdot\left[\mathrm{ZnCl}\left(\mathrm{OH}_{2}\right)(4)\right]_{n}$. 


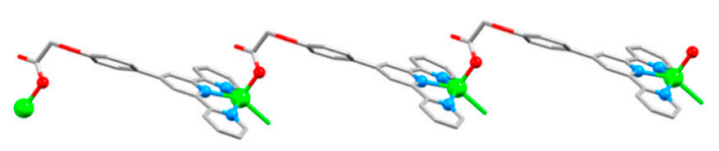

(a)

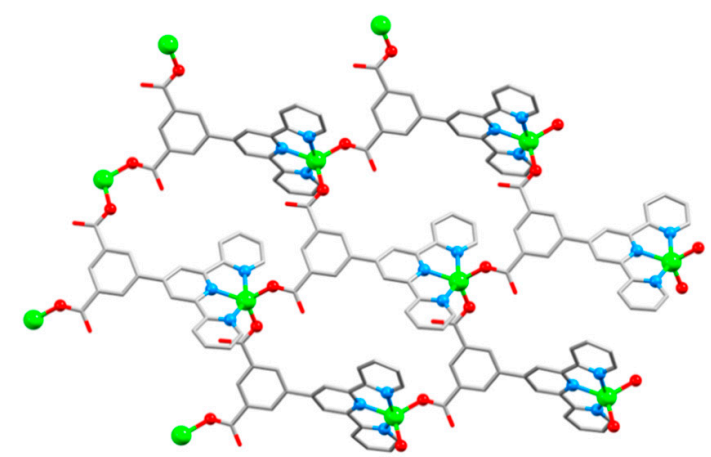

(c)

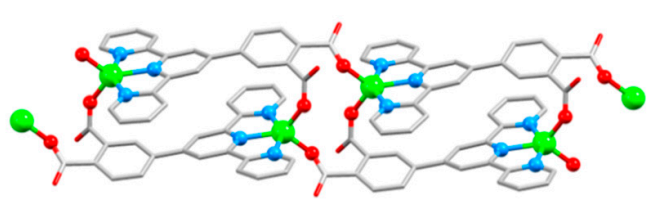

(b)

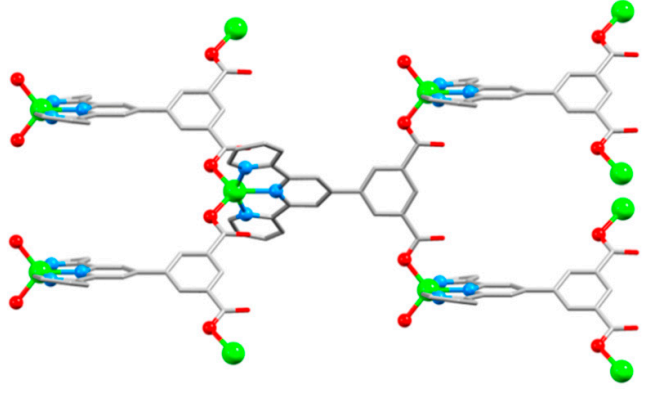

(d)

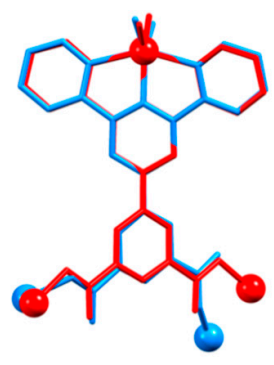

(e)

Figure 6. Parts of the 1D-coordination polymers in (a) $[\mathrm{ZnCl}(5)]_{n} \cdot 0.5 n \mathrm{H}_{2} \mathrm{O}\left(\mathrm{CSD}\right.$ refcode FUJBET), and (b) $[\mathrm{Zn}(8)]_{n}$ (refcode HOGYIO). (c) Part of the 2D-network in $[\mathrm{Zn}(9)]_{n} \cdot n \mathrm{H}_{2} \mathrm{O}$ (CSD refcode KEGTAU) and (d) part of the 3D-net in $[\mathrm{Zn}(9)]_{n} \cdot 2 n \mathrm{MeOH} \cdot n \mathrm{NMP}$ (CSD refcode KEGTEY, NMP $=N$-methyl-2-pyrrolidone). (e) An overlay of the building-block in each of $[\mathrm{Zn}(9)]_{n} \cdot n \mathrm{H}_{2} \mathrm{O}$ (blue) and $[\mathrm{Zn}(9)]_{n} \cdot 2 n \mathrm{MeOH} \cdot n \mathrm{NMP}$ (red) with $\mathrm{Zn}$ atoms in ball-representation showing the differences in the $\mathrm{O}-\mathrm{Zn}$ vectors (bottom of the diagram).

Dicarboxylic acid $\mathrm{H}_{2} \mathbf{1 0}$ is representative of a series of compounds reported by Kruger and coworkers in which the $\mathrm{R}$ group (Scheme 5) is non-coordinating [35]. The reaction between $\mathrm{Zn}\left(\mathrm{NO}_{3}\right)_{2} \cdot 6 \mathrm{H}_{2} \mathrm{O}$ and $\mathrm{H}_{2} \mathbf{1 0}$ under solvothermal conditions $\left(\mathrm{DMF} / \mathrm{H}_{2} \mathrm{O}\right.$, concentrated $\mathrm{HNO}_{3}, 90^{\circ} \mathrm{C}$ ) produced crystals of $[\mathrm{Zn}(\mathbf{1 0})]_{n}$. In this $3 \mathrm{D}$-assembly, the local environment at each $\mathrm{Zn}$ center (Figure $7 \mathrm{a}$ ) is the same as in $[\mathrm{Zn}(8)]_{n}$ and $[\mathrm{Zn}(9)]_{n}$ (Figure $6 \mathrm{~b}-\mathrm{d}$ ). Kruger describes the unit shown in Figure 7a as a 4-connecting node, and the assembly (as well as those with analogous ligands with $\mathrm{R}=2$-methylphenyl, 4-chlorophenyl, 4-nitrophenyl, thien-2-yl, thien-3-yl, pyridin-4-yl) propagates into a zeolitic gismondine gis-c $\left(4^{3} \cdot 6^{2} \cdot 8\right)$ topology; the framework is 2 -fold interpenetrating (Figure $7 \mathrm{~b}$ ). Channels with a square cross-section (ca. $9.0 \AA$ across) follow the $c$-axis and Figure 7c illustrates the solvent accessible void space. For $[\mathrm{Zn}(\mathbf{1 0})]_{n}$, this is $40 \%$, and varies from $32 \%$ to $41 \%$ for the family of structures. Gas adsorption measurements using $\mathrm{N}_{2}, \mathrm{H}_{2}, \mathrm{CO}_{2}$ and $\mathrm{CH}_{4}$ confirm that the solid-state structures exhibit permanent porosity [35]. The reaction of dicarboxylic acid $\mathrm{H}_{2} \mathbf{1 1}$ (Scheme 5) with zinc(II) acetate has been investigated by Lu and coworkers. Despite the structural similarity between $\mathrm{H}_{2} \mathbf{1 1}$ and $\mathrm{H}_{2} \mathbf{1 0}$, the 3D-assembly observed for $[\mathrm{Zn}(\mathbf{1 1})]_{n}$ in the pentahydrate contrasts with that found for $[\mathrm{Zn}(\mathbf{1 0})]_{n}$ and its analogs (see above). $[\mathrm{Zn}(\mathbf{1 1})]_{n} \cdot 5 n \mathrm{H}_{2} \mathrm{O}$ was formed under hydrothermal conditions starting with $\mathrm{K}_{2} \mathbf{1 1}$; the $\mathrm{pH}$ was adjusted to 2.0 using $\mathrm{MeCO}_{2} \mathrm{H}$ [36]. These conditions contrast with those employed in Kruger's work [35]. There are two independent $\mathrm{Zn}$ centers and ligands in the solid-state structure of $[\mathrm{Zn}(\mathbf{1 1})]_{n} \cdot 5 n \mathrm{H}_{2} \mathrm{O}$, as shown in Figure $7 \mathrm{~d}$. The assembly extends into a 4-connected sra net with $\left(4^{2} .6^{3} .8\right)$ topology, and 2-fold interpenetration occurs (Figure 7e). The structure possesses interconnected channels that run parallel to the $a, b$ and $c$-axes, although, as Figure 7e illustrates, the furan-2-yl substituents are accommodated within some of the channels. The solvent-accessible void space is ca. 29\% [36]. The same sra topology was reported by Wang, Sun and coworkers for $\left[\mathrm{Zn}_{2}(\mathbf{1 1})_{2}\right]_{n} \cdot 5 n \mathrm{H}_{2} \mathrm{O}$ (CSD refcode TACTUP) which was prepared solvothermally from $\mathrm{Zn}\left(\mathrm{NO}_{3}\right)_{2} \cdot 6 \mathrm{H}_{2} \mathrm{O}$ and $\mathrm{H}_{2} 11$ [37]. A comparison of the two structure-types depicted in Figure 7 serves to emphasize the variation that is possible with similar building blocks. 


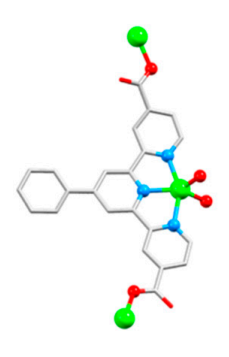

(a)

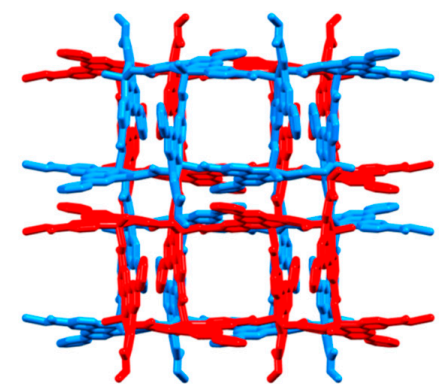

(b)

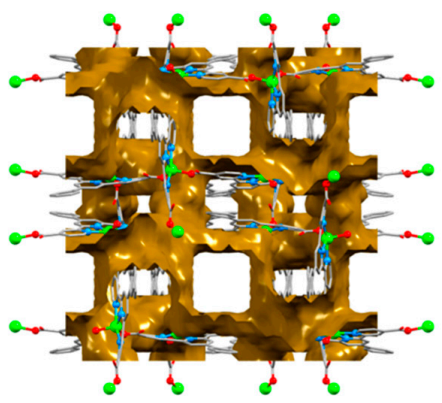

(c)

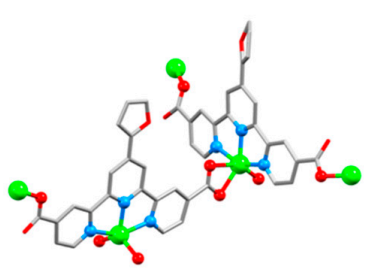

(d)

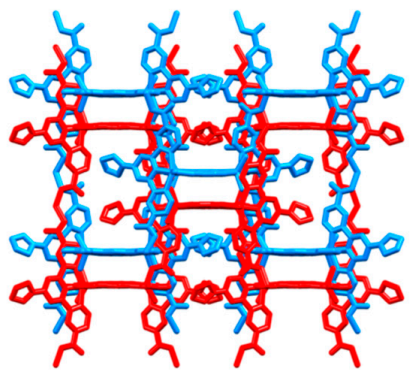

(e)

Figure 7. The structure of $[\mathrm{Zn}(\mathbf{1 0})]_{n}$ (CSD refcode DECXOB): (a) the coordination zinc(II) environment, (b) interpenetrating gis-c 3D networks and (c) representation of the solvent accessible void-space (drawn using Mercury 2020.3.1 [17]). The structure of $[\mathrm{Zn}(\mathbf{1 1})]_{n} \cdot 5 n \mathrm{H}_{2} \mathrm{O}$ (refcode PAFXUS): (d) the two independent zinc(II) and ligand environments, and (e) interpenetrating sra 3D nets viewed down the crystallographic $a$-axis.

The introduction of a third carboxylic acid functionality in $\mathrm{H}_{3} \mathbf{1 2}$ (Scheme 5) might be expected to lead to a high-dimensionality assembly. However, the hydrothermal reaction of $\mathrm{H}_{3} 12$ with zinc(II) sulfate led to a $1 \mathrm{D}$-coordination polymer $\left[\mathrm{Zn}(\mathrm{H12})\left(\mathrm{OH}_{2}\right)_{2}\right]_{n} \cdot 2 n \mathrm{H}_{2} \mathrm{O}$ in which only one $\mathrm{CO}_{2}^{-}$group is involved in coordination. Although written here as $\mathrm{H}^{2}{ }^{2-}$, the protonation state of the coordinated ligand is unclear. Each Zn center is 6-coordinate (Figure $8 \mathrm{a}$ ), and the chain is built up by a glide plane. The coordination polymer functions as a sensor for $\mathrm{Hg}^{2+}$ in aqueous solutions with its fluorescence being quenched by trace amounts of the heavy metal ion [38].
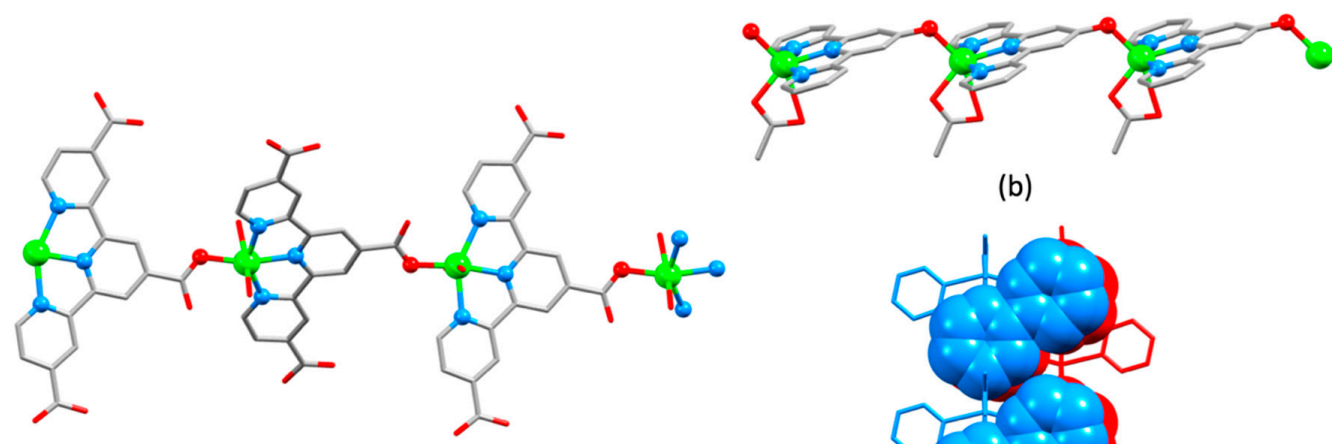

(b)

(a)

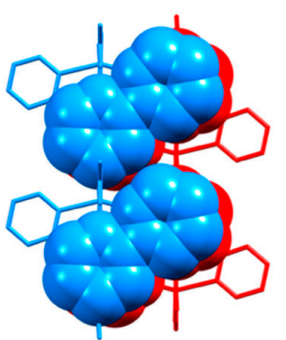

(c)

Figure 8. Part of the 1D-coordination polymers in (a) $\left[\mathrm{Zn}(\mathrm{H12})\left(\mathrm{OH}_{2}\right)_{2}\right]_{n} \cdot 2 n \mathrm{H}_{2} \mathrm{O}(\mathrm{CSD}$ refcode CESRAW), and (b) [Zn(4'$\mathrm{O}-2,2^{\prime}: 6^{\prime}, 2^{\prime \prime}$-tpy)(OAc) $]_{n}$ (refcode WUKBAH). (c) Adjacent chains in $\left[\mathrm{Zn}\left(4^{\prime}-\mathrm{O}-2,2^{\prime}: 6^{\prime}, 2^{\prime \prime} \text {-tpy)(OAc) }\right]_{n}\right.$ associate through face-to-face $\pi$-stacking. 


\subsection{An Assembly Containing Zn(II) and the Conjugate Base of $4^{\prime}$-Hydroxy-2, $2^{\prime}: 6^{\prime}, 2^{\prime \prime}$-terpyridine}

The compound $\left[\mathrm{Zn}\left(4^{\prime}-\mathrm{O}-2,2^{\prime}: 6^{\prime}, 2^{\prime \prime} \text {-tpy)(OAc) }\right]_{n}\right.$ is an unusual example of a coordination polymer employing the conjugate base of $4^{\prime}$-hydroxy-2, $2^{\prime}: 6^{\prime}, 2^{\prime \prime}$-terpyridine $\left(4^{\prime}\right.$-HO$2,2^{\prime}: 6^{\prime}, 2^{\prime \prime}$-tpy). This appears to be the only structurally characterized coordination polymer of any metal ion incorporating this ligand. The zinc(II) complex was prepared on a preparative scale from the reaction of $\mathrm{Zn}(\mathrm{OAc})_{2} \cdot 2 \mathrm{H}_{2} \mathrm{O}$ with $4^{\prime}-\mathrm{HO}-2,2^{\prime}: 6^{\prime}, 2^{\prime \prime}$-tpy, and single crystals grown by diffusion of $n$-hexane into a methanol solution of the compound proved to be $\left[\mathrm{Zn}\left(4^{\prime}-\mathrm{O}-2,2^{\prime}: 6^{\prime}, 2^{\prime \prime} \text {-tpy }\right)(\mathrm{OAc})\right]_{n}$. NMR spectroscopic data for the bulk material are consistent with a degree of dissociation in solution. The structure of the 1D-polymer is shown in Figure 8b. The $\mathrm{Zn}-\mathrm{O}_{\text {tpy }}$ bond length of 1.999(4) $\AA$ compares with distances of 2.028(4) and 2.576(4) A for the coordinated acetato ligand. Neighboring chains are associated through $\pi$-stacking of $2,2^{\prime}: 6^{\prime}, 2^{\prime \prime}$-tpy domains (Figure 8c) [19].

\subsection{Assemblies Containing $C d(I I)$ and $2,2^{\prime}: 6^{\prime}, 2^{\prime \prime}$-tpy Ligands Functionalized with Carboxylate or Sulfonate Donors}

The conjugate base of $\mathrm{H7}$ (Scheme 5) forms 1D-coordination polymers when reacted with $\mathrm{CdCl}_{2} \cdot 2.5 \mathrm{H}_{2} \mathrm{O}$ under solvothermal conditions. Depending upon the $\mathrm{pH}$, the isolated single crystals were determined to be $\left[\mathrm{Cd}_{2}(7)_{2} \mathrm{Cl}_{2}\right]_{n} \cdot n \mathrm{H}_{2} \mathrm{O}$ or $\left[\mathrm{Cd}(7) \mathrm{Cl}\left(\mathrm{H}_{2} \mathrm{O}\right)\right]_{n} \cdot n\left[\mathrm{Cd}\left(\mathrm{H}_{7}\right) \mathrm{Cl}_{2}\right]$. $n \mathrm{H}_{2} \mathrm{O}$. Figure 9a illustrates the polymer chain in the former complex; the 6-coordinate $\mathrm{Cd}$ (II) center is bound by chelating $\mathrm{CO}_{2}^{-}$and $2,2^{\prime}: 6^{\prime}, 2^{\prime \prime}$-tpy domains and a chlorido ligand. The cocrystal resulting from assembly under acidic conditions contains $1 \mathrm{D}\left[\mathrm{Cd}(7) \mathrm{Cl}\left(\mathrm{H}_{2} \mathrm{O}\right)\right]_{n}$ chains with octahedral $\mathrm{Cd}(\mathrm{II})$ (Figure $9 \mathrm{~b}$ ) and discrete $\left[\mathrm{Cd}(\mathrm{H7}) \mathrm{Cl}_{2}\right]$ molecules with 5-coordinate $\mathrm{Cd}(\mathrm{II})$ centers [39]. On going from $\mathrm{H} 7$ to $\mathrm{H} 4$ (Scheme 5), the vectorial properties of the ligand change, and the effect on the structure of the $1 \mathrm{D}$ chain in $\left[\mathrm{Cd}(4) \mathrm{Cl}\left(\mathrm{H}_{2} \mathrm{O}\right)\right]_{n} \cdot 3.75 n \mathrm{H}_{2} \mathrm{O}$ [40] compared to that in $\left[\mathrm{Cd}_{2}(7)_{2} \mathrm{Cl}_{2}\right]_{n} \cdot n \mathrm{H}_{2} \mathrm{O}$ can be seen by comparing Figure $9 \mathrm{~b}$,c. Tseng et al. [40] also illustrated that introducing a co-ligand (thiophene-2,5-dicarboxylic acid) had a significant impact on the assembly, directing it towards an 8-fold $(4,2)$ interpenetrated network. The reaction of $\mathrm{H} 4$ with cadmium(II) nitrate under hydrothermal conditions at $\mathrm{pH} 7.5$ resulted in the formation of single crystals of $\left[\mathrm{Cd}(4)_{2}\right]_{n} \cdot n \mathrm{H}_{2} \mathrm{O}$. The assembly consists of a double chain in which half of the ligands bridge between $\mathrm{Cd}$ (II) centers and half coordinate only through the carboxylate group (Figure 9d). The head-to-tail arrangement of the ligands along the chain leads to efficient inter-ligand $\pi$-stacking [41]. A similar situation is observed in the 1D-coordination polymer $\left[\mathrm{Cd}(6)_{2}\right]_{n} \cdot n \mathrm{H}_{2} \mathrm{O}$ (see Scheme 5 for the structure of $\mathrm{H6}$ ) in which half of the ligands exhibit a pendant, non-coordinated $2,2^{\prime}: 6^{\prime}, 2^{\prime \prime}$-tpy domain. The 1Dchain comprises $\mathrm{Cd}(\mathrm{II})$ centers linked by ditopic ligands $6^{-}$, and each $\mathrm{Cd}(\mathrm{II})$ is additionally bound by a monodentate $6^{-}$ligand. Once again, $\pi$-stacking between $2,2^{\prime}: 6^{\prime}, 2^{\prime \prime}$-tpy units is a dominant packing interaction [42].

Replacing the carboxylic acid functionality in ligand $\mathrm{H} 4$ by a sulfonic acid to give H13 (Figure 6) has an interesting effect on the assembly. The reaction between Na13 and $\mathrm{CdCl}_{2}$ under hydrothermal conditions produced $[\mathrm{Cd}(\mathbf{1 3}) \mathrm{Cl}]_{n}$ which possesses a 1D-ladder structure. The compound was prepared as a model system with which to compare the photophysical behaviors of lanthanoid(III) metal analogs, and the structure is described only in the supporting information in the original work [43]. Figure 10a shows the ladder assembly, in which the rungs comprise the heterocyclic ligands, and the struts comprise the $\mathrm{Cd}(\mathrm{II})$ centers and sulfonate groups. The phenylpyridine units of the ligands are arranged in a head-to-tail fashion and engage in face-to-face $\pi$-stacking interactions (Figure 10b). 


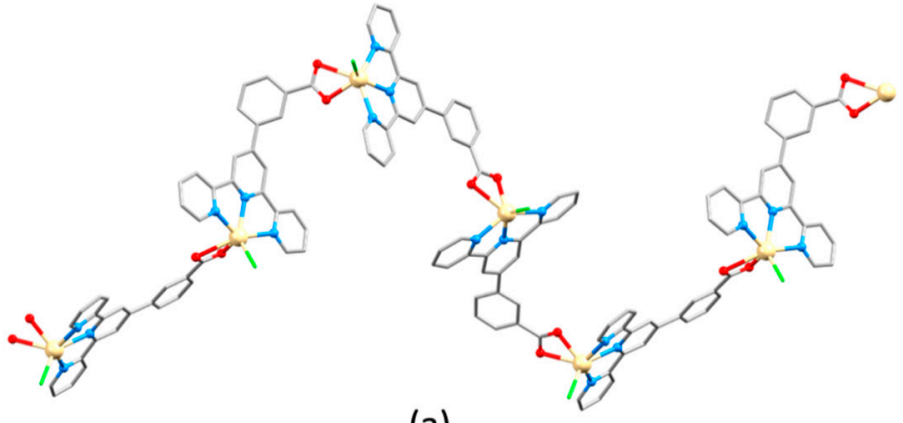

(a)

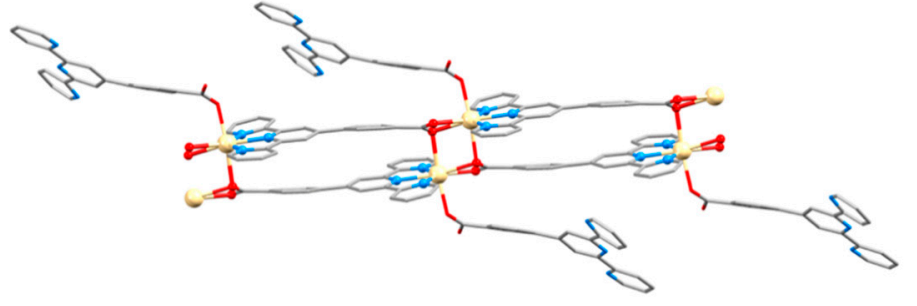

(d)

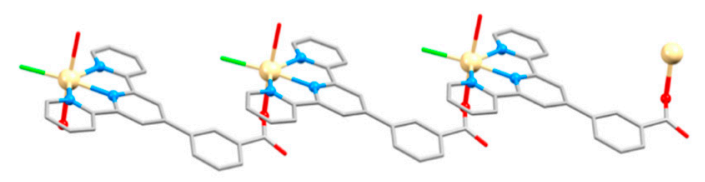

(b)

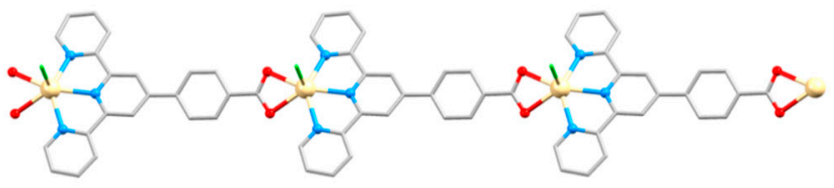

(c)

Figure 9. Part of a 1D-chain in (a) $\left[\mathrm{Cd}_{2}(7)_{2} \mathrm{Cl}_{2}\right]_{n} \cdot n \mathrm{H}_{2} \mathrm{O}\left(\right.$ recode OBOFET), (b) $\left[\mathrm{Cd}(7) \mathrm{Cl}\left(\mathrm{H}_{2} \mathrm{O}\right)\right]_{n} \cdot n\left[\mathrm{Cd}(\mathrm{H} 7) \mathrm{Cl}_{2}\right] \cdot n \mathrm{H}_{2} \mathrm{O}(\mathrm{refcode}$ OBIFIX), (c) $\left[\mathrm{Cd}(4) \mathrm{Cl}\left(\mathrm{H}_{2} \mathrm{O}\right)\right]_{n} \cdot 3.75 n \mathrm{H}_{2} \mathrm{O}$ (refcode ZUDPAR), and (d) $\left[\mathrm{Cd}(4)_{2}\right]_{n} \cdot n \mathrm{H}_{2} \mathrm{O}$ (refcode KABTOY).
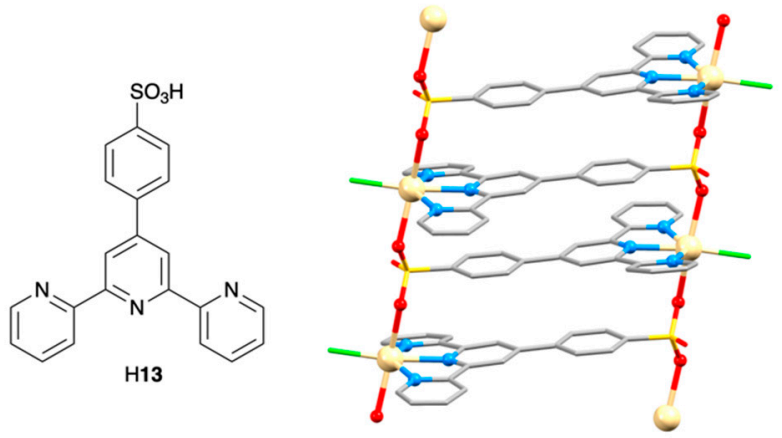

(a)

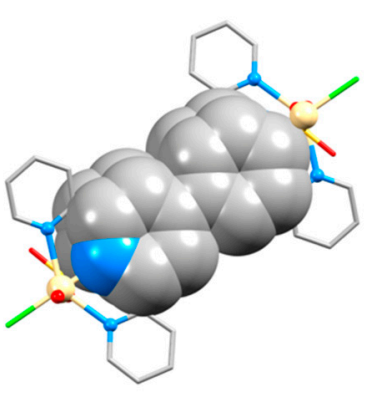

(b)

Figure 10. The structure of H13. (a) Part of the 1D-ladder in $[\mathrm{Cd}(\mathbf{1 3}) \mathrm{Cl}]_{n}$ (CSD refcode ZIQGUD) and (b) space-filling representation of the phenylpyridine units which are stacked in a head-to-tail arrangement down the ladder.

\section{3. $4,2^{\prime}: 6^{\prime}, 4^{\prime \prime}$-terpyridine}

\subsection{A 1D-Coordination Polymer with an Unfunctionalized $4,2^{\prime}: 6^{\prime}, 4^{\prime \prime}$-tpy}

In 1998, González-Garmendia and coworkers reported the synthesis and single crystal structure of $\left[\mathrm{Zn}\left(4,2^{\prime}: 6^{\prime}, 4^{\prime \prime} \text {-tpy) } \mathrm{Cl}_{2}\right]_{n}\right.$ (Figure 11a), which was the first example of a coordination polymer containing the $4,2^{\prime}: 6^{\prime}, 4^{\prime \prime}$-tpy metal-binding domain [44]. The structure demonstrates several features that recur in the related structures, described below. Most significantly, the central pyridine ring $4,2^{\prime}: 6^{\prime}, 4^{\prime \prime}$-tpy is non-coordinating. At the time of writing this review, this feature was common to all structurally characterized coordination compounds involving $4,2^{\prime}: 6^{\prime}, 4^{\prime \prime}$-tpy and its derivatives. Secondly, the V-shaped building block of $4,2^{\prime}: 6^{\prime}, 4^{\prime \prime}$-tpy is moderately rigid, with the directional properties of the outer $\mathrm{N}$-donors being independent of conformational changes involving rotation about the interring $\mathrm{C}-\mathrm{C}$ bonds (Figure 11b). Compare this with the situation for $3,2^{\prime}: 6^{\prime}, 3^{\prime \prime}$-tpy (Scheme 4). $\left[\mathrm{Zn}\left(4,2^{\prime}: 6^{\prime}, 4^{\prime \prime} \text {-tpy) } \mathrm{Cl}_{2}\right]_{n}\right.$ crystallizes as a heterochiral polymer with equal numbers of lefthanded $(M)$ and right-handed $(P)$ helices in the crystal lattice. Such helical 1D-polymers 
feature regularly in the structures of $\mathrm{Zn}(\mathrm{II}) / 4,2^{\prime}: 6^{\prime}, 4^{\prime \prime}$-tpy assemblies, although the pitch of the helix is markedly varied [45]. However, not all $\left[\mathrm{Zn}\left(4^{\prime}-\mathrm{X}-4,2^{\prime}: 6^{\prime}, 4^{\prime \prime} \text {-tpy) } \mathrm{Y}_{2}\right]_{n}(\mathrm{X}\right.$ is a coordinatively innocent group and $\mathrm{Y}^{-}$is a monodentate ligand) are helical (see below). The $\mathrm{Zn} \ldots$. Zn distance between adjacent $\mathrm{Zn}$ atoms in a chain in $\left[\mathrm{Zn}\left(4,2^{\prime}: 6^{\prime}, 4^{\prime \prime}-\mathrm{tpy}\right) \mathrm{Cl}_{2}\right]_{n}$ is 12.528(4) ̊ (Table 1).

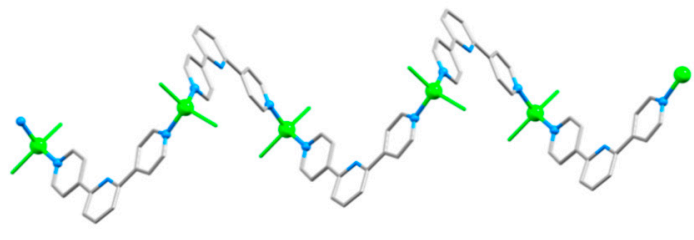

(a)

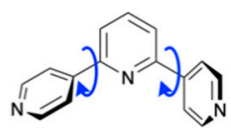

(b)

Figure 11. (a) Part of the 1D-chain in $\left[\mathrm{Zn}\left(4,2^{\prime}: 6^{\prime}, 4^{\prime \prime} \text {-tpy) } \mathrm{Cl}_{2}\right]_{n}\right.$ (CSD refcode GAQYUS). (b) Rotation about the inter-ring C-C bonds does not change the vectorial properties of the ditopic $4,2^{\prime}: 6^{\prime}, 4^{\prime \prime}$-tpy metal-binding domain.

Table 1. 1D-coordination polymers of general formula $\left[\mathrm{Zn}\left(4^{\prime}-\mathrm{X}-4,2^{\prime}: 6^{\prime}, 4^{\prime \prime}-\mathrm{tpy}\right) \mathrm{Cl}_{2}\right]_{n}$.

\begin{tabular}{|c|c|c|c|c|c|}
\hline Compound & CSD Refcode & Space Group & $\mathbf{N}-\mathbf{Z n}-\mathbf{N} /^{\circ}$ & $\mathrm{Zn} \ldots \mathrm{Zn} / \mathrm{A}$ & Ref. \\
\hline$\left[\mathrm{Zn}\left(4,2^{\prime}: 6^{\prime}, 4^{\prime \prime} \text {-tpy }\right) \mathrm{Cl}_{2}\right]_{n}$ & GAQYUS & $P 2_{1} / n$ & $98.6(2)$ & $12.528(4)$ & [44] \\
\hline$\left[\mathrm{Zn}(\mathbf{1 4}) \mathrm{Cl}_{2}\right]_{n}$ & FEPRUO & $P 2_{1} / n$ & $105.96(11)$ & $13.040(1)$ & [46] \\
\hline$\left[\mathrm{Zn}(\mathbf{1 5}) \mathrm{Cl}_{2}\right]_{n}$ & LOCTED & $P 2_{1} / n$ & $99.5(1)$ & 12.992(1) & [47] \\
\hline$\left[\mathrm{Zn}(\mathbf{1 5}) \mathrm{Cl}_{2}\right]_{n}{ }^{\mathrm{a}}$ & NOGFIZ & $P 3_{1} 21$ & $107.9 ; 100.3(2)$ & $12.564 ; 13.029(2)$ & [47] \\
\hline$\left[\mathrm{Zn}(\mathbf{1 6}) \mathrm{Cl}_{2}\right]_{n} \cdot n \mathrm{EtOH}^{n} \cdot{ }^{n} /{ }_{2} \mathrm{H}_{2} \mathrm{O}$ & NOGFOF & $P 2_{1} / n$ & 93.5(1) & $12.379(2)$ & {$[47]$} \\
\hline$\left[\mathrm{Zn}_{2}(\mathrm{H} 17) \mathrm{Cl}_{2}\right]_{n} \cdot 2 n \mathrm{EtOH} \cdot n \mathrm{H}_{2} \mathrm{O}$ & DIRMEY & Pnna & $101.1 ; 97.6$ & 12.626 & {$[48]$} \\
\hline$\left[\mathrm{Zn}(\mathbf{1 8}) \mathrm{Cl}_{2}\right]_{n}$ & DOMBIS & $P 2_{1} / n$ & $100.06(1)$ & $13.037(1)$ & [49] \\
\hline$\left[\mathrm{Zn}(\mathbf{1 9}) \mathrm{Cl}_{2}\right]_{n} \cdot n \mathrm{H}_{2} \mathrm{O}$ & SEBRID & $\operatorname{Pna2}_{1}$ & $100.3(2)$ & $12.706(1)$ & {$[50]$} \\
\hline$\left[\mathrm{Zn}(\mathbf{2 0}) \mathrm{Cl}_{2}\right]_{n}$ & AJURIG & $P 2_{1} / c$ & $104.01(10)$ & $12.8502(6)$ & {$[51]$} \\
\hline$\left[\mathrm{Zn}(\mathbf{2 1}) \mathrm{Cl}_{2}\right]_{n}$ & ELAMOV & $P 2_{1} / c$ & $103.88(8)$ & $12.523(2)$ & [14] \\
\hline$\left[\mathrm{Zn}(22) \mathrm{Cl}_{2}\right]_{n}$ & QOJBOI & $P-1$ & $\begin{array}{c}\text { 97.4(1), 98.1(1), } \\
102.8(1), 104.4(1)\end{array}$ & $\begin{array}{l}12.400(1), \\
12.325(2), \\
12.863(2)\end{array}$ & [52] \\
\hline$\left[\mathrm{Zn}(23) \mathrm{Cl}_{2}\right]_{n}$ & QOJBAU & $P-1$ & $\begin{array}{c}104.6(1), 94.3(2) \\
100.2(1), 103.0(1)\end{array}$ & $\begin{array}{c}12.899(1), \\
12.4525(9), \\
13.062(1), \\
12.3425(9)\end{array}$ & [52] \\
\hline
\end{tabular}

\footnotetext{
a Homochiral.
}

3.2. Assemblies Containing Zinc(II) and $4^{\prime}$-Functionalized $4,2^{\prime}: 6^{\prime}, 4^{\prime \prime}$-tpy Ligands with Coordinatively Innocent Substituents

A wide variety of coordinatively innocent $4^{\prime}$-functionalities has been introduced into $4,2^{\prime}: 6^{\prime}, 4^{\prime \prime}$-tpy ligands; note that $4^{\prime}$-(pyridinyl)-substituted ligands and their zinc(II) complexes are discussed later in Section 3.5. Scheme 6 illustrates those ligands (14-16, $\mathrm{H17}, 18-23)$ which react with $\mathrm{ZnCl}_{2}$ to produce $1 \mathrm{D}$-coordination polymers. Some details of the structures are given in Table 1 , and can be compared with $\left[\mathrm{Zn}\left(4,2^{\prime}: 6^{\prime}, 4^{\prime \prime}\right.\right.$ tpy) $\left.\mathrm{Cl}_{2}\right]_{n}$ (Section 3.1). The chains are typically built up along a 2-fold screw axis (refcodes GAQYUS [44], FEPRUO [46], LOCTED [47], NOGFOF [47], DOMBIS [49], AJURIG [51], ELAMOV [14]), a 2-fold rotation axis (NOGFIZ [47], DIRMEY [48]), or a glide plane (SEBRID [50]). The coordination polymers $\left[\mathrm{Zn}(22) \mathrm{Cl}_{2}\right]_{n}$ and $\left[\mathrm{Zn}(23) \mathrm{Cl}_{2}\right]_{n}$ with $4^{\prime}-(4-(1-$ naphthyl)phenyl)- and $4^{\prime}-\left(2^{\prime}, 3^{\prime}, 4^{\prime}, 5^{\prime}, 6^{\prime}\right.$-pentafluorobiphenyl-4-yl)-substituents, respectively, are of particular note. The asymmetric unit in each possesses four crystallographically independent $\mathrm{Zn}$ atoms, and the chain is built up by translational symmetry to generate a 
polymer with a distinctive crenelated profile (Figure 12a). Adjacent chains are related to each other by inversion (Figure 12b). Each embrasure in the crenelation can be likened to three sides of a metallocycle and it is significant that the assembly of $\left[\mathrm{Zn}(23) \mathrm{Cl}_{2}\right]_{n}$ polymer chains competes with the formation of the metallosquare $\left[\mathrm{Zn}(23) \mathrm{Cl}_{2}\right]_{4}$ [52]. In Figure 11b, we described the V-shaped $4,2^{\prime}: 6^{\prime}, 4^{\prime \prime}$-tpy as a moderately rigid building block. In Table 1 , the range of $\mathrm{Zn}$.. . Zn distances between adjacent zinc atoms in a chain (12.325(2)-13.062(1) $\mathrm{A}$ ) gives an indication of the flexibility of $4,2^{\prime}: 6^{\prime}, 4^{\prime \prime}$-tpy, and Figure 13 illustrates that the ligand is noticeably bowed when associated with shorter $\mathrm{Zn} \ldots$ Zn distances. We have previously commented upon the bowing of terpyridine backbones in solid-state structures [53]; this mode of flexibility is additional to conformational changes arising from bond rotation.<smiles>c1ccc(-c2cc(-c3ccncc3)nc(-c3ccncc3)c2)cc1</smiles>

14<smiles>Cc1ccc(-c2cc(-c3ccncc3)nc(-c3ccncc3)c2)cc1</smiles>

15<smiles>CCc1ccc(-c2cc(-c3ccncc3)nc(-c3ccncc3)c2)cc1</smiles>

16<smiles>O=C(O)c1ccc(-c2cc(-c3ccncc3)nc(-c3ccncc3)c2)cc1</smiles>

H17<smiles>Nc1ccc(-c2cc(-c3ccncc3)nc(-c3ccncc3)c2)cc1</smiles>

18<smiles>c1ccc(N(c2ccccc2)c2ccc(-c3cc(-c4ccncc4)nc(-c4ccncc4)c3)cc2)cc1</smiles><smiles>CCCCCCCCOc1ccc(-c2cc(-c3ccncc3)nc(-c3ccncc3)c2)cc1</smiles>

20<smiles>c1ccc(N(c2ccccc2)c2ccc(-c3cc(-c4ccncc4)nc(-c4ccncc4)c3)s2)cc1</smiles>

21<smiles>c1ccc2c(-c3ccc(-c4cc(-c5ccncc5)nc(-c5ccncc5)c4)cc3)cccc2c1</smiles>

22<smiles>Fc1c(F)c(F)c(-c2ccc(-c3cc(-c4ccncc4)nc(-c4ccncc4)c3)cc2)c(F)c1F</smiles>

23

Scheme 6. Structures of $4^{\prime}$-functionalized $4,2^{\prime}: 6^{\prime}, 4^{\prime \prime}$-tpy ligands which form $\left[\mathrm{Zn}\left(4^{\prime}-\mathrm{X}-4,2^{\prime}: 6^{\prime}, 4^{\prime \prime} \text {-tpy) } \mathrm{Cl}_{2}\right]_{n}\right.$ 1D-coordination polymers.

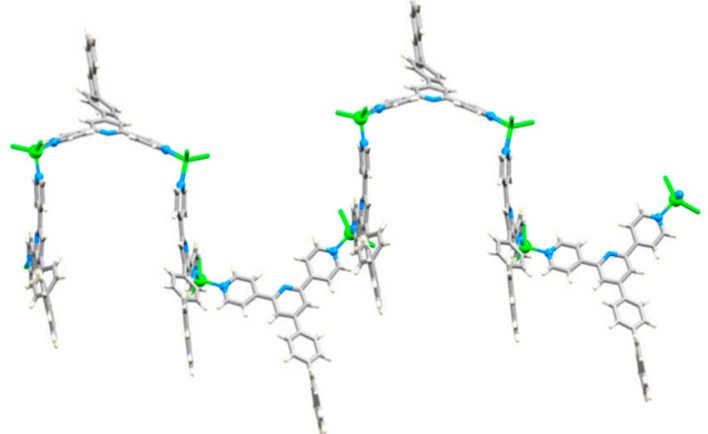

(a)

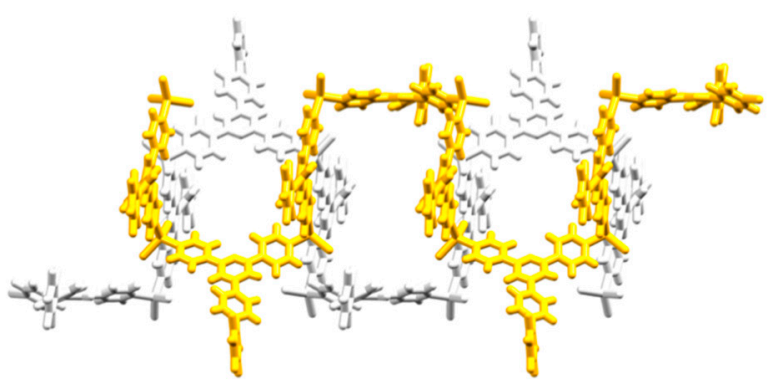

(b)

Figure 12. (a) Part of one chain of $\left[\mathrm{Zn}(22) \mathrm{Cl}_{2}\right]_{n}$ (CSD refcode QOJBOI) showing the crenelated profile. (b) Adjacent chains in $\left[\mathrm{Zn}(23) \mathrm{Cl}_{2}\right]_{n}$ are related by inversion (refcode QOJBAU). 

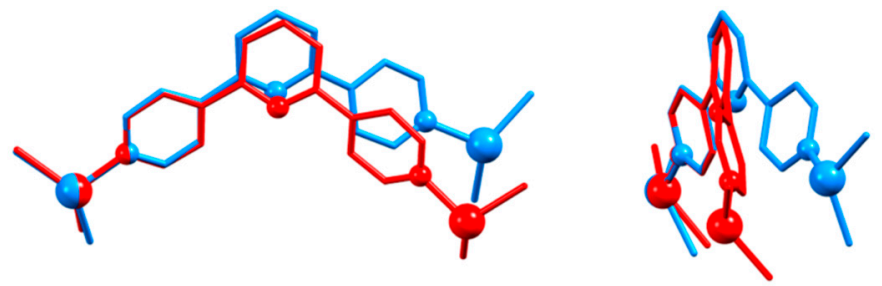

Figure 13. Two views of overlays of $\left\{\left(\mathrm{ZnCl}_{2}\right)_{2}\left(4,2^{\prime}: 6^{\prime}, 4^{\prime \prime}\right.\right.$-tpy) $\}$ units excised from the coordination polymer chains in $\left[\mathrm{Zn}(\mathbf{2 2}) \mathrm{Cl}_{2}\right]_{n}$ (red, $\mathrm{Zn} \mathrm{...} \mathrm{Zn} \mathrm{=} \mathrm{12.325(2)} \AA$ ) and $\left[\mathrm{Zn}(23) \mathrm{Cl}_{2}\right]_{n}$ (blue, $\mathrm{Zn} \mathrm{...}$ $\mathrm{Zn}=13.062(1) \AA$ ). (CSD refcodes QOJBOI and QOJBAU, see Table 1).

Ligand $\mathrm{H} 17$ (Scheme 6) is noteworthy because it remains protonated in $\left[\mathrm{Zn}_{2}(\mathrm{H17})_{2} \mathrm{Cl}_{4}\right]_{n}$. $2 n \mathrm{EtOH} \cdot n \mathrm{H}_{2} \mathrm{O}$, in contrast to the assemblies containing carboxylates described in Section 3.4. Pairs of peripheral $\mathrm{CO}_{2} \mathrm{H}$ groups in adjacent chains engage in hydrogen-bonding, leading to interconnection of the chiral $\left[\mathrm{Zn}_{2}(\mathrm{H17})_{2} \mathrm{Cl}_{4}\right]_{n}$ chains into 2D-sheets (Figure 14). Each layer contains alternating left- and right-handed helical polymer chains [48].

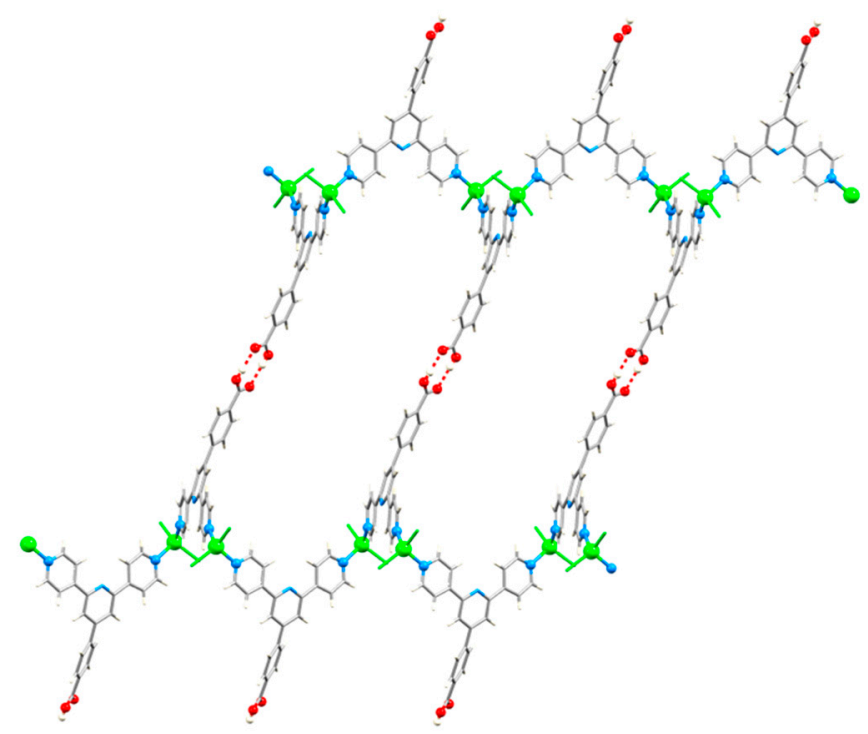

Figure 14. Hydrogen-bonded polymer chains in $\left[\mathrm{Zn}_{2}(\mathrm{H17})_{2} \mathrm{Cl}_{4}\right]_{n} \cdot 2 n \mathrm{EtOH} \cdot n \mathrm{H}_{2} \mathrm{O}$ associate into a 2D-sheet (CSD refcode DIRMEY).

A number of 1D-coordination polymers related to those described above incorporate different $\mathrm{ZnX}_{2}$ units $\left(\mathrm{X}^{-}=\mathrm{I}^{-}, \mathrm{NCS}^{-}\right.$, monodentate $\left.\mathrm{AcO}^{-}\right)$and these are summarized in Table 2. The structures of ligands 24 and 25 are depicted in Scheme 7. Each of the $\left[\mathrm{Zn}(25)(\mathrm{NCS})_{2}\right]_{n}$ and $\left[\mathrm{Zn}(25)(\mathrm{OAc})_{2}\right]_{n}$ chains (TUNNIB and TUNCIQ in Table 2 ) is built up by a glide plane and is achiral, whereas each chain in $\left[\mathrm{Zn}(\mathbf{1 4})(\mathrm{OAc})_{2}\right]_{n},\left[\mathrm{Zn}(\mathbf{2 1}) \mathrm{I}_{2}\right]_{n}$, $\left[\mathrm{Zn}(\mathbf{2 4}) \mathrm{I}_{2}\right]_{n}$, and $\left[\mathrm{Zn}(\mathbf{2 5}) \mathrm{I}_{2}\right]_{n}$ (CUXDOP, ELAMEL, FAKRUG and TUNKEU in Table 2) is propagated along a 2-fold screw axis, with the lattice containing equal numbers of right- and left-handed helical polymers [14,54-56]. A second solvate of $\left[\mathrm{Zn}(25)(\mathrm{OAc})_{2}\right]_{n}$ has been structurally characterized (NEFWED in Table 2), and although the chains in $\left[\mathrm{Zn}(25)(\mathrm{OAc})_{2}\right]_{n} \cdot 2 n \mathrm{H}_{2} \mathrm{O}[56]$ and $\left[\mathrm{Zn}(25)(\mathrm{OAc})_{2}\right]_{n} \cdot n \mathrm{MeOH} \cdot n \mathrm{H}_{2} \mathrm{O}$ [57] are very similar, the change in space group (Table 2) leads to the $1 \mathrm{D}$-polymer in $\left[\mathrm{Zn}(\mathbf{2 5})(\mathrm{OAc})_{2}\right]_{n} \cdot n \mathrm{MeOH} \cdot n \mathrm{H}_{2} \mathrm{O}$ being built up by translational symmetry. Crystals of $\left[\mathrm{Zn}(\mathbf{1 4})(\mathrm{OAc})_{2}\right]_{n}$ were formed under ambient conditions (by layering) after a period of about a month. In contrast, crystals harvested from the same crystallization tube after three days comprised the 1D-polymer $\left[\mathrm{Zn}_{2}(\mathrm{OAc})_{4}(\mathbf{1 4})\right]_{n}$ with $\left\{\mathrm{Zn}_{2}(\mathrm{OAc})_{4}\right\}$ paddle-wheel building blocks [54] (see Section 3.3). Both $\left[\mathrm{Zn}_{2}(\mathrm{OAc})_{4}(\mathbf{1 4})\right]_{n}$ and $\left[\mathrm{Zn}(\mathbf{1 4})(\mathrm{OAc})_{2}\right]_{n}$ are emissive, and exposure to $\mathrm{CF}_{3} \mathrm{CO}_{2} \mathrm{H}$ vapor resulted in a red-shift in the emission from 384 to $435 \mathrm{~nm}$ for $\left[\mathrm{Zn}_{2}(\mathrm{OAc})_{4}(\mathbf{1 4})\right]_{n}$, and from 390 to $441 \mathrm{~nm}$ for $\left[\mathrm{Zn}(\mathbf{1 4})(\mathrm{OAc})_{2}\right]_{n}$. This most likely arises from protonation of the central 
pyridine ring of coordinated ligand $\mathbf{1 4}$. However, attempts to alkylate the polymers using MeI or EtI resulted in degradation of the chain and formation of $\left[\mathrm{R}_{2} \mathbf{1 4}\right]\left[\mathrm{ZnI}_{4}\right], \mathrm{ROAc}$ and $\mathrm{Zn}(\mathrm{OAc})_{2}(\mathrm{R}=\mathrm{Me}, \mathrm{Et})$ [54]. Helical polymers are also formed in reactions of zinc(II) acetate with $4^{\prime}$-(4-(anthracen-9-yl)phenyl)-4, $2^{\prime}: 6^{\prime}, 4^{\prime \prime}$-terpyridine (26), and both homochiral polymers and racemates were isolated from the same crystallization tubes (Table 2) [58].

Table 2. $1 \mathrm{D}$-coordination polymers of general formula $\left[\mathrm{Zn}\left(4^{\prime}-\mathrm{X}-4,2^{\prime}: 6^{\prime}, 4^{\prime \prime} \text {-tpy) } \mathrm{X}_{2}\right]_{n}\right.$ with $\mathrm{X}^{-}=\mathrm{I}^{-}, \mathrm{AcO}^{-}, \mathrm{NCS}^{-}$.

\begin{tabular}{|c|c|c|c|c|c|}
\hline Compound & CSD Refcode & Space Group & $\mathbf{N}-\mathrm{Zn}-\mathrm{N} /{ }^{\circ}$ & $\mathrm{Zn} \ldots \mathrm{Zn} / \AA$ & Ref. \\
\hline$\left[\mathrm{Zn}(\mathbf{1 4})(\mathrm{OAc})_{2}\right]_{n}$ & CUXDOP & $P 2_{1} / n$ & $106.99(5)$ & $12.583(2)$ & [54] \\
\hline$\left[\mathrm{Zn}(\mathbf{2 1}) \mathrm{I}_{2}\right]_{n} \cdot n \mathrm{H}_{2} \mathrm{O}$ & ELAMEL & $P 2_{1} / c$ & $98.1(1)$ & $12.583(2)$ & {$[14]$} \\
\hline$\left[\mathrm{Zn}(24) \mathrm{I}_{2}\right]_{n} \cdot n \mathrm{C}_{6} \mathrm{H}_{4} \mathrm{Cl}_{2}$ & FAKRUG & $P 2_{1} / c$ & $105.0(1)$ & $12.6858(7)$ & {$[55]$} \\
\hline$\left[\mathrm{Zn}(25) \mathrm{I}_{2}\right]_{n} \cdot 2 n \mathrm{CHCl}_{3}$ & TUNKEU & $P 2_{1} / c$ & $104.5(1)$ & $12.771(2)$ & {$[56]$} \\
\hline$\left[\mathrm{Zn}(25)(\mathrm{OAc})_{2}\right]_{n} \cdot 2 n \mathrm{H}_{2} \mathrm{O}$ & TUNCIQ & $P 2_{1} / n$ & $106.8(2)$ & $12.516(5)$ & [56] \\
\hline$\left[\mathrm{Zn}(25)(\mathrm{NCS})_{2}\right]_{n} \cdot n \mathrm{CHCl}_{3}$ & TUNNIB & $P 2_{1} / n$ & $111.7(1)^{\mathrm{a}}$ & $12.416(3)$ & {$[56]$} \\
\hline$\left[\mathrm{Zn}(25)(\mathrm{OAc})_{2}\right]_{n} \cdot n \mathrm{MeOH} \cdot n \mathrm{H}_{2} \mathrm{O}$ & NEFWED & $P b c a$ & $110.06(9)$ & $12.1240(9)$ & {$[57]$} \\
\hline$(\mathrm{M})-\left[\mathrm{Zn}(\mathbf{2 6})(\mathrm{OAc})_{2}\right]_{n}$ & OFIVOQ & $P 2{ }_{1}{ }_{1} 2_{1}$ & $103.2(2)$ & $12.5757(9)$ & {$[58]$} \\
\hline$\left[2\left\{\mathrm{Zn}(26)(\mathrm{OAc})_{2}\right\}\right]_{n} \cdot n \mathrm{CHCl}_{3} \cdot 5 n \mathrm{MeOH} \cdot 2 n \mathrm{H}_{2} \mathrm{O}$ & OFIWEH & Pnna & 114.29 & 13.194 & [58] \\
\hline
\end{tabular}

${ }^{a} \mathrm{~N}-\mathrm{Zn}-\mathrm{N}$ angle within the polymer chain.<smiles>CC(C)(C)c1cc(-c2ccncc2)nc(-c2ccncc2)c1</smiles>

24<smiles>Fc1cccc(-c2cc(-c3ccncc3)nc(-c3ccncc3)c2)c1F</smiles>

25<smiles>c1ccc2c(-c3ccc(-c4cc(-c5ccncc5)nc(-c5ccncc5)c4)cc3)c3ccccc3cc2c1</smiles>

26

Scheme 7. Structures of $4^{\prime}$-functionalized $4,2^{\prime}: 6^{\prime}, 4^{\prime \prime}$-tpy ligands 24 and 25 without organic spacers in the $4^{\prime}$-position, and the structure of $\mathbf{2 6}$.

Earlier, we detailed how the assembly of the polymeric $\left[\mathrm{Zn}(23) \mathrm{Cl}_{2}\right]_{n}$ competes with the formation of the metallosquare $\left[\mathrm{Zn}(23) \mathrm{Cl}_{2}\right]_{4}$ [52]. In this case, both polymer and discrete metallomacrocycle were observed in the same crystallization tube. In other cases, only cyclic or polymeric structures were isolated and structurally characterized. Wu, Tian and coworkers reported that reactions of 25 (Scheme 7) with $\mathrm{ZnCl}_{2}$ and $\mathrm{ZnBr}_{2}$ under conditions of crystal growth by layering $\left(\mathrm{MeOH}\right.$ solution of $\mathrm{ZnX}$ layered over a $\mathrm{CHCl}_{3}$ solution of 25) gave single crystals of the metallohexacycles $\left[\mathrm{Zn}_{6}(25)_{6} \mathrm{Cl}_{12}\right] \cdot 6 \mathrm{H}_{2} \mathrm{O} \cdot 6 \mathrm{CHCl}_{3}$ and $\left[\mathrm{Zn}_{6}(25)_{6} \mathrm{Br}_{12}\right] \cdot 6 \mathrm{H}_{2} \mathrm{O} \cdot 6 \mathrm{CHCl}_{3}$ [56]. In contrast, we have observed that, under similar conditions of crystal growth to those used by Wu and Tian [56], $\mathrm{ZnCl}_{2}$ and ligand 25 react to give the metallosquare $\left[\mathrm{Zn}_{4}(25)_{4} \mathrm{Cl}_{8}\right] \cdot 2 \mathrm{CHCl}_{3}$ [57]. The factors that direct the assembly are not understood [59], and, in the absence of powder X-ray diffraction (PXRD) data for the bulk material, it is difficult to assess the competitive nature of these assemblies. We return to the critical need for routine PXRD later. 
3.3. Assemblies Containing $4^{\prime}$-Functionalized $4,2^{\prime}: 6^{\prime}, 4^{\prime \prime}$-tpy Ligands Connected by $\left\{\mathrm{Zn} n_{2} \mu\right.$-OAc) $\left.{ }_{4}\right\}$ Paddle-Wheel Units

Although Table 2 shows examples of 1D-coordination polymers with mononuclear $\left\{\mathrm{Zn}(\mathrm{OAc})_{2}\right\}$ building blocks, the tendency for dimerization to form $\left\{\mathrm{Zn}_{2}(\mu-\mathrm{OAc})_{4}\right\}$ paddlewheel units means that reactions between zinc(II) acetate and $4^{\prime}$-functionalized $4,2^{\prime}: 6^{\prime}, 4^{\prime \prime}$-tpy ligand might typically be expected to lead to $1 \mathrm{D}$-chains of general formula $\left[\mathrm{Zn}_{2}(\mu-\mathrm{OAc})_{4} \mathrm{~L}\right]_{n}$. The combination of the linear and V-shaped directional properties, respectively, of the paddle-wheel and the ligand (Scheme 8) results in the formation of zigzag chains. A characteristic example is $\left[\mathrm{Zn}_{2}(\mu-\mathrm{OAc})_{4}(27)\right]_{n}$ (see Scheme 9 for 27 and related ligands), the structure of which is shown in Figure 15 [60]. This also shows the typical packing of adjacent zigzag chains into 2D-sheets. Packing of the layers involves face-to-face $\pi$-stacking of $4,2^{\prime}: 6^{\prime}, 4^{\prime \prime}$-tpy domains, with the acetato groups from one layer accommodated in pockets in an adjacent layer. Structures analogous to that observed for $\left[\mathrm{Zn}_{2}(\mu-\mathrm{OAc})_{4}(27)\right]_{n}$ are found for $\left[\mathrm{Zn}_{2}(\mu-\mathrm{OAc})_{4}(\mathbf{1 4})\right]_{n} \cdot 0.3 n \mathrm{CH}_{2} \mathrm{Cl}_{2}$ (refcode CUXDUV) [54], [ $\left.\mathrm{Zn}_{2}(\mu-\mathrm{OAc})_{4}(\mathbf{2 8})\right]_{n}$ (refcode CUXCUU) [60], and [ $\left.\mathrm{Zn}_{2}(\mu-\mathrm{OAc})_{4}(29)\right]_{n}($ refcode QOTROI) [61]. Note that in the case of $\left[\mathrm{Zn}_{2}(\mu-\mathrm{OAc})_{4}(\mathbf{1 4})\right]_{n} \cdot 0.3 n \mathrm{CH}_{2} \mathrm{Cl}_{2}$, crystals grew from a layering experiment under ambient conditions within 3 days and the polymer was isolated in $82 \%$ yield. However, over longer crystallization periods under the same conditions, the colorless needles of $\left[\mathrm{Zn}_{2}(\mu-\right.$ $\left.\mathrm{OAc})_{4}(\mathbf{1 4})\right]_{n} \cdot 0.3 n \mathrm{CH}_{2} \mathrm{Cl}_{2}$ which initially formed were largely replaced by pale-yellow blocks of $\left[\mathrm{Zn}(\mathbf{1 4})(\mathrm{OAc})_{2}\right]_{n}$ (see Table 2) [54]. Once again, this highlights the competitive nature of the assembly processes, and underlines the need for routine analysis of bulk samples by using PXRD.

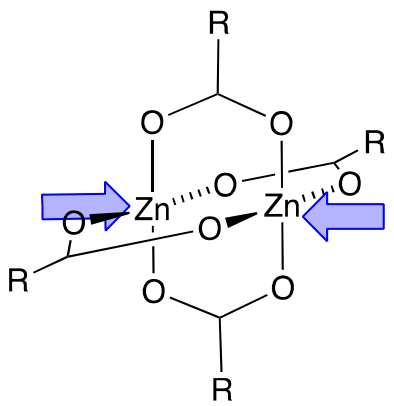<smiles></smiles>

Scheme 8. Linear and V-shaped directional properties, respectively, of the Lewis acidic $\left\{\mathrm{Zn}_{2}(\mu-\mathrm{OAc})_{4}\right\}$ paddle-wheel and Lewis basic $4,2^{\prime}: 6^{\prime}, 4^{\prime \prime}$-tpy ligand building blocks.<smiles>Brc1ccc(-c2cc(-c3ccncc3)nc(-c3ccncc3)c2)cc1</smiles>

27<smiles>CSc1ccc(-c2cc(-c3ccncc3)nc(-c3ccncc3)c2)cc1</smiles>

28<smiles>CN(C)c1ccc(-c2cc(-c3ccncc3)nc(-c3ccncc3)c2)cc1</smiles>

29<smiles>c1ccc(-c2ccc(-c3cc(-c4ccncc4)nc(-c4ccncc4)c3)cc2)cc1</smiles>

30

Scheme 9. Ligands that form $\left[\mathrm{Zn}_{2}(\mu-\mathrm{OAc})_{4}\left(4^{\prime}-\mathrm{X}-4,2^{\prime}: 6^{\prime}, 4^{\prime \prime} \text {-tpy) }\right]_{n}\right.$ type $1 \mathrm{D}$-zigzag polymers. See Scheme 6 for ligand 14. 

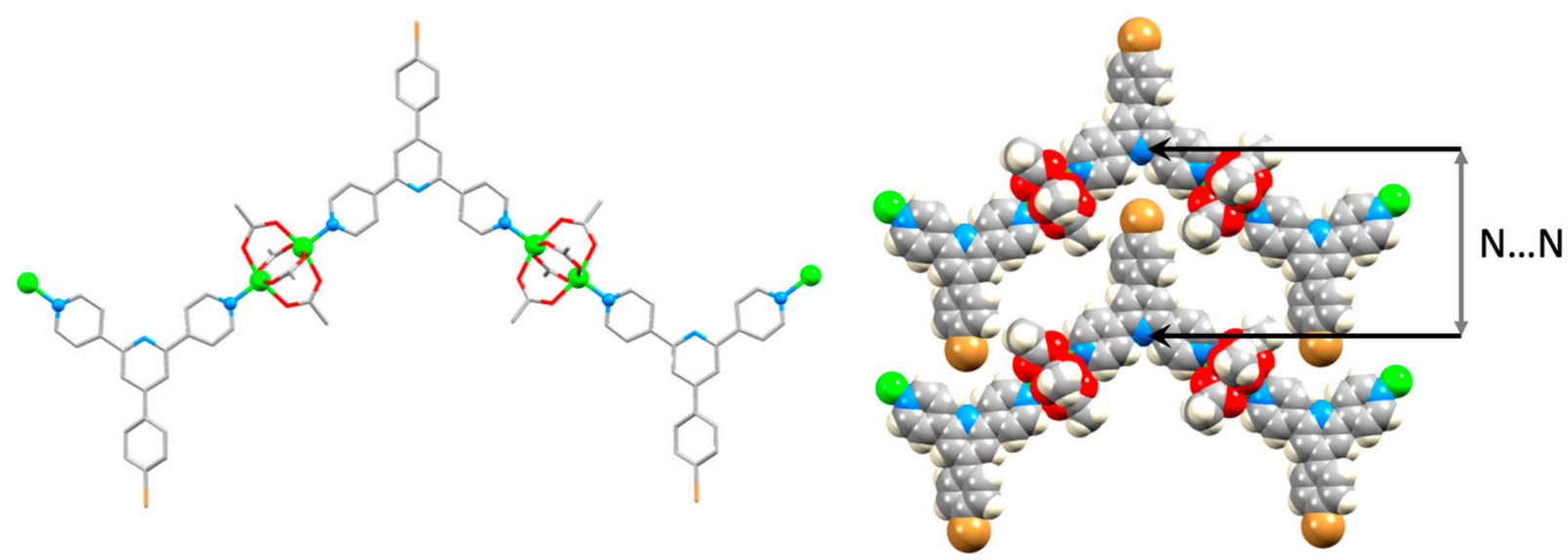

Figure 15. Part of the $1 \mathrm{D}$-zigzag coordination polymer chain in $\left[\mathrm{Zn}_{2}(\mu-\mathrm{OAc})_{4}\left(4^{\prime}-\left(4-\mathrm{BrC}_{6} \mathrm{H}_{4}\right)-4,2^{\prime}: 6^{\prime}, 4^{\prime \prime} \text {-tpy) }\right]_{n}\right.$ (CSD refcode CUXCOO) and a space-filling representation of parts of two adjacent chains showing packing to form 2D-layers. The defined N ... N distance gives a measure of the separation between chains in a given layer (see text).

A zigzag polymer is also assembled when ligand 30 reacts with zinc(II) acetate under conditions of crystal growth by layering. In $\left[\mathrm{Zn}_{2}(\mu-\mathrm{OAc})_{4}(30)\right]_{n}$, (CSD refcode RIJFUN), face-to-face $\pi$-stacking of both pairs of biphenyl domains and pairs of $4,2^{\prime}: 6^{\prime}, 4^{\prime \prime}$-tpy units contribute to packing interactions [62]. The zigzag chains are arranged into 2D-sheets in a similar manner to the chains in polymers containing $14,27,28$, and 29 , but the greater steric demands of the biphenyl unit force the chains further apart. The $\mathrm{N} \ldots \mathrm{N}$ distance defined in Figure 15 is $16.151 \AA$ in $\left[\mathrm{Zn}_{2}(\mu-\mathrm{OAc})_{4}(\mathbf{3 0})\right]_{n}$, and this compares to $15.294,15.077$, 14.902 and $14.898 \AA$ in the assemblies with $\mathbf{1 4}, \mathbf{2 7}, 28$ and 29 . While the mode of packing of chains into $2 \mathrm{D}$-sheets remains the same in $\left[\mathrm{Zn}_{2}(\mu-\mathrm{OAc})_{4}\left(4^{\prime}-\mathrm{X}-4,2^{\prime}: 6^{\prime}, 4^{\prime \prime} \text {-tpy }\right)\right]_{n}$ assemblies with $4^{\prime}-X-4,2^{\prime}: 6^{\prime}, 4^{\prime \prime}$-tpy $=\mathbf{1 4}, 27,28,29$, and 30 , the different substituents influence the arrangement of the layers with respect to one another (as exemplified in Figure 16) in order to optimize packing interactions. Note that the solvent-accessible void space is small, and within this series, only $\left[\mathrm{Zn}_{2}(\mu-\mathrm{OAc})_{4}(\mathbf{1 4})\right]_{n} \cdot 0.3 n \mathrm{CH}_{2} \mathrm{Cl}_{2}$ with the $4^{\prime}$-phenyl substituent in ligand 14 incorporates solvent.

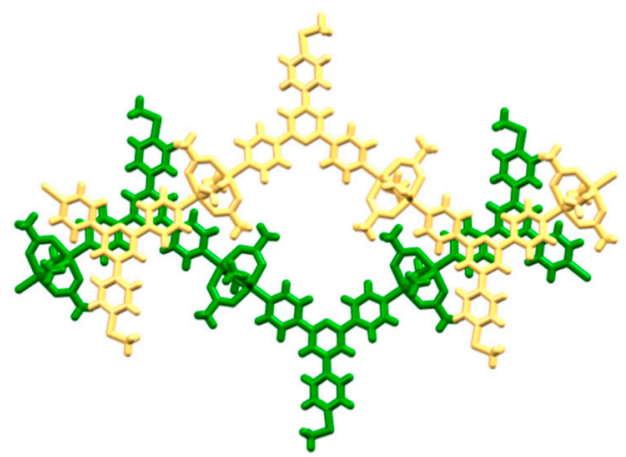

(a)

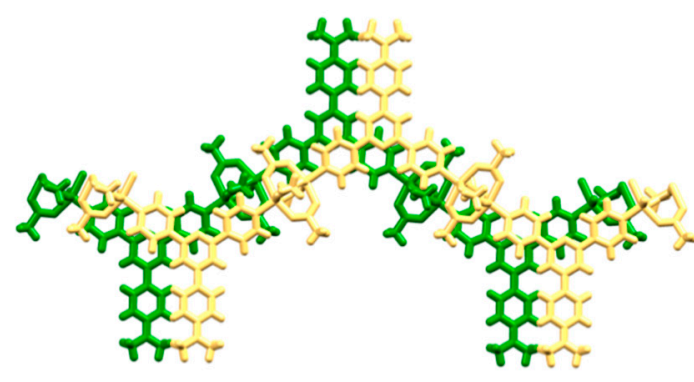

(b)

Figure 16. In $\left[\mathrm{Zn}_{2}(\mu-\mathrm{OAc})_{4}\left(4^{\prime}-\mathrm{X}-4,2^{\prime}: 6^{\prime}, 4^{\prime \prime} \text {-tpy) }\right]_{n}\right.$ type 1D-zigzag polymers, face-to-face $\pi$-stacking occurs between chains, and the arrangement is influenced by the $X$ substituent. For example: (a) $\left[\mathrm{Zn}_{2}(\mu-\mathrm{OAc})_{4}(28)\right]_{n}$ (CSD refcode CUXCUU), and (b) $\left[\mathrm{Zn}_{2}(\mu-\mathrm{OAc})_{4}(29)\right]_{n}$ (refcode QOTROI). Note that the mode of packing into 2D-sheets is analogous in both compounds (see Figure 15).

Systematic investigations are typically lacking for coordination polymers containing a given family of ligands. We have carried out one such study for combinations of zinc(II) acetate and $4^{\prime}$-(4- $\left.\mathrm{ROC}_{6} \mathrm{H}_{4}\right)-4,2^{\prime}: 6^{\prime}, 4^{\prime \prime}$-tpy ligands in which $\mathrm{R}=$ methyl, ethyl, ${ }^{n}$ propyl, ${ }^{n}$ butyl, ${ }^{n}$ pentyl, ${ }^{n}$ hexyl, ${ }^{n}$ heptyl, ${ }^{n}$ octyl, ${ }^{n}$ nonyl and ${ }^{n}$ decyl [63]. For the smaller substituents (OMe, OEt, $\left.\mathrm{O}^{n} \mathrm{Pr}\right),\left[\mathrm{Zn}_{2}(\mu-\mathrm{OAc})_{4}\left(4^{\prime}-\mathrm{X}-4,2^{\prime}: 6^{\prime}, 4^{\prime \prime}-\text { tpy }\right)\right]_{n}$ assemblies were observed (CSD refcodes 
SOXSEF, SOXSIJ, SOXSOP) which are similar to that found for $\left[\mathrm{Zn}_{2}(\mu-\mathrm{OAc})_{4}(\mathbf{2 8})\right]_{n}$ with the SMe substituent (CSD refcode CUXCUU) [60]. The N ... N distance (defined in Figure 15) increases from 15.214 to $16.077 \AA$ from OMe to $\mathrm{O}^{n} \mathrm{Pr}$. On going to the longer chains, several changes occur. Firstly, there is competition between the assembly of a coordination polymer and a discrete complex of type $\left[\mathrm{Zn}_{2}(\mu-\mathrm{OAc})_{4}\left(4^{\prime}-\left(4-\mathrm{ROC}_{6} \mathrm{H}_{4}\right)-4,2^{\prime}: 6^{\prime}, 4^{\prime \prime} \text {-tpy }\right)_{2}\right]$. The latter is the sole isolated product for the ligands with ${ }^{n}$ octyl, ${ }^{n}$ nonyl and ${ }^{n}$ decyl tails, and the structure of one example is shown in Figure 17. Single-crystal structures for the coordination polymers with the ${ }^{n}$ pentyl, ${ }^{n}$ hexyl and ${ }^{n}$ heptyl tails (refcodes SOXTUW, SOXGIX and SOXTAC, respectively) confirm the presence of 1D-zigzig polymer chains and packing into 2D sheets in the manner depicted in Figure 15; cavities within a sheet are occupied by solvent. Changes in the packing of sheets demonstrate the response to the increased steric demands of the alkyloxy tails [63].

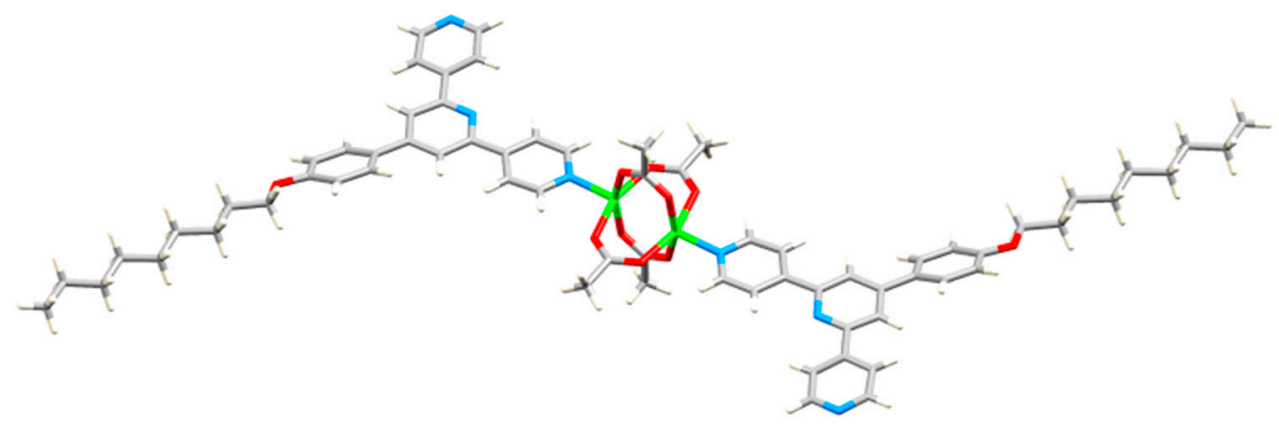

Figure 17. The structure of the discrete complex $\left[\mathrm{Zn}_{2}(\mu-\mathrm{OAc})_{4}\left(4^{\prime}-\left(4-\left({ }^{n} \text { nonyloxy }\right) \text { phenyl }\right)-4,2^{\prime}: 6^{\prime}, 4^{\prime \prime}-\mathrm{tpy}\right)_{2}\right]$ (CSD refcode SOXVAE) in which the ligands are monodentate.

In all the assemblies discussed in the section so far, the ligands have contained a phenyl group or phenylene spacer in the $4^{\prime}$-position of the $4,2^{\prime}: 6^{\prime}, 4^{\prime \prime}$-tpy. The structural similarities between the ligands in $\left[\mathrm{Zn}_{2}(\mu-\mathrm{OAc})_{4}\left(4^{\prime}-\mathrm{X}-4,2^{\prime}: 6^{\prime}, 4^{\prime \prime} \text {-tpy) }\right]_{n}\right.$ 1D-coordination polymers result in similar packing interactions within this series of compounds. In contrast, ligand 24 (Scheme 7) contains a tert-butyl substituent attached directly to the central ring of the $4,2^{\prime}: 6^{\prime}, 4^{\prime \prime}$-tpy metal-binding domain. Once again, zigzig chains that pack together to form 2D-sheets are assembled, and it is significant that in $\left[\mathrm{Zn}_{2}(\mu-\mathrm{OAc})_{4}(24)\right]_{n}$, packing between the zigzag 1D-chains, is dominated by face-to-face $\pi$-stacking of $4,2^{\prime}: 6^{\prime}, 4^{\prime \prime}$-tpy units (Figure 18a). The ball-like tert-butyl groups are accommodated in cavities between acetato units in the next sheet (Figure 18b) [55]. Note how the stacking of chains in $\left[\mathrm{Zn}_{2}(\mu-\mathrm{OAc})_{4}(24)\right]_{n}$ differs from the arrangement in chains with phenylene spacers (compare Figure 18a with Figure 16). The N ... N separation in $\left[\mathrm{Zn}_{2}(\mu-\mathrm{OAc})_{4}(\mathbf{2 4})\right]_{n}$ (see Figure 15) is $14.892 \AA$.

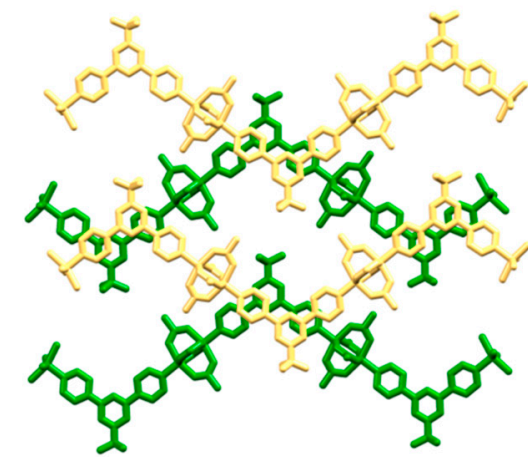

(a)

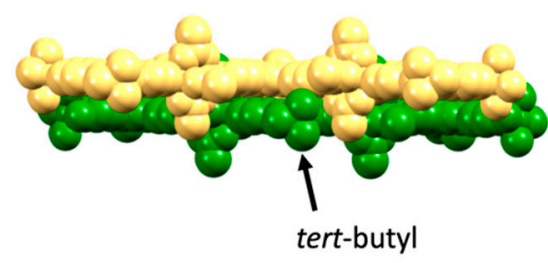

(b)

Figure 18. (a) Stacking of zigzag chains in $\left[\mathrm{Zn}_{2}(\mu-\mathrm{OAc})_{4}(24)\right]_{n}$ (CSD refcode FAKROA) with $\pi$ stacking between $4,2^{\prime}: 6^{\prime}, 4^{\prime \prime}$-tpy units, and (b) a space-filling representation of the chains shown in (a) viewed from the side to show the location of a tert-butyl group between a pair of acetato units in the adjacent layer. 
Before leaving this section, two examples of reactions of zinc(II) acetate with $4,2^{\prime}: 6^{\prime}, 4^{\prime \prime}$ tpy ligands illustrate, not for the first time, that serendipity contributes significantly to assembly processes. Ligand 22 (Scheme 6) and $\mathrm{Zn}(\mathrm{OAc})_{2} \cdot 2 \mathrm{H}_{2} \mathrm{O}$ react under conditions of crystal growth by layering to produce the expected $1 \mathrm{D}$-polymer $\left[\mathrm{Zn}_{2}(\mu-\mathrm{OAc})_{4}(22)\right]_{n}$. However, only preliminary crystallographic data could be obtained for this compound, and during attempts to grow better single crystals, a few $\mathrm{X}$-ray quality crystals of the 1D-coordination polymer $\left[2\left\{\mathrm{Zn}_{7}(\mu-\mathrm{OAc})_{10}\left(\mu_{4}-\mathrm{O}\right)_{2}(22)\right\}\right]_{n} \cdot n \mathrm{CH}_{2} \mathrm{Cl}_{2}$ were obtained. The compound crystallizes in the $P 2{ }_{1} 2_{1} 2_{1}$ space group, and the chiral 1D-chain (Figure 19a) is built up along a 2-fold screw axis. Although crystallization in $P 2{ }_{1} 2_{1} 2_{1}$ space group precludes the presence of crystallographic inversion centers, the $\left\{\mathrm{Zn}_{7}(\mu-\mathrm{OAc})_{10}\left(\mu_{4}-\mathrm{O}\right)_{2}\right\}$ cluster is close to being centrosymmetric. It appears that the packing of chains of the same handedness allows the peripheral naphthyl groups in $\mathbf{2 2}$ to be accommodated within a cleft between a pair of $4,2^{\prime}: 6^{\prime}, 4^{\prime \prime}$-tpy units [58]. A layering method was also used to grow single crystals from the reaction between ligand $\mathbf{2 3}$ (Scheme 6) and $\mathrm{Zn}(\mathrm{OAc})_{2} \cdot 2 \mathrm{H}_{2} \mathrm{O}$ [64]. Both block- and plate-shaped crystals were obtained in the same crystallization tube. Preliminary crystallographic data for the blocks confirmed the assembly of the 1D-polymer $\left[\mathrm{Zn}_{2}(\mu-\mathrm{OAc})_{4}(23)\right]_{n}$ with a zigzag structure analogous to that shown in Figure 15. However, the plates proved to be an unusual 1D, quadruple-stranded chain containing $\left\{\mathrm{Zn}_{5}(\mathrm{OAc})_{10}\right\}$ units (Figure 19b). The packing of the chains in $\left[\mathrm{Zn}_{5}(\mathrm{OAc})_{10}(23)_{4}\right]_{n} \cdot 11 n \mathrm{H}_{2} \mathrm{O}$ (Figure 19c) resembles that of the single zigzag chains (Figure 15). PXRD analysis of the bulk material revealed that the dominant product was $\left[\mathrm{Zn}_{5}(\mathrm{OAc})_{10}(23)_{4}\right]_{n} \cdot 11 n \mathrm{H}_{2} \mathrm{O}$, rather than the more typical single chain $\left[\mathrm{Zn}_{2}(\mu-\mathrm{OAc})_{4}(23)\right]_{n}$. However, the reasons for this remain obscure.

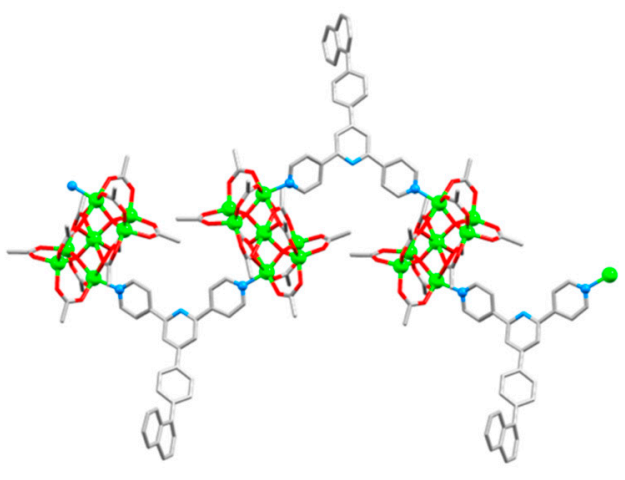

(a)

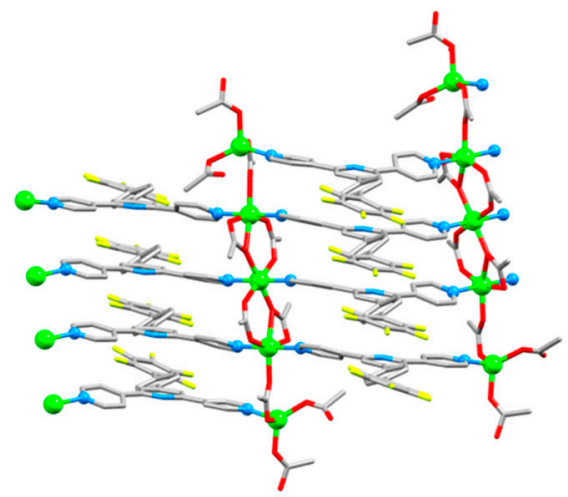

(b)

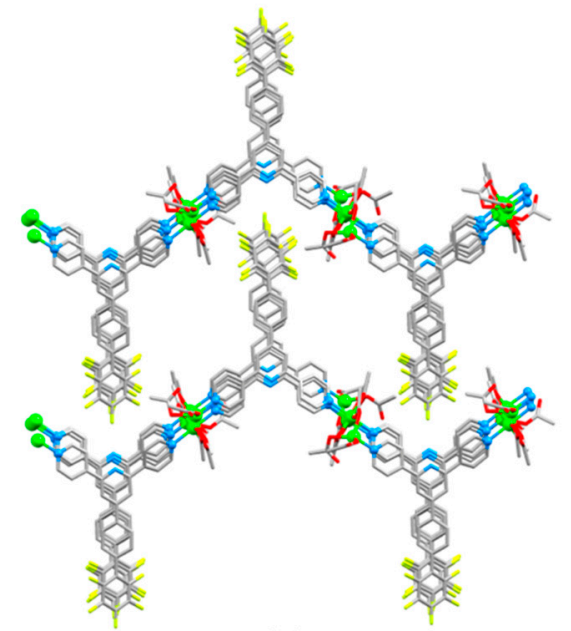

(c)

Figure 19. (a) Part of one helical chain in $\left[2\left\{\mathrm{Zn}_{7}(\mu-\mathrm{OAc})_{10}\left(\mu_{4}-\mathrm{O}\right)_{2}(22)\right\}\right]_{n} \cdot n \mathrm{CH}_{2} \mathrm{Cl}_{2}(\mathrm{CSD}$ refcode OFIWAD). (b) Part of the $1 \mathrm{D}$, quadruple-stranded chain in $\left[\mathrm{Zn}_{5}(\mathrm{OAc})_{10}(23)_{4}\right]_{n} \cdot 11 n \mathrm{H}_{2} \mathrm{O}$ (refcode QIJHEY) and (c) packing of adjacent chains to form a thick 2D-sheet (compare with Figure 15).

The discussion in this section has revealed that, although $\left\{\mathrm{Zn}_{2}(\mu-\mathrm{OAc})_{4}\right\}$ paddle-wheel building blocks are ubiquitous [65] and are ideally suited for connecting divergent $4,2^{\prime}: 6^{\prime}, 4^{\prime \prime}$ tpy metal-binding domains into 1D-coordination polymers, crystallization conditions may lead to competing assemblies. These may involve the incorporation of $\mathrm{Zn}(\mathrm{OAc})_{2}$ units with monodentate acetato ligands, or the assembly of $\mathrm{Zn}_{x}(\mathrm{OAc})_{y}$ clusters. Single products from a reaction cannot be assumed, and we again emphasize the need for routine PXRD to ensure that a single crystal structure is representative of the bulk crystalline material.

3.4. Assemblies Containing Zinc(II) and 4,2':6', $4^{\prime \prime}$-tpy Ligands Functionalized in the $4^{\prime}$-Position with Carboxylates

In Section 3.2, we described the structure of the 1D-coordination polymer $\left[\mathrm{Zn}_{2}\left(\mathrm{H}_{17}\right)_{2} \mathrm{Cl}_{4}\right]_{n}[48]$. Rather atypically, the carboxylic acid group in H17 (Scheme 6) remains protonated upon 
coordination. In other coordination assemblies involving H17 (see below) and those with ligands $\mathrm{H} 31-\mathrm{H} 34$ and $\mathrm{H}_{2} 35-\mathrm{H}_{2} 37$ (Scheme 10), deprotonation leads to $4,2^{\prime}: 6^{\prime}, 4^{\prime \prime}$-tpy ligands with carboxylate coordination sites. As we shall see, the presence of an anionic carboxylate donor often leads to preferential coordination of the latter with respect to metal-binding by pyridine donors, with the result that a significant number of assemblies feature pendant, non-coordinated pyridine units.

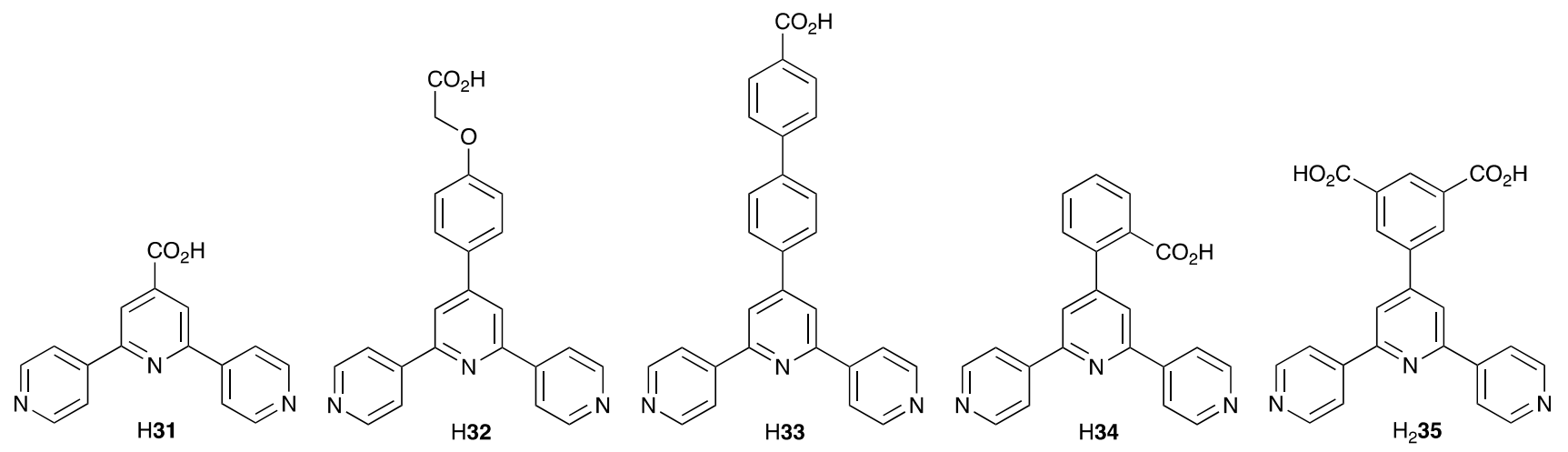<smiles>O=C(O)c1ccc(-c2cc(-c3ccc(C(=O)O)cc3)cc(-c3cc(-c4ccncc4)nc(-c4ccncc4)c3)c2)cc1</smiles><smiles>O=C(O)c1cc(Oc2ccc(-c3cc(-c4ccncc4)nc(-c4ccncc4)c3)cc2)cc(C(=O)O)c1</smiles>

Scheme 10. Structures of $4,2^{\prime}: 6^{\prime}, 4^{\prime \prime}$-tpy ligands functionalized in the $4^{\prime}$-position with substituents containing carboxylic acid moeities. See Scheme 6 for the structure of H17.

The reaction of zinc(II) acetate and $\mathrm{H} 31$ (Scheme 10) under solvothermal conditions $\left(\mathrm{H}_{2} \mathrm{O} / \mathrm{DMF}, \mathrm{pH} 4.0,140{ }^{\circ} \mathrm{C}\right)$ resulted in the formation of $\left[\mathrm{Zn}_{2}(31)_{2}\left(\mathrm{O}_{2} \mathrm{CH}\right)_{2}\right]_{n} \cdot 3.5 n \mathrm{H}_{2} \mathrm{O}$, with the formato ligand being derived from hydrolysis of DMF. Adjusting the ratio of solvents from 4:1 to 3:2, and raising the $\mathrm{pH}$ to 4.5 switches the assembly to $\left[\mathrm{Zn}_{2}(31)_{2}\left(\mathrm{O}_{2} \mathrm{CH}\right)_{2}\left(\mathrm{OH}_{2}\right)_{2}\right]_{n}$. $n \mathrm{H}_{2} \mathrm{O}$. In contrast, keeping the original conditions but replacing DMF by DMA (DMA = dimethylacetamide) led to $\left[\left\{\mathrm{Zn}_{2}(31)_{2}\left(\mathrm{OH}_{2}\right)_{4}\right\}_{n}\right] \cdot\left[\mathrm{MeCO}_{2}\right]_{2 n} \cdot n \mathrm{H}_{2} \mathrm{O}$. A further change in solvent ratio $\left(\mathrm{H}_{2} \mathrm{O}: \mathrm{DMA}=7: 3\right)$ and an increase in temperature to $160^{\circ} \mathrm{C}$ resulted in crystals of $\left[\mathrm{Zn}_{2}(31)_{2}\left(\mathrm{O}_{2} \mathrm{CMe}\right)_{2}\right]_{n} \cdot n \mathrm{H}_{2} \mathrm{O} \cdot\left[\mathrm{Zn}_{2}(31)_{2}\left(\mathrm{O}_{2} \mathrm{CH}\right)_{2}\right]_{n} \cdot 3.5 n \mathrm{H}_{2} \mathrm{O}$ and $\left[\mathrm{Zn}_{2}(31)_{2}\left(\mathrm{O}_{2} \mathrm{CMe}\right)_{2}\right]_{n}$. $n \mathrm{H}_{2} \mathrm{O}$ possess similar 2-fold interpenetrating $3 \mathrm{D}$-nets, and Figure 20a depicts part of the $\left[\mathrm{Zn}_{2}(31)_{2}\left(\mathrm{O}_{2} \mathrm{CH}\right)_{2}\right]_{n}$ network. Each $\mathrm{Zn}$ (II) center is tetrahedrally sited, being bound by two $\mathrm{N}$-donors from two different $31^{-}$ligands, one carboxylate group from a $31^{-}$ligand, and one monodentate formato ligand. In $\left[\mathrm{Zn}_{2}(31)_{2}\left(\mathrm{O}_{2} \mathrm{CMe}\right)_{2}\right]_{n} \cdot n \mathrm{H}_{2} \mathrm{O}$, the acetato ligand is classed as bidentate $(\mathrm{Zn}-\mathrm{O}=2.037(5)$ and 2.482(7) $⿱$ ) $)$. Both $\left[\mathrm{Zn}_{2}(31)_{2}\left(\mathrm{O}_{2} \mathrm{CH}\right)_{2}\left(\mathrm{OH}_{2}\right)_{2}\right]_{n} \cdot n \mathrm{H}_{2} \mathrm{O}$ and $\left[\left\{\mathrm{Zn}_{2}(31)_{2}\left(\mathrm{OH}_{2}\right)_{4}\right\}_{n}\right] \cdot\left[\mathrm{MeCO}_{2}\right]_{2 n} \cdot n \mathrm{H}_{2} \mathrm{O}$ feature 2D-nets with $6^{3}(h c b)$ topology (Figure 20b). Each net is essentially planar with axial $\mathrm{H}_{2} \mathrm{O}$, or $\mathrm{H}_{2} \mathrm{O}$ and $\mathrm{HCO}_{2}{ }^{-}$ligands decorating the upper and lower surfaces of a sheet [66]. Under hydrothermal conditions ( $\mathrm{pH}$ 4.0, $\left.160{ }^{\circ} \mathrm{C}\right), \mathrm{H} 31$ reacts with $\mathrm{ZnSO}_{4} \cdot 7 \mathrm{H}_{2} \mathrm{O}$, giving single crystals of $\left[\mathrm{Zn}(31)_{2}\right]_{n} \cdot n \mathrm{H}_{2} \mathrm{O}$. This assembly comprises a 2D $(4,4)$ net (Figure 20c) and a noticeable feature is that the $4,2^{\prime}: 6^{\prime}, 4^{\prime \prime}$ tpy unit binds to zinc(II) through only one $\mathrm{N}$-donor. Thus, each $31^{-}$ligand is ditopic. In other $(4,4)$ nets, $4,2^{\prime}: 6^{\prime}, 4^{\prime \prime}$-tpy typically acts as a ditopic $N, N^{\prime}$-linker (see Section 3.7) and, therefore, the presence of the $4^{\prime}-\mathrm{CO}_{2}{ }^{-}$is a critical factor is switching the coordination mode. Figure 20d shows that in $\left[\mathrm{Zn}(31)_{2}\right]_{n} \cdot n \mathrm{H}_{2} \mathrm{O}$, the uncoordinated terminal 
pyridyl groups protrude from above or below the sheet. Zhu and coworkers describe the 2D-sheet as being constructed from left- and right-handed helical chains, the chains being connected through $\mathrm{Zn}$ (II) centers, to give 2D-sheets based either on left- or righthanded helices [66]. Under hydrothermal conditions at $\mathrm{pH}$ 4.0, $\mathrm{H} 31$ reacts with $\mathrm{ZnCl}_{2}$ to give crystals of $\left[\mathrm{Zn}(31) \mathrm{Cl}_{n} \cdot n \mathrm{H}_{2} \mathrm{O}\right.$. Phthalic acid was present in the reaction mixture but was not incorporated as a co-ligand. However, in the absence of phthalic acid, no crystalline material was obtained [67]. This phenomenon is seen repeatedly, and we highlight further examples later in the review. A comparison of Figure 21a with Figure 20a illustrates that the 2-fold interpenetrating assembly in $[\mathrm{Zn}(31) \mathrm{Cl}]_{n} \cdot n \mathrm{H}_{2} \mathrm{O}$ mimics that in $\left[\mathrm{Zn}_{2}(31)_{2}\left(\mathrm{O}_{2} \mathrm{CH}\right)_{2}\right]_{n} \cdot 3.5 n \mathrm{H}_{2} \mathrm{O}$. Both compounds crystallize in the $P b c n$ space groups and the cell dimensions are similar: for $[\mathrm{Zn}(31) \mathrm{Cl}]_{n} \cdot n \mathrm{H}_{2} \mathrm{O}$ (refcode XEXPUN), $a=20.452(3)$, $b=7.2803(10), c=21.203(3) \AA$, and for $\left[\mathrm{Zn}_{2}(31)_{2}\left(\mathrm{O}_{2} \mathrm{CH}\right)_{2}\right]_{n} \cdot 3.5 n \mathrm{H}_{2} \mathrm{O}$ (refcode KEPKEY), $a=20.453(3), b=7.6063(13), c=21.826(3) \AA$.

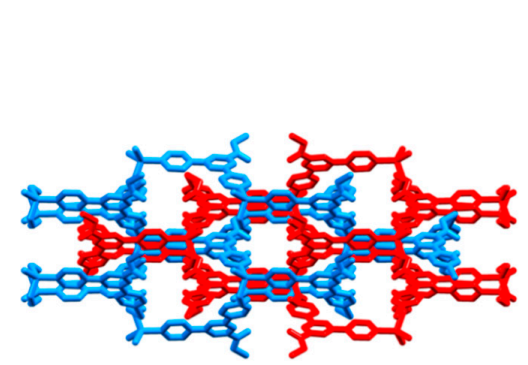

(a)

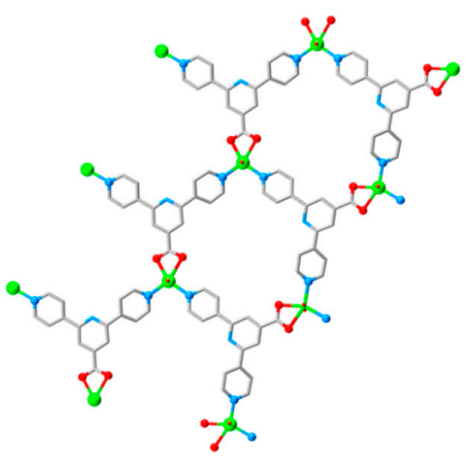

(b)

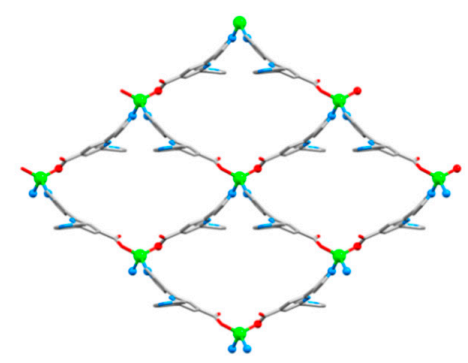

(c)

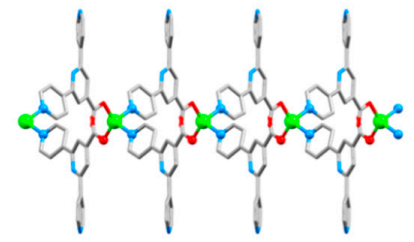

(d)

Figure 20. (a) Part of the 2-fold interpenetrating 3D-nets in $\left[\mathrm{Zn}_{2}(31)_{2}\left(\mathrm{O}_{2} \mathrm{CH}\right)_{2}\right]_{n} \cdot 3.5 n \mathrm{H}_{2} \mathrm{O}(\mathrm{CSD}$ refcode KEPKEY). (b) Part of the 2D, $6^{3}$ net in $\left[\left\{\mathrm{Zn}_{2}(31)_{2}\left(\mathrm{OH}_{2}\right)_{4}\right\}_{n}\right] \cdot\left[\mathrm{MeCO}_{2}\right]_{2 n} \cdot n \mathrm{H}_{2} \mathrm{O}$ (refcode KEPKOY). Parts of the $(4,4)$ net in $\left[\mathrm{Zn}(31)_{2}\right]_{n} \cdot n \mathrm{H}_{2} \mathrm{O}$ (refcode KEPLAV) viewed (c) down the crystallographic $c$-axis, and (d) down the $a$-axis, i.e., into the plane of the 2D-sheet.

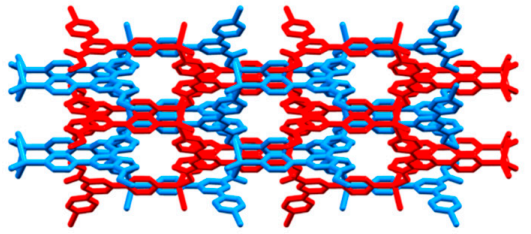

(a)

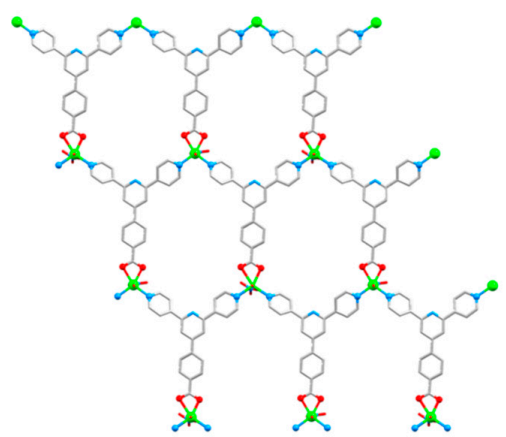

(b)

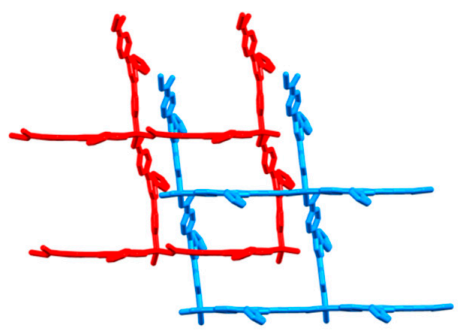

(c)

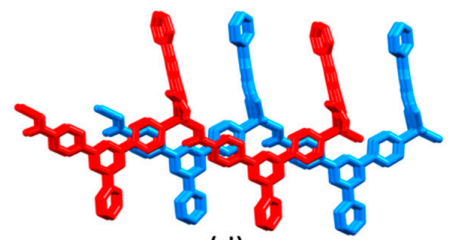

(d)

Figure 21. (a) Part of the 2-fold interpenetrating 3D-nets in $[\mathrm{Zn}(31) \mathrm{Cl}]_{n} \cdot n \mathrm{H}_{2} \mathrm{O}(\mathrm{CSD}$ refcode XEXPUN); note the similarity with Figure 20a. (b) Part of the 2D-net found in $\left[\left\{\mathrm{Zn}_{3}(31)_{3}\left(\mathrm{NO}_{3}\right)_{2}\left(\mathrm{OH}_{2}\right)_{4}\right\}_{n}\right]\left[\mathrm{NO}_{3}\right]_{n} \cdot 5 n \mathrm{DMF} \cdot 2 n \mathrm{H}_{2} \mathrm{O}$ (refcode DIDNUC). (c) Interpenetrated 2D-nets in $\left[\mathrm{Zn}_{2}(\mathbf{1 7})_{4}\right]_{n} \cdot 0.875 n \mathrm{H}_{2} \mathrm{O}$ (CSD refcode GEYTEL); (d) the same structure was determined for $\left[\mathrm{Zn}_{2}(\mathbf{1 7})_{4}\right]_{n} \cdot n \mathrm{H}_{2} \mathrm{O}$ (CSD recode JEYYUK). 
Ligands H17 and H31 (Schemes 6 and 10) differ in that the former contains a phenylene spacer between the $4,2^{\prime}: 6^{\prime}, 4^{\prime \prime}$-tpy and carboxylic acid domains. Solvothermal conditions $\left(\mathrm{H}_{2} \mathrm{O} / \mathrm{DMA}, \mathrm{HNO}_{3}, 80^{\circ} \mathrm{C}\right)$ were used for the reaction of $\mathrm{Zn}\left(\mathrm{NO}_{3}\right)_{2} \cdot 6 \mathrm{H}_{2} \mathrm{O}$ with $\mathrm{H} 17$, and the product was shown by $X$-ray diffraction to be $\left[\left\{\mathrm{Zn}_{3}(17)_{3}\left(\mathrm{NO}_{3}\right)_{2}\left(\mathrm{OH}_{2}\right)_{4}\right\}_{n}\right]\left[\mathrm{NO}_{3}\right]_{n} \cdot 5 n$ DMF. $2 n \mathrm{H}_{2} \mathrm{O}$ [68]. A 2D-net assembles (Figure 21b) and is closely related to that observed in $\left[\left\{\mathrm{Zn}_{2}(\mathbf{3 1})_{2}\left(\mathrm{OH}_{2}\right)_{4}\right\}_{n}\right] \cdot\left[\mathrm{MeCO}_{2}\right]_{2 n} \cdot n \mathrm{H}_{2} \mathrm{O}$ (Figure 20b). Under different solvothermal conditions $\left(\mathrm{H}_{2} \mathrm{O} / \mathrm{MeCN}, \mathrm{HNO}_{3}, 160{ }^{\circ} \mathrm{C}\right)$, the reaction between $\mathrm{Zn}\left(\mathrm{NO}_{3}\right)_{2} \cdot 6 \mathrm{H}_{2} \mathrm{O}$ and $\mathrm{H} 17$ led to $\left[\mathrm{Zn}_{2}(\mathbf{1 7})_{4}\right]_{n} \cdot 0.875 n \mathrm{H}_{2} \mathrm{O}$, consisting of 2-fold interpenetrating 2D-nets in which ligand $17^{-}$binds to $\mathrm{Zn}(\mathrm{II})$ through only one pyridine ring [30]. The same assembly is produced from $\mathrm{Zn}\left(\mathrm{NO}_{3}\right)_{2} \cdot 6 \mathrm{H}_{2} \mathrm{O}$ and $\mathrm{H} 17$ under different conditions $\left(\mathrm{H}_{2} \mathrm{O} / \mathrm{DMA}, \mathrm{pH}\right.$ 6.0, $\left.180{ }^{\circ} \mathrm{C}\right)$, although it is formulated as $\left[\mathrm{Zn}_{2}(\mathbf{1 7})_{4}\right]_{n} \cdot n \mathrm{H}_{2} \mathrm{O}$ [69]. A comparison of the two structures (both in space group $P-1$ ) reveals them to be isostructural. Cell dimensions for $\left[\mathrm{Zn}_{2}(\mathbf{1 7})_{4}\right]_{n} \cdot 0.875 n \mathrm{H}_{2} \mathrm{O}$ (CSD refcode GEYTEL) are $a=15.120(4), b=15.143(4)$, $c=17.514(5) \AA, \alpha=69.388(7), \beta=86.529(8), \gamma=79.694(9)^{\circ}$ [30], while those reported for $\left[\mathrm{Zn}_{2}(\mathbf{1 7})_{4}\right]_{n} \cdot n \mathrm{H}_{2} \mathrm{O}$ (CSD recode JEYYUK) are $a=15.102(6), b=15.117(6), c=17.397(7) \AA$, $\alpha=86.631(5) \beta=69.642(4), \gamma=79.346(5)^{\circ}$ [69]. The $2 \mathrm{D} \rightarrow 2 \mathrm{D}$ parallel interpenetration is shown in Figure 21c. Figure 21d illustrates the projection of arene substituents above and below the $2 \mathrm{D}$-sheets, and face-to-face $\pi$-stacking between arene rings in adjacent layers locks the assembly together. In $\left[\mathrm{Zn}_{2}(\mathbf{1 7})_{2} \mathrm{Cl}_{2}\right]_{n} \cdot 0.5 n \mathrm{H}_{2} \mathrm{O}$ (refcode JUHYOC), $\mathbf{1 7}^{-}$behaves in a tritopic manner, and a $6^{3}$ net assembles, and undergoes 2-fold interpenetration [70].

In $\left[\mathrm{Zn}_{2}(\mathbf{1 7})_{4}\right]_{n} \cdot n \mathrm{H}_{2} \mathrm{O}$ and $\left[\mathrm{Zn}_{2}(\mathbf{1 7})_{4}\right]_{n} \cdot 0.875 n \mathrm{H}_{2} \mathrm{O}$ (Figure $21 \mathrm{c}, \mathrm{d}$ ), the $4,2^{\prime}: 6^{\prime}, 3^{\prime \prime}$-tpy unit was monodentate, and this is also observed in $\left[\mathrm{Zn}(32)_{2}\right]_{n}$ (see Scheme 10 for H32). Note that ligands $\mathrm{H} 17$ and $\mathrm{H} 32$ differ only by the introduction of an $\mathrm{OCH}_{2}$ unit, and this has a significant effect on the assembly. [Zn(32) $\left.{ }_{2}\right]_{n}$ was prepared under hydrothermal conditions

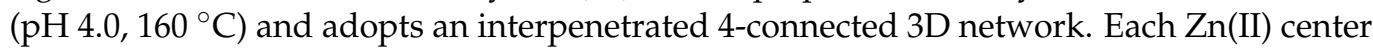
is bound by two pyridine rings (from different ligands) and two monodentate carboxylates (from different ligands) as shown in Figure 22a, and the structure propagates into a dia network which undergoes 3-fold interpenetration [71]. Upon moving from H17 and H32 to H33 (Scheme 10), the distance between the $4,2^{\prime}: 6^{\prime}, 4^{\prime \prime}$-tpy and carboxylic acid domains increases further; note that $\mathrm{H} 33$ possesses a relatively rigid backbone. The reaction of $\mathrm{H} 33$ with $\mathrm{Zn}\left(\mathrm{NO}_{3}\right)_{2} \cdot 6 \mathrm{H}_{2} \mathrm{O}$ under solvothermal conditions $\left(\mathrm{H}_{2} \mathrm{O} / \mathrm{DMF}, 120^{\circ} \mathrm{C}\right)$ produced $\left[\mathrm{Zn}(33)_{2}\right]_{n} \cdot x n \mathrm{H}_{2} \mathrm{O}$ ( $x$ was not determined). As in the examples above, the $4,2^{\prime}: 6^{\prime}, 4^{\prime \prime}$-tpy domain in $33^{-}$coordinates only through one pyridine ring, but in contrast to the coordination environment in $\left[\mathrm{Zn}(32)_{2}\right]_{n}$ (Figure 22a), the $\mathrm{Zn}$ (II) centers in $\left[\mathrm{Zn}(33)_{2}\right]_{n}$ are dinuclear (Figure 22b). Each unit acts as an 8-connected node (only six ligand linkers are shown in Figure $22 \mathrm{~b}$ for clarity). The 3D-assembly is described by the authors as a $(2,8)$-connected network with a topological point symbol of $\left\{4^{24} \cdot 6^{4}\right\}$; see Section 3.8 for a comparison with the cadmium analog. The MOF was used as a multi-responsive fluorescent sensor for simultaneously detecting $\mathrm{Hg}^{2+},\left[\mathrm{CrO}_{4}\right]^{2-}$ and $\left[\mathrm{Cr}_{2} \mathrm{O}_{7}\right]^{2-}$ ions in aqueous solution with low detection limits [72].

$\mathrm{Hu}$ and coworkers have reported a series of six zinc(II)-containing assemblies with the conjugate base of H34 (Scheme 10) [73]. Crystals were all grown under hydrothermal conditions $\left(180^{\circ} \mathrm{C}\right)$, and we include here only those structures in which there is no coligand. The reaction of $\mathrm{ZnCl}_{2}$ and $\mathrm{H} 34$ gave $[\mathrm{Zn}(34) \mathrm{Cl}]_{n}$, while with $\mathrm{Zn}(\mathrm{OAc})_{2} \cdot 2 \mathrm{H}_{2} \mathrm{O}$, crystals of $\left[\mathrm{Zn}_{2}(34)_{4}\right]_{n} \cdot 2 n \mathrm{H}_{2} \mathrm{O}$ were obtained. It is relevant to compare the structures of these assemblies with those containing $17^{-}$, because linkers $17^{-}$and $34^{-}$are isomers. We described earlier that in $\left[\mathrm{Zn}_{2}(\mathbf{1 7})_{2} \mathrm{Cl}_{2}\right]_{n} \cdot 0.5 n \mathrm{H}_{2} \mathrm{O}$ [70], the ligand bound three $\mathrm{Zn}$ centers and assembled a $6^{3}$ net. In $\left[\mathrm{Zn}(34) \mathrm{Cl}_{n}\right.$, the ligand is again tritopic (Figure 23a), but the differing vectorial properties of the donor atoms compared to those in $17^{-}$lead to a $2 \mathrm{D}$ sheet architecture which the authors describe in terms of 1D-loop chains, which are further linked by a terminal nitrogen atom and carboxylate group. As Figure 23b illustrates, the structure is not easy to envisage. $\left[\mathrm{Zn}_{2}(34)_{4}\right]_{n} \cdot 2 n \mathrm{H}_{2} \mathrm{O}$ is also a $2 \mathrm{D}$-network, but in this assembly, $34^{-}$is ditopic and coordinates through one pyridine ring and the carboxylate group. Figure 23c shows the coordination modes of the two independent ligands. The 
structure propagates into a 2D sheet, and the phenyl rings are involved in face-to-face contacts between the layers (Figure 23d). Figure 23 shows that a feature common to both $[\mathrm{Zn}(34) \mathrm{Cl}]_{n}$ and $\left[\mathrm{Zn}_{2}(34)_{4}\right]_{n} \cdot 2 n \mathrm{H}_{2} \mathrm{O}$ is that the arene rings of the 2-carboxyphenyl groups are located on the upper and lower surfaces of the 2D-nets.

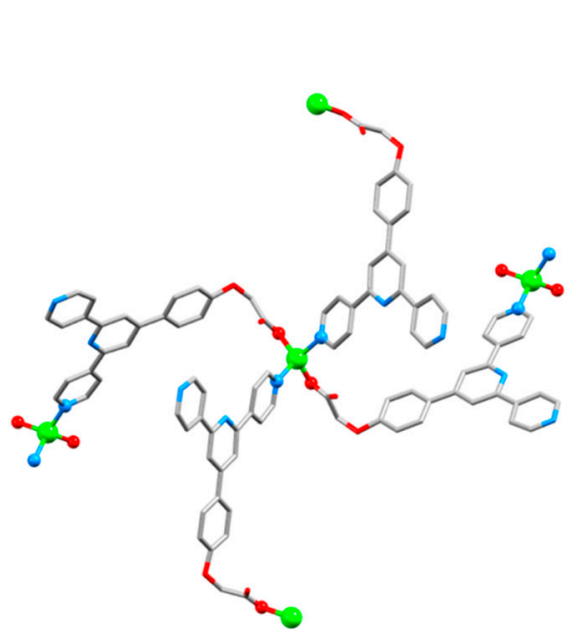

(a)

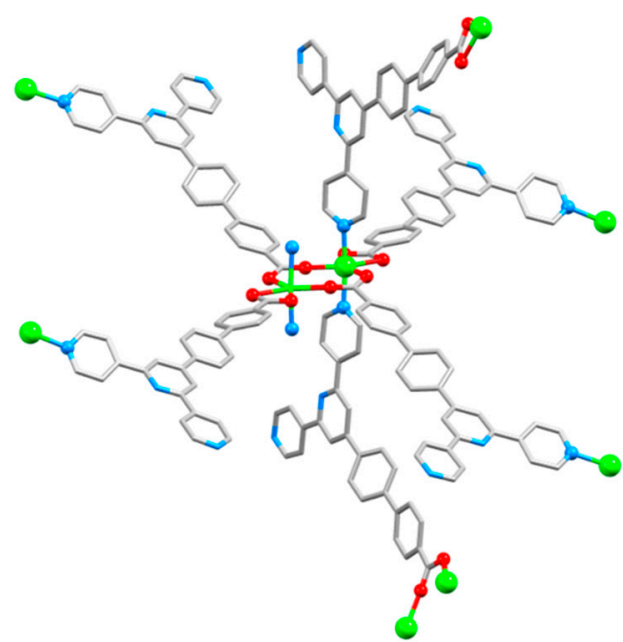

(b)

Figure 22. (a) Coordination environment of $\mathrm{Zn}(\mathrm{II})$ in $\left[\mathrm{Zn}(32)_{2}\right]_{n}$ which leads to the metal center being a 4-connecting node in a dia net (CSD refcode ZIDREL). (b) Coordination environment around the 8-connecting node in $\left[\mathrm{Zn}(33)_{2}\right]_{n}$ (refcode TEZJOA); for clarity, two of the eight ligand-linkers are represented only with the coordinated nitrogen atom.

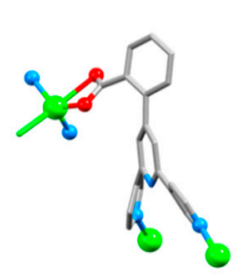

(a)

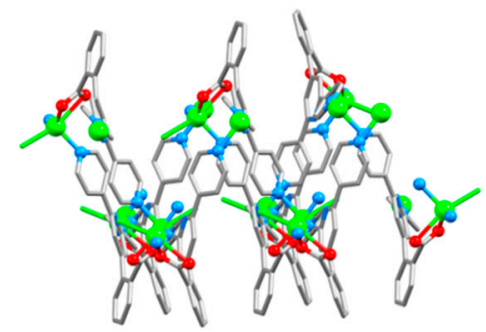

(b)

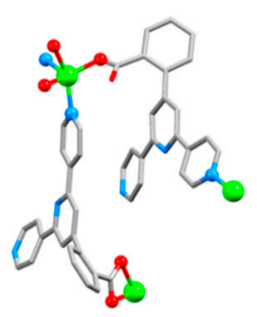

(c)

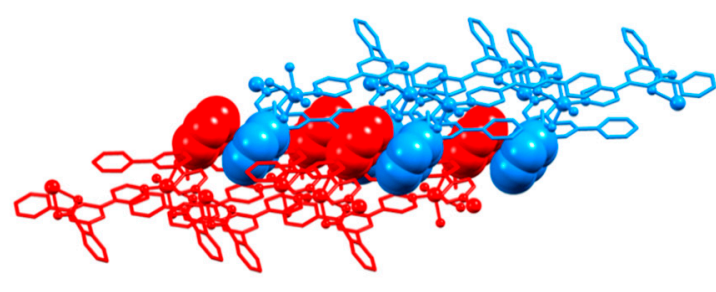

(d)

Figure 23. (a) The tritopic binding-mode of $34^{-}$in $[\mathrm{Zn}(34) \mathrm{Cl}]_{n}(\mathrm{CSD}$ refcode FIZVUH) and (b) part of a $2 \mathrm{D}-\mathrm{sheet}$ in $[\mathrm{Zn}(34) \mathrm{Cl}]_{n}$. (c) The two crystallographically independent $34^{-}$linkers in $\left[\mathrm{Zn}_{2}(34)_{4}\right]_{n} \cdot 2 n \mathrm{H}_{2} \mathrm{O}$ (refcode FIZWAO), and (d) $\pi$-stacking between phenyl rings in adjacent $2 \mathrm{D}$ sheets in $\left[\mathrm{Zn}_{2}(34)_{4}\right]_{n} \cdot 2 n \mathrm{H}_{2} \mathrm{O}$.

Dicarboxylic acids $\mathrm{H}_{2} 35, \mathrm{H}_{2} 36$ and $\mathrm{H}_{2} 37$ (Scheme 10) all act as tetratopic ligands with zinc(II). Feng and coworkers have described the solvothermal reaction of $\mathrm{H}_{2} 35$ with $\mathrm{Zn}\left(\mathrm{NO}_{3}\right)_{2} \cdot 6 \mathrm{H}_{2} \mathrm{O}\left(\mathrm{DMA}, 120^{\circ} \mathrm{C}\right)$ leading to crystals of $[\mathrm{Zn}(35)]_{n} \cdot n \mathrm{DMA} \cdot 2 n \mathrm{H}_{2} \mathrm{O}$ [74]. The compound (refcode WUWBUO) crystallizes in the triclinic $P-1$ space group and cell dimensions are identical to those of $[\mathrm{Zn}(35)]_{n} \cdot 1.25 n \mathrm{H}_{2} \mathrm{O}$ and $[\mathrm{Zn}(35)]_{n} \cdot 4.17 n \mathrm{H}_{2} \mathrm{O}$, the structures of which have been deposited to the CSD as communications [75,76]. Both the $\mathrm{Zn}$ (II) center and $35^{2-}$ ligand in $[\mathrm{Zn}(35)]_{n}$ are 4-connecting nodes, and both are distorted tetrahedral. Figure 24a illustrates part of the 3D-network (with dia topology) that is assembled; the view highlights the hexagonal channels running parallel to the $a$-axis. Two-fold interpenetration occurs as shown in Figure 24b. On going from $\mathrm{H}_{2} 35$ to $\mathrm{H}_{2} 36$, additional phenylene spacers are introduced (Scheme 10). The solvothermal reaction of $\mathrm{H}_{2} 36$ with $\mathrm{Zn}\left(\mathrm{NO}_{3}\right)_{2} \cdot 6 \mathrm{H}_{2} \mathrm{O}$ $\left(\mathrm{DMF}, 100{ }^{\circ} \mathrm{C} \text { ) yielded crystals of }[\mathrm{Zn}(36)]_{n} \cdot 4 n \mathrm{DMF}[77] \text {. As in [Zn(35) }\right]_{n}$, both $\mathrm{Zn}(\mathrm{II})$ and $36^{2-}$ in $[\mathrm{Zn}(36)]_{n} \cdot 4 n \mathrm{DMF}$ are 4 -connecting, approximately tetrahedral nodes (Figure $25 \mathrm{a}$ ). However, in this case a lon net assembles, with 2-fold interpenetration (Figure 25b). The 
lon net includes boat-form six-membered rings which are not present in a dia net [78]. The activated $[\mathrm{Zn}(36)]_{n}$ MOF has high porosity with a micropore volume of $0.89 \mathrm{~m}^{3} \mathrm{~g}^{-1}$. In addition, $[\mathrm{Zn}(36)]_{n} \cdot 4 n \mathrm{DMF}$ exhibits efficient luminescence sensing for $\mathrm{Cu}^{2+}$ ions [77]. The conformational flexibility of $\mathrm{H}_{2} 37$ (Scheme 10) contrasts with that of $\mathrm{H}_{2} 35$ and $\mathrm{H}_{2} 36$. The reaction of $\mathrm{H}_{2} 37$ with $\mathrm{Zn}\left(\mathrm{NO}_{3}\right)_{2} \cdot 6 \mathrm{H}_{2} \mathrm{O}$ under solvothermal conditions $\left(\mathrm{MeCN} / \mathrm{H}_{2} \mathrm{O} / \mathrm{NaOH}\right.$, $140{ }^{\circ} \mathrm{C}$ ) produced crystals of solvated $[\mathrm{Zn}(37)]_{n}$. Both the ligand (Figure $25 \mathrm{c}$ ) and $\mathrm{Zn}(\mathrm{II})$ center are 4-connecting nodes. A complex 3D-net assembles and, as in the previous examples, the large voids present in the net, lead to 2 -fold interpenetration. In common with related MOFs, the presence of solvent-accessible voids coupled with the non-coordinated pyridine ring of the $4,2^{\prime}: 6^{\prime}, 4^{\prime \prime}$-tpy domain make $[\mathrm{Zn}(37)]_{n}$ a candidate for fluorescence sensing for both metal cations and small molecules [79].

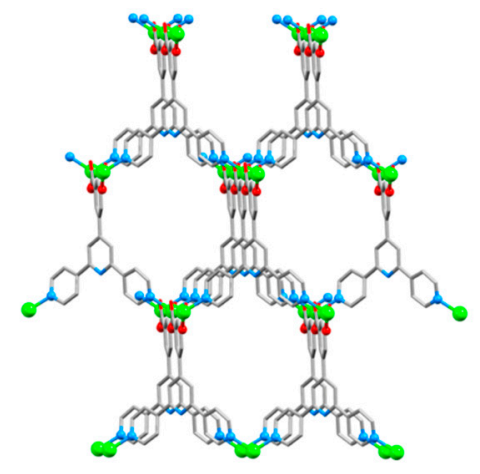

(a)

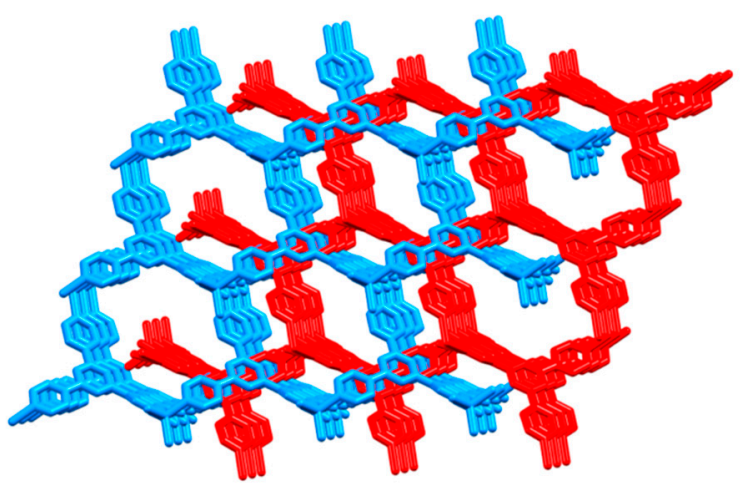

(b)

Figure 24. (a) Part of one 3D-network in $[\mathrm{Zn}(35)]_{n}$ with both $\mathrm{Zn}(\mathrm{II})$ and the ligand acting at 4connecting nodes (CSD refcode HOSMEK). The nets in QIDQUS and WUWBUO are identical. (b) The 2-fold interpenetration of 3D-nets in $[\mathrm{Zn}(35)]_{n}$.

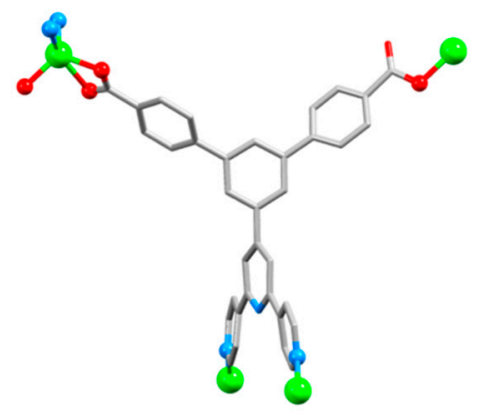

(a)

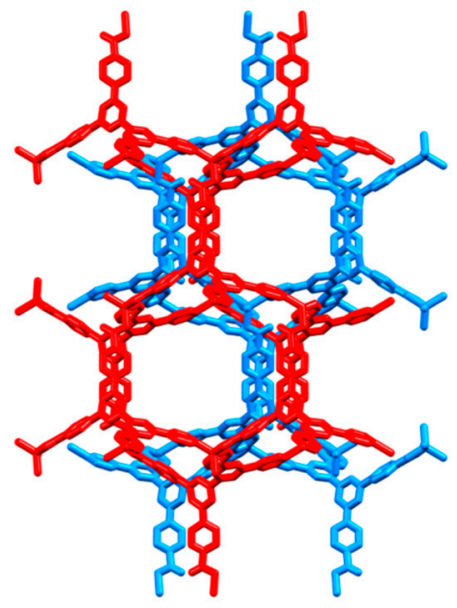

(b)

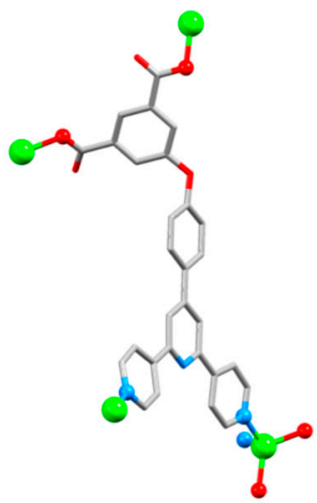

(c)

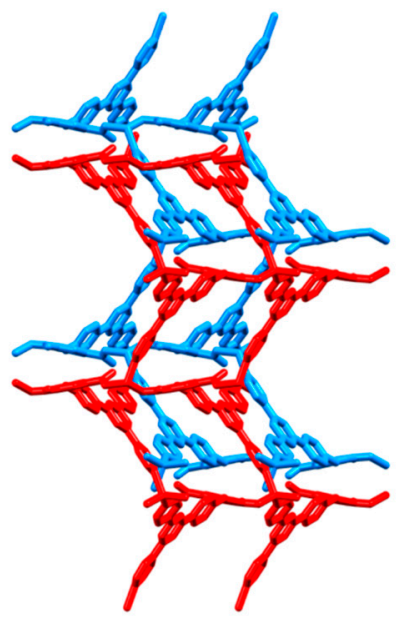

(d)

Figure 25. (a) The tetratopic binding-mode of $36^{2-}$ in $[\mathrm{Zn}(36)]_{n} \cdot 4 n \mathrm{DMF}$ (CSD refcode QOZSIJ) and (b) the 2-fold interpenetration of lon-nets in $[\mathrm{Zn}(36)]_{n} \cdot 4 n \mathrm{DMF}$. (c) The $37^{2-}$ ligand is a 4-connecting node in $[\mathrm{Zn}(37)]_{n}$ (refcode SAHWEG). (d) Part of the 2-fold interpenetrating 3D-nets in $[\mathrm{Zn}(37)]_{n}$ viewed down the crystallographic $c$-axis.

3.5. Assemblies Containing Zinc(II) and 4,2': $6^{\prime}, 4^{\prime \prime}$-tpy Ligands Functionalized in the $4^{\prime}$-Position with a Pyridinyl Group or Other Nitrogen Heterocycles

The introduction into a 4,2': $6^{\prime}, 4^{\prime \prime}$-tpy unit of an additional nitrogen-containing heterocyclic substituent is a popular strategy for increasing the dimensionality of a coordination assembly. However, just as we have noted that the $4,2^{\prime}: 6^{\prime}, 4^{\prime \prime}$-tpy may bind in either a monoor ditopic manner, it is difficult to predict whether the added heterocyclic substituent will 
be coordinatively active or innocent. Scheme 11 summarizes the ligands discussed in this section; note that ligands $\mathbf{3 8}, \mathbf{3 9}$ and $\mathbf{4 0}$ are isomers of each other.<smiles>c1cc(-c2cc(-c3ccncc3)nc(-c3ccncc3)c2)ccn1</smiles>

38<smiles>c1cncc(-c2cc(-c3ccncc3)nc(-c3ccncc3)c2)c1</smiles>

39<smiles>c1ccc(-c2cc(-c3ccncc3)nc(-c3ccncc3)c2)nc1</smiles>

40<smiles>Clc1cnccc1-c1cc(-c2ccncc2)nc(-c2ccncc2)c1</smiles>

41<smiles>c1cc(-c2cc(-c3ccc(-c4cnccn4)cc3)cc(-c3ccncc3)n2)ccn1</smiles><smiles>c1cc(-c2cc(-c3ccc(-c4nnn[nH]4)cc3)cc(-c3ccncc3)n2)ccn1</smiles>

$\mathrm{H} 46$

Scheme 11. Structures of $4,2^{\prime}: 6^{\prime}, 4^{\prime \prime}$-tpy ligands functionalized in the $4^{\prime}$-position with a pyridinyl group or other nitrogen heterocycles.

Ligand 38 appears both as a ditopic and tritopic building block in coordination assemblies with zinc(II). Reactions with zinc(II) halides yield varying products, and whether this is a consequence of reactions conditions or serendipity is difficult to assess in the absence of PXRD data for bulk materials. Hu and coworkers reported that, under hydrothermal conditions $\left(160^{\circ} \mathrm{C}\right), \mathrm{ZnCl}_{2} \cdot 2 \mathrm{H}_{2} \mathrm{O}$ and 38 react to give single crystals of $\left[\mathrm{Zn}(38) \mathrm{Cl}_{2}\right]_{n}$. The structure is a helical 1D-coordination polymer with pendant, non-coordinated pyridin-4-yl substituents (Figure 26a) [80]. In contrast, Dehnen and coworkers observed the assembly of interlocked molecular cages in $\left[\mathrm{Zn}_{12}(38)_{8} \mathrm{Cl}_{24}\right]_{n} \cdot n \mathrm{CHCl}_{3}$ when crystals were grown by layering a chloroform solution of 38 over a methanol solution of $\mathrm{ZnCl}_{2}$ [81]. Dehnen reported that a change to $\mathrm{ZnI}_{2}$ resulted in the assembly of a 1D-chain [81], but in contrast, we have observed that reacting $\mathrm{ZnI}_{2}$ with $\mathbf{3 8}$ under conditions of crystal growth by layering resulted in the assembly of polycatenated icosahedral $\left[\mathrm{Zn}_{12}(38)_{8} \mathrm{I}_{24}\right]$ cages [59], analogous to those in $\left[\mathrm{Zn}_{12}(38)_{8} \mathrm{Cl}_{24}\right]_{n} \cdot n \mathrm{CHCl}_{3}$ [81]. Retaining a layering technique, we also demonstrated that the introduction of a chloro-substituent on going from ligand 38 to 41 (Scheme 11) affects the outcome of the reaction with $\mathrm{ZnI}_{2}$. Instead of the assembly of an $\left[\mathrm{Zn}_{12}(38)_{8} \mathrm{I}_{24}\right]$ cage, crystals of the 1D-polymer $\left[\mathrm{Zn}(41) \mathrm{I}_{2}\right]_{n} \cdot 0.25 n \mathrm{H}_{2} \mathrm{O}$ were isolated. A combination of 41 and zinc(II) chloride also gave a 1D-coordination polymer, $\left[\mathrm{Zn}(\mathbf{4 1}) \mathrm{Cl}_{2}\right]_{n}[59]$.

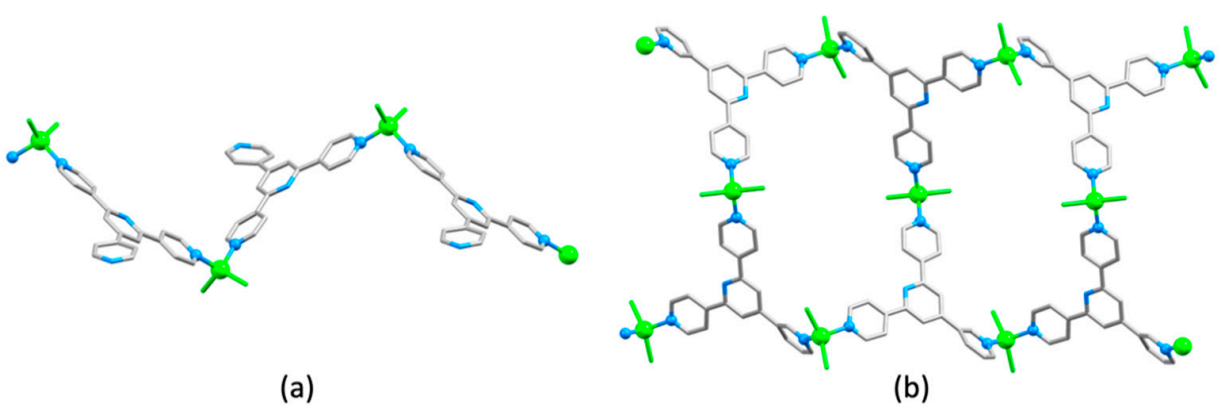

Figure 26. (a) Part of the 1D-polymer in $\left[\mathrm{Zn}(38) \mathrm{Cl}_{2}\right]_{n}$ (CSD refcode AGUPEY), showing non-coordinated $4^{\prime}$-(pyridin-4yl) substituents. (b) Part of 1 D-ladder in $\left[\mathrm{Zn}_{3}(39)_{2} \mathrm{Cl}_{6}\right]_{n} \cdot n \mathrm{H}_{2} \mathrm{O}$ (refcode ZOKFAI). 
We saw earlier that, under hydrothermal conditions, $\mathrm{Hu}$ and coworkers assembled $\left[\mathrm{Zn}(38) \mathrm{Cl}_{2}\right]_{n}$ with a simple 1D-polymer assembly (Figure 26a) [80]. An interesting change occurs when moving from 38 to its isomer 39. Again, under solvothermal conditions, $\mathrm{ZnCl}_{2}$ reacts with 39 to produce $\left[\mathrm{Zn}_{3}(39)_{2} \mathrm{Cl}_{6}\right]_{n} \cdot n \mathrm{H}_{2} \mathrm{O}$. This consists of a $1 \mathrm{D}$-coordination polymer in which 39 acts as a tritopic ligand, leading to a ladder-type of assembly (Figure 26b) [82]. Unfortunately, there is no example of a coordination assembly featuring the third ligand isomer 40 with a zinc(II) halide, so no direct comparisons are possible. However, a comparison can be made between the structures of the coordination polymers formed in the reactions of $\mathrm{Zn}(\mathrm{OAc})_{2} \cdot 2 \mathrm{H}_{2} \mathrm{O}$ and ligands 38 or 40 . Zhang et al. reported that crystal growth by layering at room temperature led to the assembly of $\left[\mathrm{Zn}_{2}(\mu-\mathrm{OAc})_{4}(38)\right]_{n} \cdot 1.5 n \mathrm{MeOH}$ and $\left[\mathrm{Zn}(\mathrm{OAc})_{2}(40)\right]_{n}[61]$. Both contain 1D-chains, and the $4^{\prime}$-pyridinyl substituent is noncoordinated. The assembly in $\left[\mathrm{Zn}_{2}(\mu-\mathrm{OAc})_{4}(38)\right]_{n} \cdot 1.5 n \mathrm{MeOH}$ falls into the category of the structures described in Section 3.3, while $\left[\mathrm{Zn}(\mathrm{OAc})_{2}(40)\right]_{n}$ possesses a helical 1D-polymer. In both crystal growth experiments, a ratio of Zn:ligand of 2:1 was used, and the difference in the assemblies is not unique (see Table 2 and discussion) but is not easily explained.

The pyrimidin-5-yl functionalities in ligands 42 and 43 remain non-coordinated in the $1 \mathrm{D}$-coordination polymers $\left[\mathrm{Zn}(42) \mathrm{Cl}_{2}\right]_{n},\left[\mathrm{Zn}(42) \mathrm{I}_{2}\right]_{n}$ and $\left[\mathrm{Zn}(43) \mathrm{I}_{2}\right]_{n} \cdot n \mathrm{MeOH}[83]$. In contrast, Granifo et al. reported that 44 combined with $\mathrm{Zn}(\mathrm{acac})_{2}$ (Hacac = pentane-2,4dione) in a preparative scale reaction to give a mixture of needle-like and block-like crystals. These were separated by hand, and structural analysis confirmed the assembly of the mononuclear complex [ $\mathrm{Zn}(44)_{2}(\mathrm{acac})_{2}$ ] (in which 44 is monodentate, coordinating through one pyridine ring) and a coordination polymer $\left[\mathrm{Zn}(44)(\mathrm{acac})_{2}\right]_{n}$ (Figure 27b) [84]. The coordination mode of $\mathbf{4 4}$ is atypical since, although the ligand is ditopic, the preference is for coordination through one pyridine and one pyrimidine ring rather than through both the outer pyridine rings of the $4,2^{\prime}: 6^{\prime}, 4^{\prime \prime}$-tpy unit. The formation of $\left[\mathrm{Zn}(44)_{2}(\mathrm{acac})_{2}\right]$ and $\left[\mathrm{Zn}(44)(\mathrm{acac})_{2}\right]_{n}$ is yet another example of competition between assemblies formed under the same synthetic conditions, and illustrates once again, the difficulties in predictive crystal engineering with these families of ligands. Granifo and coworkers have also prepared 45 in which a pyrazin-2-yl group replaces the pyrimidin-5-yl functionality in 44 . The coordination behavior of 45 in $\left[\mathrm{Zn}(45)(\mathrm{acac})_{2}\right]_{n}$ [85] mimics that of 44 in $\left[\mathrm{Zn}(45)(\mathrm{acac})_{2}\right]_{n}$ as can be seen from the overlay of the two polymer chains in Figure 27b.

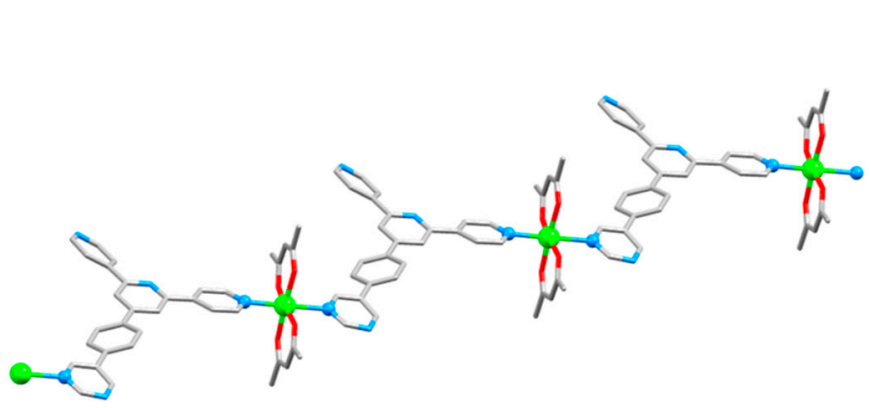

(a)

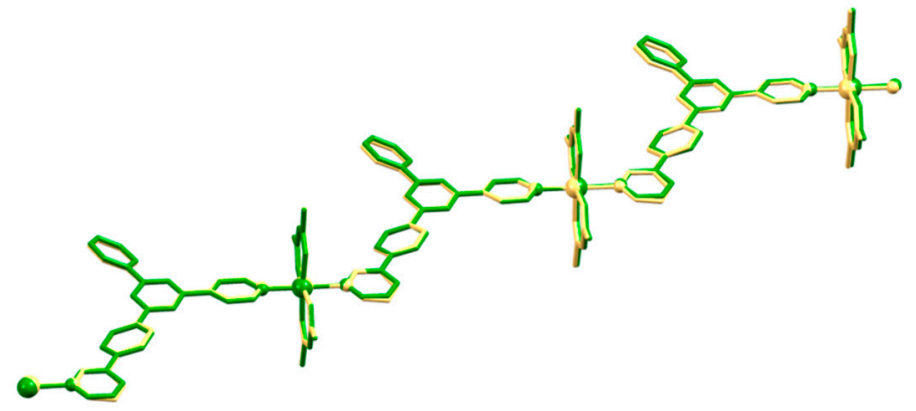

(b)

Figure 27. (a) Part of the $1 \mathrm{D}$-chain in $\left[\mathrm{Zn}(44)(\mathrm{acac})_{2}\right]_{n}$ (CSD refcode QIXYON) showoing coordination to $\mathrm{Zn}$ (II) through pyrimidine and pyridine donors. (b) Overlay of parts of the polymers in $\left[\mathrm{Zn}(44)(\mathrm{acac})_{2}\right]_{n}$ (shown in cream) and $\left[\mathrm{Zn}(45)(\mathrm{acac})_{2}\right]_{n}$ (in green, refcode QIXYON01).

The tetrazole-functionalized compound H46 (Scheme 11) binds zinc(II) to form $\left[\mathrm{Zn}_{3}(46)_{6}\left(\mathrm{OH}_{2}\right)_{2}\right]_{n} \cdot 2 \mathrm{H}_{2} \mathrm{O}$ No synthetic details are available for this CSD communication [86]. $\left[\mathrm{Zn}_{3}(46)_{6}\left(\mathrm{OH}_{2}\right)_{2}\right]_{n} \cdot 2 \mathrm{H}_{2} \mathrm{O}$ crystallizes in the monoclinic space group $\mathrm{C} 2 / c$, and Figure $28 \mathrm{a}, \mathrm{b}$ displays two views of the basic building block. Central to this is a linear $\mathrm{Zn}_{3}$ core, with each $\mathrm{Zn}$... Zn vector bridged by three triazolato-units. Of the six $4,2^{\prime}: 6^{\prime}, 4^{\prime \prime}$-tpy domains associated with this trinuclear core, four bind to $\mathrm{Zn}$ (II) centers in neighboring $\mathrm{Zn}_{3}$ units, and two are non-coordinating (Figure 28a). The assembly propagates into a 2D-network, as 
illustrated in Figure 28c,d. Although the architecture is unusual in terms of the coordination mode of the $4,2^{\prime}: 6^{\prime}, 4^{\prime \prime}$-tpy domains, it is pertinent to note that a search of the CSD [16] revealed that the $\left\{\mathrm{Zn}_{3}(\mu \text {-triazolato })_{6}\right\}$ unit is well represented, and it is therefore likely that the assembly of this motif directs the assembly in $\left[\mathrm{Zn}_{3}(46)_{6}\left(\mathrm{OH}_{2}\right)_{2}\right]_{n} \cdot 2 \mathrm{H}_{2} \mathrm{O}$.

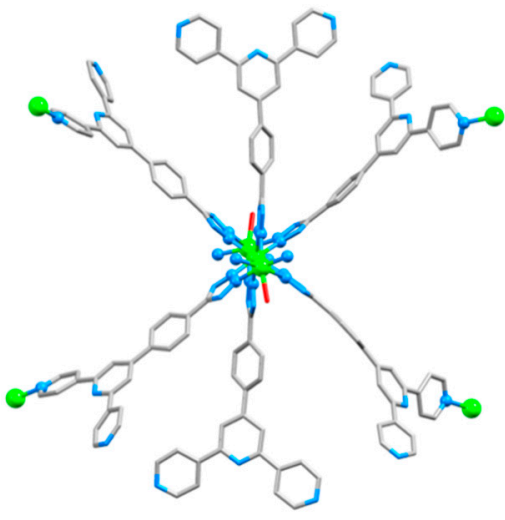

(a)

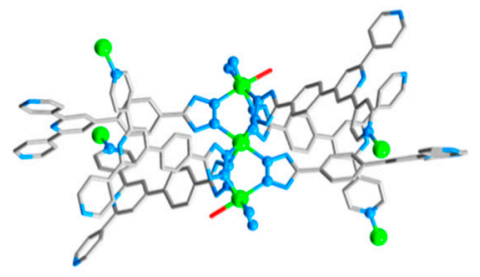

(b)

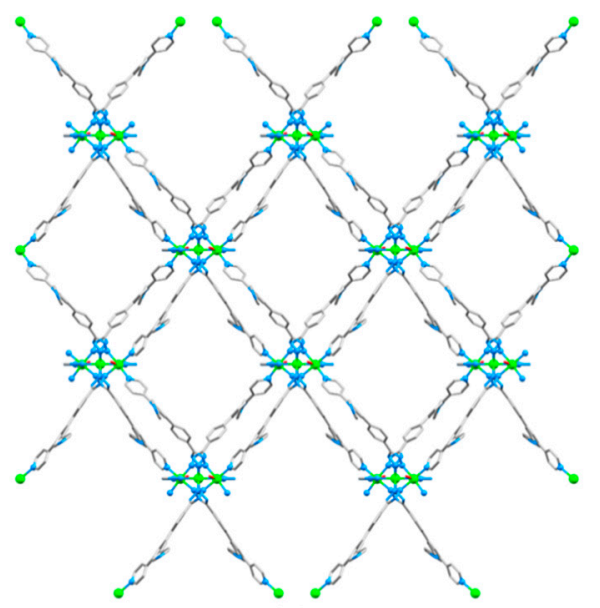

(c)

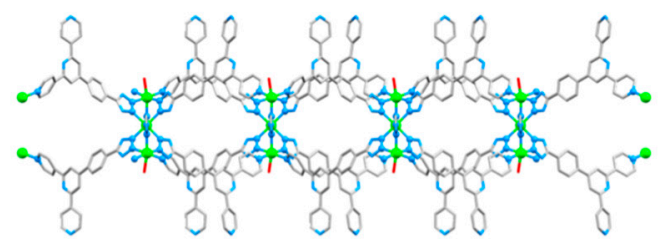

(d)

Figure 28. The structure of $\left[\mathrm{Zn}_{3}(46)_{6}\left(\mathrm{OH}_{2}\right)_{2}\right]_{n} \cdot 2 \mathrm{H}_{2} \mathrm{O}$ (CSD refcode NUBZUI). Two views of the $\left\{\mathrm{Zn}_{3}(46)_{6}\left(\mathrm{OH}_{2}\right)_{2}\right\}$ building block showing (a) four coordinating and two non-coordinating 4,2':6' $4^{\prime \prime}$-tpy units, and (b) the $\left\{\mathrm{Zn}_{3}(\mu \text {-triazolato })_{6}\right\}$ node. Part of one $2 \mathrm{D}$-network, viewed (c) down the crystallographic $c$-axis, and (d) down the $a$-axis; the non-coordinated $4,2^{\prime}: 6^{\prime}, 4^{\prime \prime}$-tpy units with their phenylene spacers are omitted for clarity.

\subsection{An Assembly Containing Zinc(II) and a $4,2^{\prime}: 6^{\prime}, 4^{\prime \prime}$-tpy Ligand Functionalized in the} $4^{\prime}$-Position with an Oxygen Heterocycle

$4^{\prime}$-(1,3-Benzodioxol-5-yl)-4,2':6', $4^{\prime \prime}$-terpyridine (47) appears to be the sole example of a 4,2':6 $6^{\prime}, 4^{\prime \prime}$-tpy bearing a $4^{\prime}$-substituent with an $O$-heterocyclic unit. Its reactions with $\mathrm{ZnI}_{2}$ and $\mathrm{Zn}(\mathrm{OAc})_{2} \cdot 2 \mathrm{H}_{2} \mathrm{O}$ under ambient conditions of crystal growth by layering, led to crystals of $\left[\mathrm{Zn}(47) \mathrm{I}_{2}\right]_{n}$ and $\left[\mathrm{Zn}_{2}(\mu-\mathrm{OAc})_{4}(47)_{2}\right]$, respectively. The iodido complex is a 1D-coordination polymer with the chain (Figure 29a) built up by a glide plane. In contrast, $\left[\mathrm{Zn}_{2}(\mu-\mathrm{OAc})_{4}(47)_{2}\right]$ is a discrete molecular complex (Figure $29 \mathrm{~b}$ ), again illustrating a $4,2^{\prime}: 6^{\prime}, 4^{\prime \prime}$-tpy acting as a monodentate ligand. Little can be concluded about the differences in the assemblies, since the PXRD for the bulk material for $\left[\mathrm{Zn}(47) \mathrm{I}_{2}\right]_{n}$ indicates the presence of another phase, and PXRD data could not be obtained for the bulk sample of $\left[\mathrm{Zn}_{2}(\mu-\right.$ $\mathrm{OAc})_{4}(47)_{2}$ ] because of decomposition in air [61].

\subsection{Assemblies Containing Cadmium(II) and 4'-Functionalized 4,2':6', $4^{\prime \prime}$-tpy Ligands with Coordinatively Innocent Substituents}

We now move to cadmium(II) coordination polymers containing $4,2^{\prime}: 6^{\prime}, 4^{\prime \prime}$-tpy linkers. No structurally characterized example with a simple $4,2^{\prime}: 6^{\prime}, 4^{\prime \prime}$-tpy has been reported, although assemblies with coordinatively innocent substituents in the $4^{\prime}$-position of $4,2^{\prime}: 6^{\prime}, 4^{\prime \prime}$-tpy are well represented. Scheme 12 summarizes some of the ligands referred to in this section. 


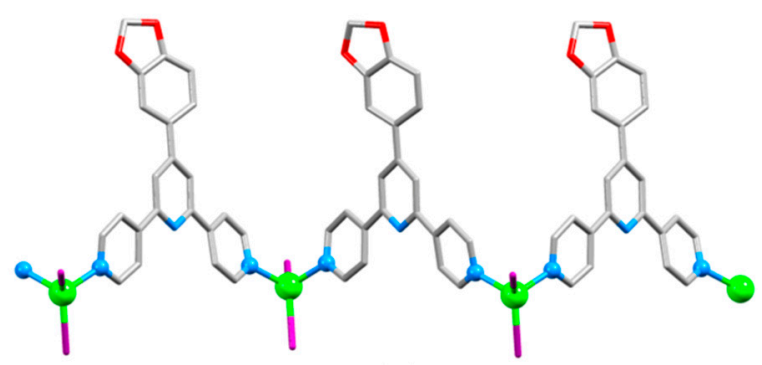

(a)

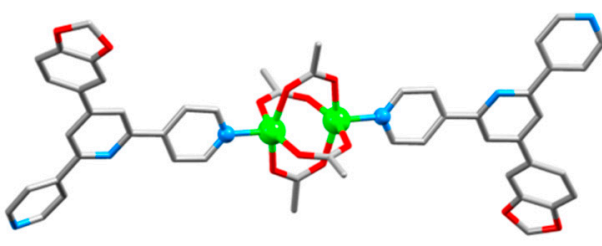

(b)

Figure 29. (a) Part of the 1D-polymer in $\left[\mathrm{Zn}(47) \mathrm{I}_{2}\right]_{n}$ (CSD refcode QOTSAV), and (b) the structure of the discrete complex $\left[\mathrm{Zn}_{2}(\mu-\mathrm{OAc})_{4}(47)_{2}\right]$ (refcode QOTRUO).<smiles>COc1ccc(-c2cc(-c3ccncc3)nc(-c3ccncc3)c2)cc1OC</smiles>

48<smiles>COc1ccc(-c2cc(-c3ccncc3)nc(-c3ccncc3)c2)cc1</smiles>

49<smiles>C#Cc1ccc(-c2cc(-c3ccncc3)nc(-c3ccncc3)c2)cc1</smiles>

50<smiles>N#Cc1cccc(-c2cc(-c3ccncc3)nc(-c3ccncc3)c2)c1</smiles>

51

Scheme 12. Structures of some ligands with non-coordinating $4^{\prime}$-functionalities that form coordination assemblies with cadmium(II). Other relevant ligands are 14 (Scheme 6), 28, 29 and 30 (Scheme 9).

Crystal growth by layering has been used for the assembly of $\left[\mathrm{Cd}\left(\mathbf{1 4}_{2}\right)_{2}\left(\mathrm{NO}_{3}\right)_{2}\right]_{n}$. $n \mathrm{MeOH} \cdot n \mathrm{CHCl}_{3}$ [87], which consists of a $(4,4)$ net with $\mathrm{Cd}(\mathrm{II})$ acting as a 4-connecting node. This contrasts with the numerous 1D-polymers that are observed for combinations of zinc(II) salts with $4,2^{\prime}: 6^{\prime}, 4^{\prime \prime}$-tpy ligands with non-coordinating substituents, and highlights the fact that the higher coordination numbers favored by $\mathrm{Cd}(\mathrm{II})$ can lead to higher dimensionality assemblies. Similar $(4,4)$-nets are formed when $\mathrm{Cd}\left(\mathrm{NO}_{3}\right)_{2} \cdot 4 \mathrm{H}_{2} \mathrm{O}$, $\mathrm{CdBr}_{2}$ or $\mathrm{CdI}_{2}$ reacts with 48 (Figure 30a) [88], or when $\mathrm{Cd}\left(\mathrm{NO}_{3}\right)_{2} \cdot 4 \mathrm{H}_{2} \mathrm{O}$ combines with $4^{\prime}$-(4-ROC $\left.{ }_{6} \mathrm{H}_{4}\right)-4,2^{\prime}: 6^{\prime}, 4^{\prime \prime}$-tpy in which $\mathrm{R}={ }^{n}$ pentyl, ${ }^{n}$ hexyl, or ${ }^{n}$ heptyl [89]. However, for smaller R groups, the assembly switches to either a ladder (for $\mathrm{R}=\mathrm{Me}$, ligand 49) [90] or a $(6,3)$ net (for $\mathrm{R}={ }^{n}$ propyl) [89]. The ladder in $\left[\mathrm{Cd}_{2}(49)_{3}\left(\mathrm{NO}_{3}\right)_{4}\right]_{n} \cdot n \mathrm{MeOH} \cdot n \mathrm{CHCl}_{3}$ is of interest because ditopic $4,2^{\prime}: 6^{\prime}, 4^{\prime \prime}$-tpy units comprise both the rungs and the rails of the ladder (Figure 30b). This is also observed in $\left[\mathrm{Cd}_{2}(\mathbf{2 8})_{3}\left(\mathrm{NO}_{3}\right)_{4}\right]_{n} \cdot 4 n \mathrm{MeOH} \cdot 2 n \mathrm{CHCl}_{3}$ [91], and $\left[\mathrm{Cd}_{2}(\mathbf{5 0})_{3}\left(\mathrm{NO}_{3}\right)_{4}\right]_{n} \cdot 2 n \mathrm{MeOH} \cdot 3 n \mathrm{CHCl}_{3} \cdot n \mathrm{H}_{2} \mathrm{O}$ [91]. In contrast, when $\mathrm{Cd}(\mathrm{OAc})_{2} \cdot \mathrm{H}_{2} \mathrm{O}$ is used in place of the nitrate salt, the tendency for dinuclear $\left\{\mathrm{Cd}_{2}(\mathrm{OAc})_{4}\right\}$ units to form directs the assembly to a ladder in which each rung is built from a $\left\{\mathrm{Cd}_{2}(\mathrm{OAc})_{4}\right\}$ group and the $4,2^{\prime}: 6^{\prime}, 4^{\prime \prime}$-tpy linkers form the rails (Figure 30c) [62]. This latter polymer, $\left[\mathrm{Cd}_{2}(\mathrm{OAc})_{4}(30)_{2}\right]_{n}$. $1.75 n \mathrm{MeOH} \cdot 0.5 n \mathrm{H}_{2} \mathrm{O}$, also incorporates $4^{\prime}$-biphenyl substituents, and the structure shown in Figure 30c illustrates that face-to-face $\pi$-stacking of biphenyl groups within a chain occurs. To what extent this also helps to direct the assembly is difficult to assess. We noted above that, when compared to $\mathrm{Zn}(\mathrm{II})$, the higher coordination numbers typically found for Cd(II) may be a means of accessing higher dimensionality structures. However, there are always examples to underline the dangers of 'rule making'. Under ambient conditions, ligand 29 (Scheme 6) reacted with $\mathrm{Cd}\left(\mathrm{NO}_{3}\right)_{2} \cdot 4 \mathrm{H}_{2} \mathrm{O}$ to give crystals of the 1D-coordination polymer $\left[\mathrm{Cd}(29)\left(\mathrm{OH}_{2}\right)_{2}\left(\mathrm{NO}_{3}\right)_{2}\right]_{n} \cdot n \mathrm{H}_{2} \mathrm{O}$ (Figure 31a) [91]. The coordinated aqua ligands block sites for extension of the assembly into a $2 \mathrm{D}$-sheet (e.g., as in $\left[\mathrm{Cd}_{2}\left(\mathbf{2 8}_{3}\right)_{3}\left(\mathrm{NO}_{3}\right)_{4}\right]_{n}$, see above). The zig-zag chains in $\left[\mathrm{Cd}(29)\left(\mathrm{OH}_{2}\right)_{2}\left(\mathrm{NO}_{3}\right)_{2}\right]_{n} \cdot n \mathrm{H}_{2} \mathrm{O}$ nest into one another to form $2 \mathrm{D}$-sheets, and the latter pack in a similar manner to the $\left[\mathrm{Zn}_{2}(\mathrm{OAc})_{4}\left(4^{\prime}-\mathrm{X}-4,2^{\prime}: 6^{\prime}, 4^{\prime \prime} \text {-tpy }\right)\right]_{n}$ chains described in Figures 15 and 16. The 1D-polymer $\left[\mathrm{Cd}_{2}(\mathbf{5 1})_{2}\left(\mathrm{SO}_{4}\right)_{2}\left(\mathrm{H}_{2} \mathrm{O}\right)_{6}\right]_{n} \cdot n \mathrm{H}_{2} \mathrm{O}$ assembled in the reaction of $\mathrm{CdSO}_{4}$ with ligand $\mathbf{5 1}$ (Scheme 12) under solvothermal conditions 
$\left(\mathrm{EtOH} / \mathrm{H}_{2} \mathrm{O}, 120^{\circ} \mathrm{C}\right)$. As in $\left[\mathrm{Cd}(29)\left(\mathrm{OH}_{2}\right)_{2}\left(\mathrm{NO}_{3}\right)_{2}\right]_{n}$, the trans-arrangement of coordinated $4,2^{\prime}: 6^{\prime}, 4^{\prime \prime}$-tpy units leads to a zig-zag chain in $\left[\mathrm{Cd}_{2}(\mathbf{5 1})_{2}\left(\mathrm{SO}_{4}\right)_{2}\left(\mathrm{H}_{2} \mathrm{O}\right)_{6}\right]_{n}$ (Figure 31b).

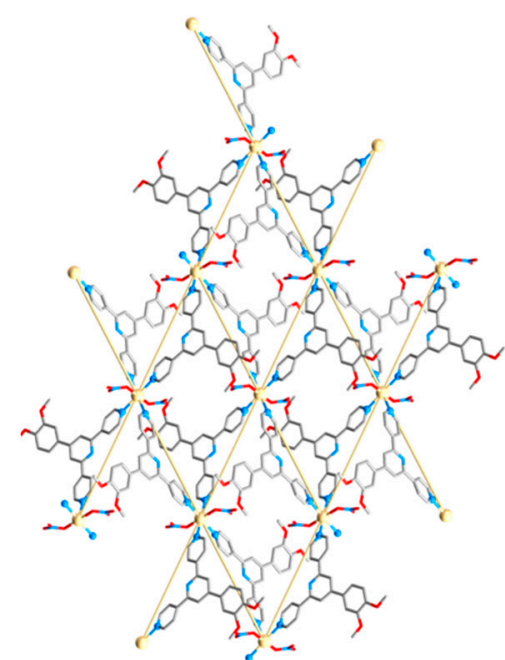

(a)

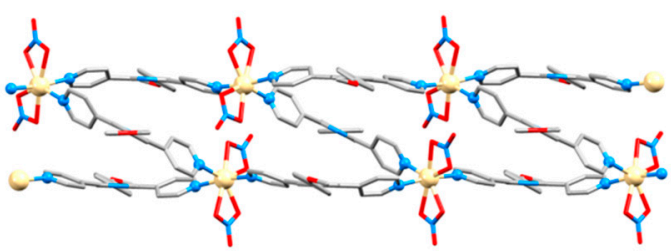

(b)

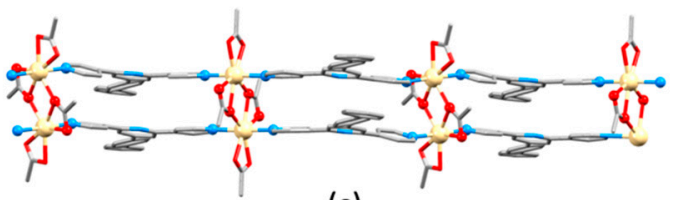

(c)
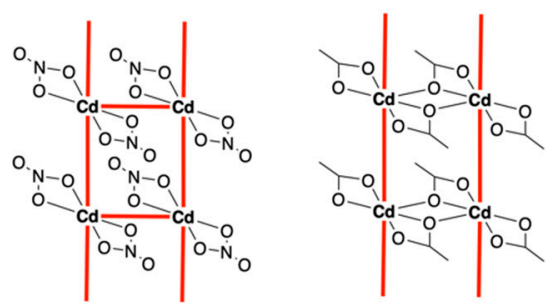

Figure 30. (a) Part of one $(4,4)$ net in $\left[\mathrm{Cd}(48)_{2}\left(\mathrm{NO}_{3}\right)_{2}\right]_{n}$ (CSD refcode COGWEC); each Cd atom is a 4-connecting node and the rhombuses in the net are highlighted. Part of the 1D-ladder $(\mathbf{b})$ in $\left[\mathrm{Cd}_{2}(49)_{3}\left(\mathrm{NO}_{3}\right)_{4}\right]_{n} \cdot n \mathrm{MeOH} \cdot n \mathrm{CHCl}{ }_{3}\left(\mathrm{CSD}_{\mathrm{refcode}}\right.$ BUDZIL), and (c) $\left[\mathrm{Cd}_{2}(\mathrm{OAc})_{4}(30)_{2}\right]_{n} \cdot 1.75 n \mathrm{MeOH} \cdot 0.5 n \mathrm{H}_{2} \mathrm{O}$ (CSD refcode RIGJEY). Right: a schematic representation of the different ladder assemblies.

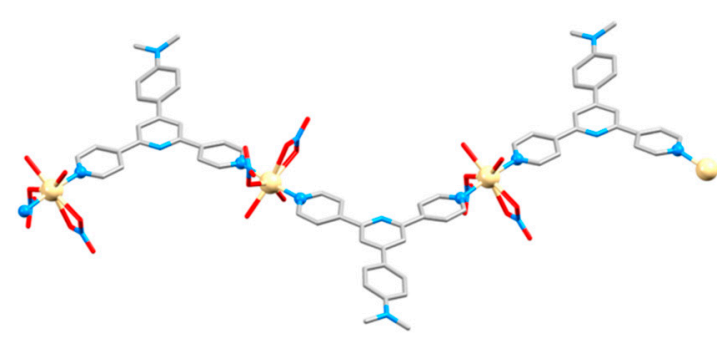

(a)

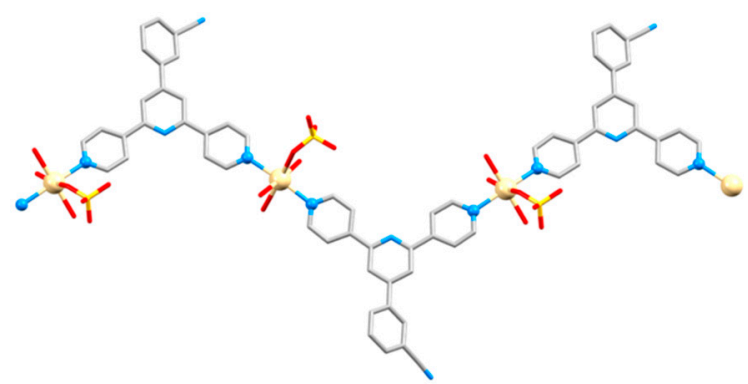

(b)

Figure 31. Part of the 1D-ladder (a) in $\left[\mathrm{Cd}(29)\left(\mathrm{OH}_{2}\right)_{2}\left(\mathrm{NO}_{3}\right)_{2}\right]_{n} \cdot n \mathrm{H}_{2} \mathrm{O}(\mathrm{CSD}$ refcode VAKWOV) and in (b) $\left[\mathrm{Cd}_{2}(51)_{2}\left(\mathrm{SO}_{4}\right)_{2}\left(\mathrm{H}_{2} \mathrm{O}\right)_{6}\right]_{n} \cdot n \mathrm{H}_{2} \mathrm{O}$ (refcode NUNZON).

\subsection{Assemblies Containing Cadmium(II) and 4,2': $6^{\prime}, 4^{\prime \prime}$-tpy Ligands Functionalized in the $4^{\prime}$-Position with Carboxylate or Sulfonate Donors}

In Section 3.4, we reviewed coordination polymers and networks derived from reactions of zinc(II) salts and 4,2': $6^{\prime}, 4^{\prime \prime}$-tpy ligands functionalized with carboxylate donors. We now turn to assemblies combining some of the same ligands (H17, H31, H33, H34 and $\mathrm{H}_{2} 37$ ) with cadmium(II). The structures of these ligands are given in Schemes 6 and 10.

Carboxylic acids H31, H17, and H33 differ in having no, one and two phenylene spacers, respectively, between the $4,2^{\prime}: 6^{\prime}, 4^{\prime \prime}$-tpy and carboxylic acid domains. The solvothermal reaction $\left(\mathrm{DMF} / \mathrm{H}_{2} \mathrm{O}, \mathrm{pH} 4.0,160^{\circ} \mathrm{C}\right)$ of $\mathrm{CdBr}_{2}$ and $\mathrm{H} 31$ produced crystals of $\left[\mathrm{Cd}_{2}(31)_{4}\right]_{n}[66]$. The compound crystallizes in the monoclinic space group $P 2_{1} / n$ and the asymmetric unit contains two crystallographically independent ligands and two independent Cd(II) centers. Both metal centers are bound by three $N$-donors of three different $31^{-}$ligands and by two bidentate carboxylates from two different ligands, making each $\mathrm{Cd}$ (II) center a 5-connecting node (Figure 32a). The coordination behaviors of the $4,2^{\prime}: 6^{\prime}, 4^{\prime \prime}$-tpy units in the two independent $31^{-}$ligands differ in that one coordinates through both outer pyridine rings, and the 
second through only one (Figure 32a). Thus, every other $31^{-}$ligand is a 3-connecting node, and the remaining ligands are purely linkers. The structure extends into a $(3,5)$-connected 3D-network, and is 2-fold interpenetrating (Figure 32b). A comparison should be made between this structure and that of $\left[\mathrm{Zn}(31)_{2}\right]_{n} \cdot n \mathrm{H}_{2} \mathrm{O}$ (Figure 20d), and the effects of the higher coordination number of $\mathrm{Cd}(\mathrm{II})$ versus $\mathrm{Zn}$ (II) are clear. In addition to $\left[\mathrm{Zn}(31)_{2}\right]_{n} \cdot n \mathrm{H}_{2} \mathrm{O}$ and $\left[\mathrm{Cd}_{2}(31)_{4}\right]_{n}$, Zhou and coworkers have also investigated the consequences of introducing a series of co-ligands [66]. Hu and coworkers have reported $\left[\mathrm{Cd}_{2}(31)_{4}\right]_{n} \cdot 2 n \mathrm{H}_{2} \mathrm{O}$,

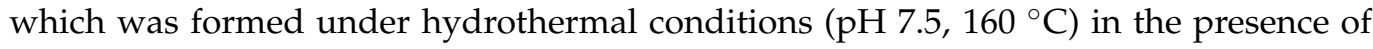
oxalic acid. Although oxalate is not incorporated into the assembly as a coligand, the presence of oxalic acid in the reaction mixture was essential for the growth of single crystals of $\left[\mathrm{Cd}_{2}(31)_{4}\right]_{n} \cdot 2 n \mathrm{H}_{2} \mathrm{O}$ [92]. This is reminiscent of separate observations from the same group that, under hydrothermal conditions, single crystals of $[\mathrm{Zn}(31) \mathrm{Cl}]_{n} \cdot n \mathrm{H}_{2} \mathrm{O}$ could only be obtained if phthalic acid were present [67]. $\left[\mathrm{Cd}_{2}(31)_{4}\right]_{n} \cdot 2 n \mathrm{H}_{2} \mathrm{O}$ crystallizes in the orthorhombic space group $\mathrm{Pbcn}$, making it structurally distinct from $\left[\mathrm{Cd}_{2}(\mathbf{3 1})_{4}\right]_{n}$ described above. However, a comparison of Figure 32a and c reveals that in both $\left[\mathrm{Cd}_{2}(31)_{4}\right]_{n}$ and the dihydrate, one ligand $31^{-}$acts as a 3 -connecting node, and one ligand bridges two $\mathrm{Cd}(\mathrm{II})$ centers. The assembly in $\left[\mathrm{Cd}_{2}(31)_{4}\right]_{n} \cdot 2 n \mathrm{H}_{2} \mathrm{O}$ is, like, $\left[\mathrm{Cd}_{2}(31)_{4}\right]_{n}$, a 2-fold interpenetrating, $(3,5)$-connected 3D-network [92].

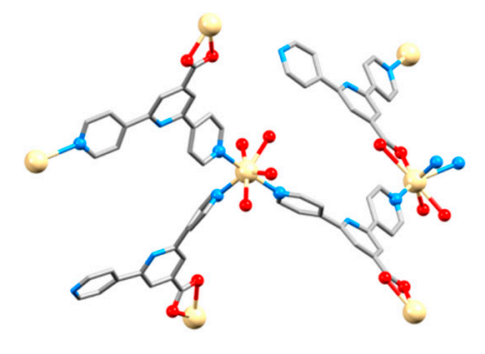

(a)

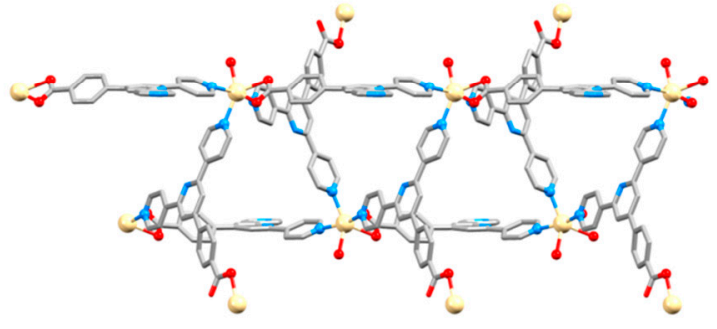

(d)

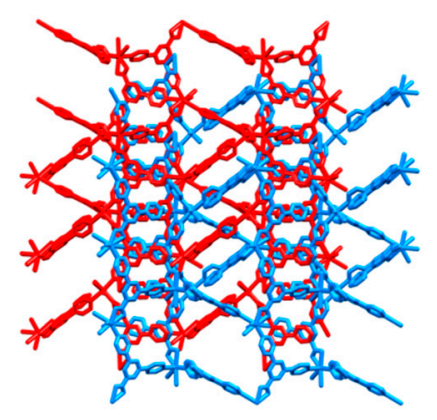

(b)

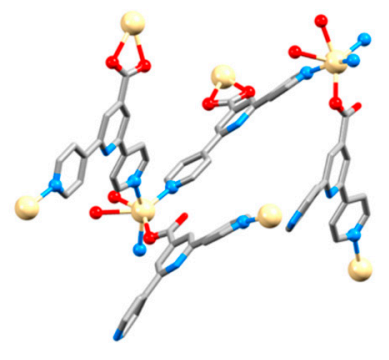

(c)

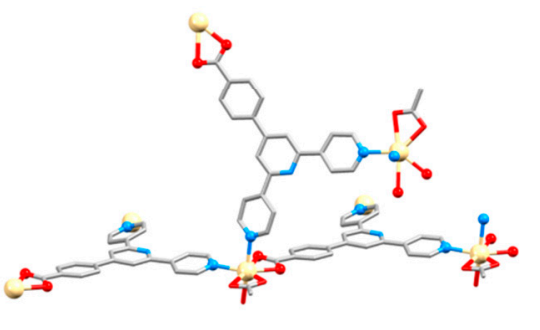

(e)

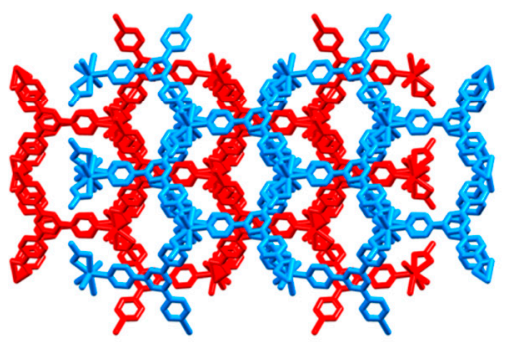

(f)

Figure 32. (a) The Cd(II) coordination environments and ligand coordination modes in $\left[\mathrm{Cd}_{2}(31)_{4}\right]_{n}$ (CSD refcode KEPLID), and (b) the 2-fold interpenetrated 3D-network in $\left[\mathrm{Cd}_{2}(31)_{4}\right]_{n}$. (a,c) The $\mathrm{Cd}(\mathrm{II})$ coordination environments and ligand coordination modes in $\left[\mathrm{Cd}_{2}(\mathbf{3 1})_{4}\right]_{n} \cdot 2 n \mathrm{H}_{2} \mathrm{O}$ (CSD refcode XIDCEU). (d) Part of the 2D-net in $\left[\mathrm{Cd}(\mathbf{1 7})_{2}\right]_{n} \cdot 2 n \mathrm{DMF}($ refcode HEKTEY). (e) In $\left[\mathrm{Cd}(\mathbf{1 7})(\mathrm{OAc})\left(\mathrm{OH}_{2}\right)\right]_{n} \cdot n \mathrm{DMA} \cdot n \mathrm{H}_{2} \mathrm{O}\left(\mathrm{CSD}\right.$ refcode HEKTAU), both the Cd(II) center and $\mathbf{1 7}^{-}$ligand are 3-connecting nodes. (f) The 2-fold interpenetrating ths nets in $\left[\mathrm{Cd}(\mathbf{1 7})(\mathrm{OAc})\left(\mathrm{OH}_{2}\right)\right]_{n} \cdot n \mathrm{DMA} \cdot n \mathrm{H}_{2} \mathrm{O}$.

Ligand H17 and H34 are isomers (Schemes 6 and 10). $\left[\mathrm{Cd}(\mathbf{1 7})_{2}\right]_{n} \cdot 2 n \mathrm{DMF}$ and $\left[\mathrm{Cd}(\mathbf{1 7})(\mathrm{OAc})\left(\mathrm{OH}_{2}\right)\right]_{n} \cdot n \mathrm{DMA} \cdot n \mathrm{H}_{2} \mathrm{O}$ were formed under solvothermal conditions using $\mathrm{Cd}(\mathrm{OAc})_{2} \cdot 2 \mathrm{H}_{2} \mathrm{O}$ and $\mathrm{H} 17$ in DMA $/ \mathrm{H}_{2} \mathrm{O}$, or $\mathrm{Cd}\left(\mathrm{NO}_{3}\right)_{2} \cdot 4 \mathrm{H}_{2} \mathrm{O}$ and $\mathrm{H} 17$ in DMF $/ \mathrm{H}_{2} \mathrm{O}$ with, in the latter case, 4, $4^{\prime}$-oxybis(benzoic acid) added, presumably, as a potential coligand. Consistent with observations described above, crystal growth was dependent upon the presence of this additional component, suggesting a possible templating role. The structure of $\left[\mathrm{Cd}(\mathbf{1 7})_{2}\right]_{n} \cdot 2 n \mathrm{DMF}$ (which crystallizes in the monoclinic $\mathrm{C} 2 / c$ space group) is a $(3,5)$-connected $2 \mathrm{D}$ network, part of which is displayed in Figure 32d. This contrasts with the interpenetrated $(3,5)$-connected $3 \mathrm{D}$ nets in $\left[\mathrm{Cd}_{2}(31)_{4}\right]_{n} \cdot 2 n \mathrm{H}_{2} \mathrm{O}$ and 
$\left[\mathrm{Cd}_{2}(31)_{4}\right]_{n}$, and the change in assembly appears to be associated with the introduction of the phenylene spacer in $17^{-}$. As in $\left[\mathrm{Cd}_{2}(31)_{4}\right]_{n} \cdot 2 n \mathrm{H}_{2} \mathrm{O}$ and $\left[\mathrm{Cd}_{2}(31)_{4}\right]_{n}$, there are two crystallographically independent ligands in $\left[\mathrm{Cd}(\mathbf{1 7})_{2}\right]_{n} \cdot 2 n \mathrm{DMF}$. One acts as a 3 -connecting node, and one coordinates only through one pyridine ring and the $\mathrm{CO}_{2}{ }^{-}$unit [93]. In $\left[\mathrm{Cd}(\mathbf{1 7})(\mathrm{OAc})\left(\mathrm{OH}_{2}\right)\right]_{n} \cdot n \mathrm{DMA} \cdot n \mathrm{H}_{2} \mathrm{O}$, every $\mathbf{1 7}^{-}$ligand is crystallographically equivalent, as is every $\mathrm{Cd}(\mathrm{II})$ center. Each act as a 3-connecting node (Figure 32e), generating a (10-3)-b (or ths) 3D-net. The large voids in the net lead to 2-fold interpenetration (Figure 32f). The activated forms of $\left[\mathrm{Cd}(\mathbf{1 7})(\mathrm{OAc})\left(\mathrm{OH}_{2}\right)\right]_{n}$ and $\left[\mathrm{Cd}(\mathbf{1 7})_{2}\right]_{n}$ show selective adsorption of $\mathrm{CO}_{2}$ over $\mathrm{N}_{2}$, and of $\mathrm{H}_{2} \mathrm{O}$ over $\mathrm{MeOH}$ [93]. Hu and coworkers reacted $\mathrm{H17}$ with $\mathrm{CdCl}_{2}$ under hydrothermal conditions and obtained single crystals of $\left[\mathrm{Cd}_{2}\left(\mathbf{1 7}_{4}\right]_{n} \cdot 3.5 n \mathrm{H}_{2} \mathrm{O}\right.$. Another variation of the coordination mode of $\mathbf{1 7}^{-}$is exemplified in this compound; every ligand is a linker, coordinating through one pyridine $\mathrm{N}$-donor and a bidentate carboxylate group. Each Cd(II) center is a 4-connecting node and a $(4,4)$ (or sql) net assembles (Figure 33a). As Figure $33 \mathrm{~b}$ illustrates, $2 \mathrm{D} \rightarrow 2 \mathrm{D}$ parallel interpenetration of the nets occurs to reduce the void space [70]. In Figure 23, we illustrated coordination assemblies formed between Zn(II) and the conjugate base of $\mathrm{H} 34$ (Scheme 10). These networks from the group of $\mathrm{Hu}$ [73] are complemented by that of $\left[\mathrm{Cd}_{2}(34)_{4}\right]_{n} \cdot n \mathrm{H}_{2} \mathrm{O}$, single crystals of which were grown under hydrothermal conditions $\left(\mathrm{pH} 5,180^{\circ} \mathrm{C}\right)$ from the reaction between $\mathrm{CdCl}_{2} \cdot 2.5 \mathrm{H}_{2} \mathrm{O}$ and $\mathrm{H} 34$. Whereas the analogous reaction between $\mathrm{ZnCl}_{2}$ and $\mathrm{H} 34$ gave $[\mathrm{Zn}(34) \mathrm{Cl}]_{n}$, the cadmiumcontaining assembly contains no chlorido ligands. Each $34^{-}$ligand coordinates to one $\mathrm{Cd}(\mathrm{II})$ through one pyridine ring and to a second $\mathrm{Cd}$ (II) through a bidentate carboxylate group. Each $\mathrm{Cd}(\mathrm{II})$ center is a 4-connecting node, leading to the $(4,4)$ net depicted in Figure 33c.

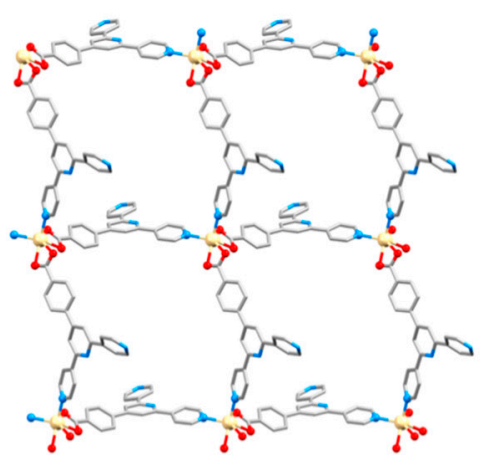

(a)

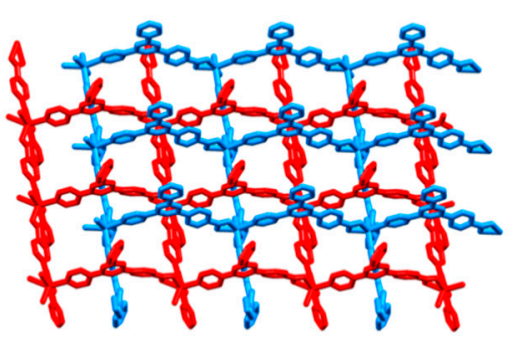

(b)

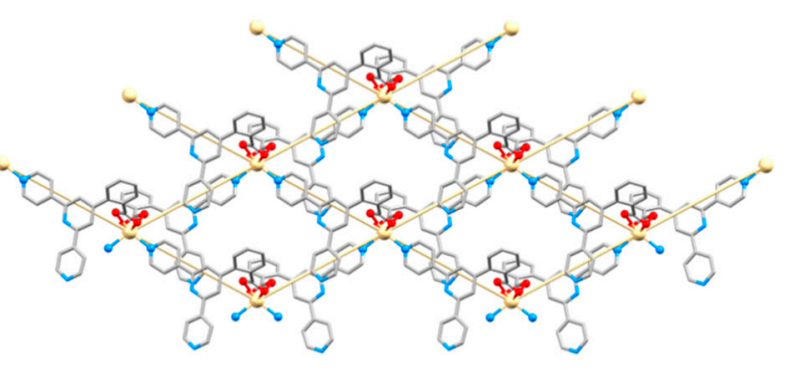

(c)

Figure 33. (a) Part of one 2D-sheet in $\left[\mathrm{Cd}_{2}(\mathbf{1 7})_{4}\right]_{n} \cdot 3.5 n \mathrm{H}_{2} \mathrm{O}(\mathrm{CSD}$ refcode JUHYUI), and (b) $2 \mathrm{D} \rightarrow 2 \mathrm{D}$ parallel interpenetration of the nets in this assembly. (c) Part of the 2D-net in $\left[\mathrm{Cd}_{2}(34)_{4}\right]_{n} \cdot n \mathrm{H}_{2} \mathrm{O}$ with rhombuses highlighted (refcode FIZWES).

The introduction of an additional phenylene spacer on going from $\mathrm{H} 17$ to H33 (Schemes 6 and 10) had a significant influence on the coordination assembly formed with $\mathrm{Zn}$ (II) (Figures 21 and 22 and accompanying discussion). Similarly, whereas the structure of $\left[\mathrm{Cd}(\mathbf{1 7})_{2}\right]_{n} \cdot 2 n \mathrm{DMF}$ is a $2 \mathrm{D}$-net (Figure $32 \mathrm{~d}$ ), that of $\left[\mathrm{Cd}(33)_{2}\right]_{n} \cdot n \mathrm{DMF} \cdot 2 n \mathrm{H}_{2} \mathrm{O}$ is a $3 \mathrm{D}-$ network. $\left[\mathrm{Cd}(33)_{2}\right]_{n} \cdot n \mathrm{DMF} \cdot 2 n \mathrm{H}_{2} \mathrm{O}$ was formed under solvothermal conditions $\left(\mathrm{DMF} / \mathrm{H}_{2} \mathrm{O}\right.$, $\left.120{ }^{\circ} \mathrm{C}\right)$ from the reaction of $\mathrm{Cd}\left(\mathrm{NO}_{3}\right)_{2} \cdot 4 \mathrm{H}_{2} \mathrm{O}$ and $\mathrm{H} 33$. Interestingly, $\left\{\mathrm{Cd}_{2}\left(\mathrm{O}_{2} \mathrm{C}\right)_{4}\right\}$ units assemble (Figure 34a) and bear a resemblance to the 8-connecting dizinc nodes in $\left[\mathrm{Zn}(33)_{2}\right]_{n}$ (Figure $34 \mathrm{~b}$, and see also Figure 22b). The 3D-network in $\left[\mathrm{Cd}(33)_{2}\right]_{n} \cdot n \mathrm{DMF} \cdot 2 n \mathrm{H}_{2} \mathrm{O}$ is described by the authors as having a topological point symbol of $\left\{3^{3} \cdot 4^{7} \cdot 5^{8} \cdot 6\right\}$ [94]. A comparison of the structure of $\left[\mathrm{Cd}(33)_{2}\right]_{n} \cdot n \mathrm{DMF} \cdot 2 n \mathrm{H}_{2} \mathrm{O}$ (CSD refcode BOBRIW) with that of $\left[\mathrm{Zn}(33)_{2}\right]_{n}$ (refcode TEZJOA) reveals that both compounds crystallize in the monoclinic space group $P 2_{1} / c$ with similar cell dimensions $(a=21.8088(7), b=10.3071(3), c=29.9710(12) \AA$, $\beta=126.602(2)^{\circ}$ for $\left[\mathrm{Cd}(33)_{2}\right]_{n} \cdot n \mathrm{DMF} \cdot 2 n \mathrm{H}_{2} \mathrm{O}$, and $a=21.5531(7), b=10.2884(4), c=29.7127(12) \AA$, $\beta=126.180(2)^{\circ}$ for $\left.\left[\mathrm{Zn}(33)_{2}\right]_{n}\right)$ consistent with very similar assemblies. $\left[\mathrm{Cd}(33)_{2}\right]_{n}$ was shown to be a selective and very sensitive luminescent probe to detect ascorbic acid [94]. The dicarboxylic acid $\mathrm{H}_{2} 37$ forms single crystals of $\left[\mathrm{Cd}(37)\left(\mathrm{OH}_{2}\right)\right]_{n} \cdot n \mathrm{MeCN} \cdot 2 n \mathrm{H}_{2} \mathrm{O}$ when reacted 
with $\mathrm{H}_{2} 37$ under solvothermal conditions. The $\left[\mathrm{Cd}(37)\left(\mathrm{OH}_{2}\right)\right]_{n}$ assembly comprises 2-fold interpenetrated 3D-networks and is essentially isostructural with solvated $[\mathrm{Zn}(37)]_{n}$ (see Figure 25) [79].

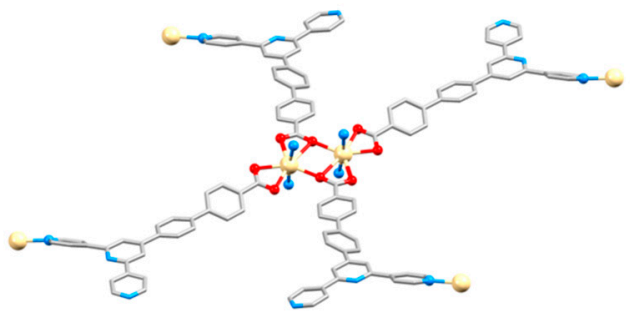

(a)

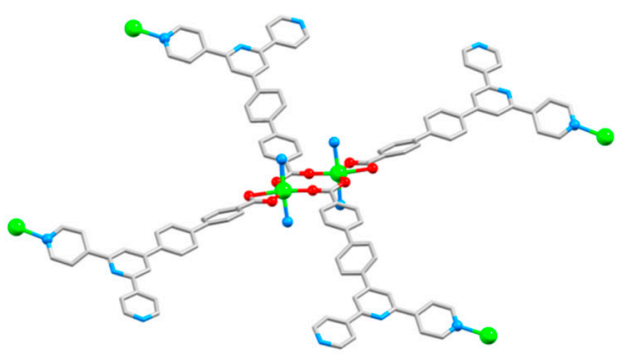

(b)

Figure 34. (a) The $\left\{\mathrm{Cd}_{2}\left(\mathrm{O}_{2} \mathrm{C}\right)_{4}\right\}$ node showing four of the eight coordinated ligands in $\left[\mathrm{Cd}(33)_{2}\right]_{n} \cdot n \mathrm{DMF} \cdot 2 n \mathrm{H}_{2} \mathrm{O}(\mathrm{CSD}$ refcode BOBRIW), compared with (b) the corresponding unit in $\left[\mathrm{Zn}(33)_{2}\right]_{n}$ (refcode TEZJOA).

In comparison for carboxylato-functionalized terpyridine ligands, there are far fewer examples bearing sulfonato metal-binding domains. Figure 6 illustrated the 1D-ladder assembly in $[\mathrm{Cd}(\mathbf{1 3}) \mathrm{Cl}]_{n}$ in which $\mathrm{H} 13$ contains a 2,2': $6^{\prime}, 2^{\prime \prime}$-tpy unit [43]. For the divergent $4,2^{\prime}: 6^{\prime}, 4^{\prime \prime}$-tpy, $\left[\mathrm{Cd}(\mathbf{5 2})\left(\mathrm{OH}_{2}\right)_{2}\right]_{n}\left(\mathrm{H}_{2} 52\right.$ is defined in Figure 35$)$ is a sole example of a cadmium(II)-containing coordination polymer with a sulfonato-functionalized $4,2^{\prime}: 6^{\prime}, 4^{\prime \prime}$ tpy ligand for which structural data are available. Two independent reports of the synthesis and structure of $\left[\mathrm{Cd}(\mathbf{5 2})\left(\mathrm{OH}_{2}\right)_{2}\right]_{n}$ appeared in $2015[95,96]$. The compound was prepared under hydrothermal conditions from $\mathrm{H}_{2} 52$ and either $\mathrm{CdCO}_{3}$ or $\mathrm{CdCl}_{2} \cdot 2.5 \mathrm{H}_{2} \mathrm{O}$, and crystallizes in the triclinic space group $P-1$. As Figure 35 a shows, the $\mathrm{Cd}(\mathrm{II})$ center is 7 -coordinate (distorted pentagonal bipyramidal), being bound by a monodentate $\mathrm{SO}_{3}{ }^{-}$group from one $52^{2-}$ ligand, a bidentate $\mathrm{SO}_{3}{ }^{-}$from a second $52^{2-}$, as well as by pyridine rings from two different $\mathbf{5 2}^{2-}$ ligands, and two aqua ligands. Both $\mathbf{5 2 ^ { 2 - }}$ and $\mathrm{Cd}(\mathrm{II})$ are, therefore, 4 -connecting nodes, and the structure propagates into a 3D dia network. The large voids in a single net result in 2-fold interpenetration (Figure 35b). Interestingly, when zinc(II) acetate combined with $\mathrm{H}_{2} 52$ under the same hydrothermal conditions as for the preparation of $\left[\mathrm{Cd}(52)\left(\mathrm{OH}_{2}\right)_{2}\right]_{n}$, single crystals of the mononuclear complex $\left[\mathrm{Zn}(\mathrm{H} 52)_{2}\left(\mathrm{OH}_{2}\right)_{4}\right] \cdot 6 \mathrm{H}_{2} \mathrm{O}$ were obtained and PXRD data confirmed that the single crystal was representative of the bulk material [95]. The preference for mononuclear over polymeric assembly is not readily explained.
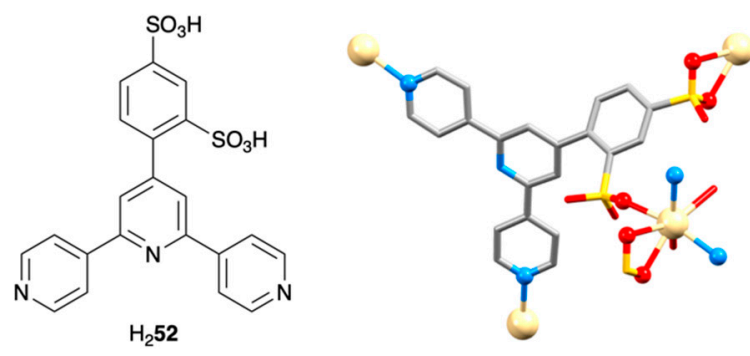

(a)

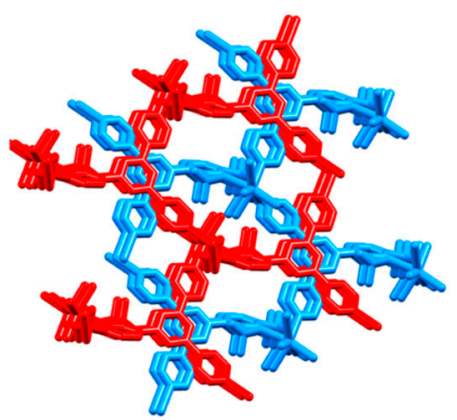

(b)

Figure 35. The structure of $\mathrm{H}_{2}$ 52. In $\left[\mathrm{Cd}(\mathbf{5 2})\left(\mathrm{OH}_{2}\right)_{2}\right]_{n},(\mathbf{a})$ both $\mathbf{5 2}^{2-}$ and $\mathrm{Cd}(\mathrm{II})$ are 4-connecting nodes, and (b) the coordination assembly comprises 2-fold, interpenetrating 3D networks (CSD refcodes QJARAU and QJARAU01). 


\subsection{Assemblies Containing Cadmium(II) and $4,2^{\prime}: 6^{\prime}, 4^{\prime \prime}$-tpy Ligands Functionalized in the 4'-Position with a Pyridinyl Group}

Rather surprisingly, there are few examples of structurally characterized coordination assemblies incorporating $\mathrm{Cd}(\mathrm{II})$ and $4,2^{\prime}: 6^{\prime}, 4^{\prime \prime}$-tpy ligands with pyridinyl functionalities. Zhang and Li reported the formation of $\left[\mathrm{Cd}(38) \mathrm{I}_{2}\right]_{n}$ under hydrothermal conditions (see Scheme 11 for ligand 38) [97]. The assembly is a 1D-polymer (Figure 36) which may be described as a ladder. Each Cd(II) center is 5-coordinate, and is bound by three different molecules of 38. The structure is in contrast to the 1D-ladder in $\left[\mathrm{Zn}_{3}(39)_{2} \mathrm{Cl}_{6}\right]_{n} \cdot n \mathrm{H}_{2} \mathrm{O}$ (Figure 26b), in which each $\mathrm{Zn}$ (II) ion is tetrahedrally sited [82]. Zhang et al. also demonstrated that when the co-ligand benzene-1,4-dicarboxylic acid was added to the $\mathrm{CdI}_{2} / 38$ reaction mixture, the role of $\mathbf{3 8}$ was reduced to that of a pendant, monodentate ligand and the network was directed purely by benzene-1,4-dicarboxylic acid [97].

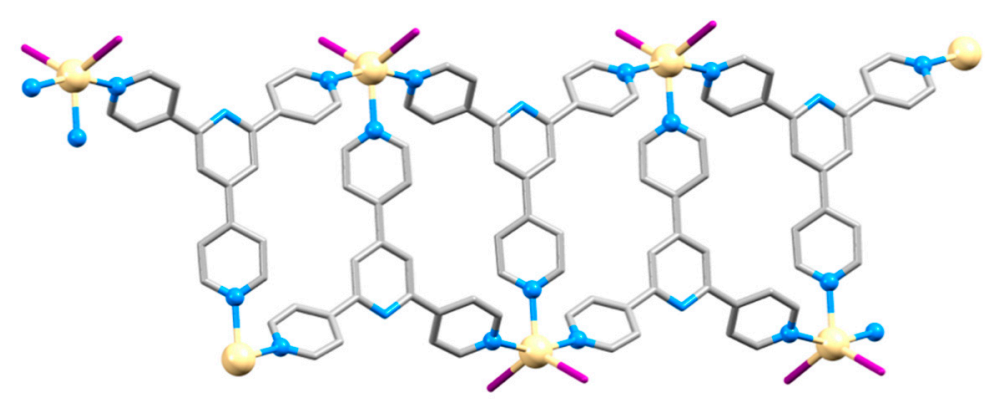

Figure 36. Part of the 1D-ladder in $\left[\mathrm{Cd}(38) \mathrm{I}_{2}\right]_{n}$ (DSC refcode USECEC).

\subsection{Ligands Containing Two 4,2':6', $4^{\prime \prime}$-tpy Metal-Binding Domains: 4-Connecting Nodes}

A strategy for increasing the dimensionality of a coordination assembly is to incorporate ligands that can function as directing nodes. Ditopic ligands such as those in Scheme 9 function only as linkers. In contrast, we have described examples in which the introduction into a $4,2^{\prime}: 6^{\prime}, 4^{\prime \prime}$-tpy unit of a substituent capable of binding a metal ion may allow the ligand to act as a directing node. For example, $36^{2-}$ in $[\mathrm{Zn}(36)]_{n} \cdot 4 n \mathrm{DMF}$ is a 4-connecting node (Figure 25a). Another strategy is to design ligands which possess more than one divergent tpy unit. Examples of ligands which form coordination networks with zinc(II) are displayed in Scheme 13. Crystals of all the zinc(II) complexes described in the section were grown under ambient conditions using layering methods. In an extension of the Hanan one-pot strategy [7] shown in Scheme 3, ligands 53-58 were prepared by reaction of an appropriate dialdehyde with four equivalents of 4-acetylpyridine under basic conditions [98-101].<smiles>Oc1cc(-c2cc(-c3ccncc3)nc(-c3ccncc3)c2)c(O)cc1-c1cc(-c2ccncc2)nc(-c2ccncc2)c1</smiles><smiles>c1ccc(CCCOc2cc(-c3cc(-c4ccncc4)nc(-c4cc(-c5ccncc5)nc(-c5ccncc5)c4)c3)c(OCCCc3ccccc3)cc2-c2ccncc2)cc1</smiles><smiles></smiles>
$55 \mathrm{R}={ }^{n}$ octy $56 \mathrm{R}={ }^{n}$ decyl

Scheme 13. Structures of ligands containing two $4,2^{\prime}: 6^{\prime}, 4^{\prime \prime}$-tpy metal-binding domains.

A combination of 53 and $\mathrm{ZnBr}_{2}$ or $\mathrm{ZnI}_{2}$ in a 1,2- $\mathrm{C}_{6} \mathrm{H}_{4} \mathrm{Cl}_{2} / \mathrm{MeOH}$ solvent system resulted in the growth of crystals of $\left[\mathrm{Zn}_{2} \mathrm{Br}_{4}(53)\right]_{n} \cdot 2 n \mathrm{C}_{6} \mathrm{H}_{4} \mathrm{Cl}_{2}$ or $\left[\mathrm{Zn}_{2} \mathrm{I}_{4}(53)\right]_{n} \cdot 2.3 n \mathrm{C}_{6} \mathrm{H}_{4} \mathrm{Cl}_{2}$, 
respectively. Both compounds crystallize in the monoclinic space group $P 2_{1} / n$ and are isostructural. Ligand 53 acts as a 4-connecting node and directs the assembly of a 2Dnetwork. The $(4,4)$ net is shown in Figure 37a for $\left[\mathrm{Zn}_{2} \mathrm{Br}_{4}(53)\right]_{n} \cdot 2 n \mathrm{C}_{6} \mathrm{H}_{4} \mathrm{Cl}_{2}$. The net has a corrugated profile and the methoxy substituents point above and below the sheet (Figure 37b) [99]. When the $n$-alkyloxy substituent is lengthened to hexyl, octyl or decyl in ligands 54, 55 or 56, reactions with zinc(II) chloride or bromide lead to the formation of the $2 \mathrm{D} \rightarrow 2 \mathrm{D}$ parallel interpenetrated networks $\left[\mathrm{Zn}_{2} \mathrm{Cl}_{4}(54)\right]_{n},\left[\mathrm{Zn}_{2} \mathrm{Cl}_{4}(55)\right]_{n} \cdot 4 n \mathrm{H}_{2} \mathrm{O}$, $\left[\mathrm{Zn}_{2} \mathrm{Br}_{4}(55)\right]_{n}$, and $\left[\mathrm{Zn}_{2} \mathrm{Cl}_{4}(56)\right]_{n} \cdot 2 n \mathrm{MeOH}[98-101]$. The topology of a single $(4,4)$ net in each compound mimics that in $\left[\mathrm{Zn}_{2} \mathrm{Br}_{4}(53)\right]_{n} \cdot 2 n \mathrm{C}_{6} \mathrm{H}_{4} \mathrm{Cl}_{2}$ and $\left[\mathrm{Zn}_{2} \mathrm{I}_{4}(53)\right]_{n} \cdot 2 \cdot 3 n \mathrm{C}_{6} \mathrm{H}_{4} \mathrm{Cl}_{2}$. However, the long alkyloxy chains are directed through the sheet (Figure 37c) and this appears to contribute to the assembly process. Figure 37d illustrates the interpenetrated networks in $\left[\mathrm{Zn}_{2} \mathrm{Cl}_{4}(55)\right]_{n} \cdot 4 n \mathrm{H}_{2} \mathrm{O}$ [98] and this is representative of the series $\left[\mathrm{Zn}_{2} \mathrm{Cl}_{4}(54)\right]_{n}$, $\left[\mathrm{Zn}_{2} \mathrm{Cl}_{4}(55)\right]_{n} \cdot 4 n \mathrm{H}_{2} \mathrm{O},\left[\mathrm{Zn}_{2} \mathrm{Br}_{4}(55)\right]_{n}$, and $\left[\mathrm{Zn}_{2} \mathrm{Cl}_{4}(56)\right]_{n} \cdot 2 n \mathrm{MeOH}$. The introduction of a phenyl substituent in a terminal position in the chain as in ligand $\mathbf{5 7}$ (Scheme 13) has a profound effect on the assembly process. The reaction between 57 and $\mathrm{ZnBr}_{2}$ yielded single crystals of $\left[\mathrm{Zn}_{2} \mathrm{Br}_{4}(57)\right]_{n} \cdot n \mathrm{H}_{2} \mathrm{O}$. This crystallizes in the trigonal space group $R-3$ with a $3 \mathrm{D}$-architecture, consisting of 2 -fold interpenetrating $n b o$ nets (Figure 37e). The assembly is directed by the 4-connecting ligand nodes, and the nets are closely associated by virtue of $\pi$-stacking between the pendant phenyl rings in 57 and $4,2^{\prime}: 6^{\prime}, 4^{\prime \prime}$-tpy domains in an adjacent net. This results in a highly porous network with a solvent accessible void space of ca. $65 \%$ [101].

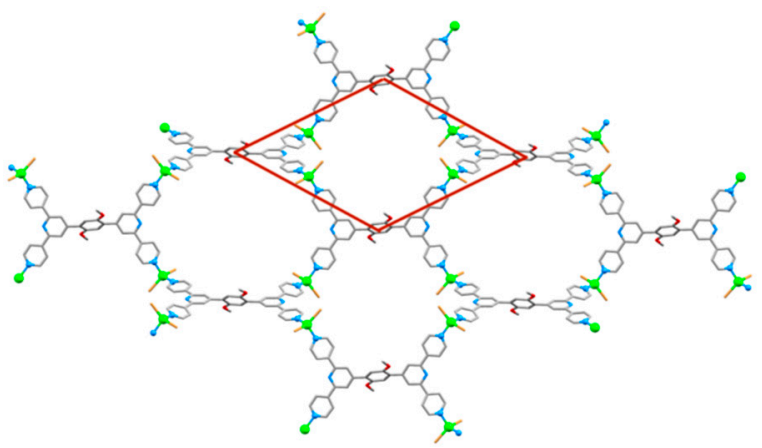

(a)

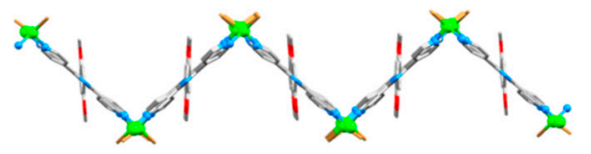

(b)

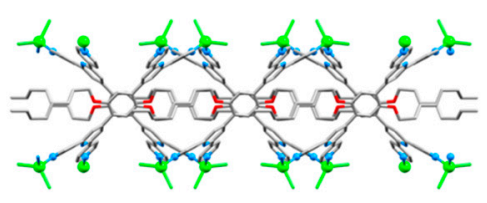

(c)

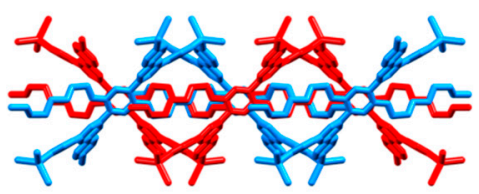

(d)

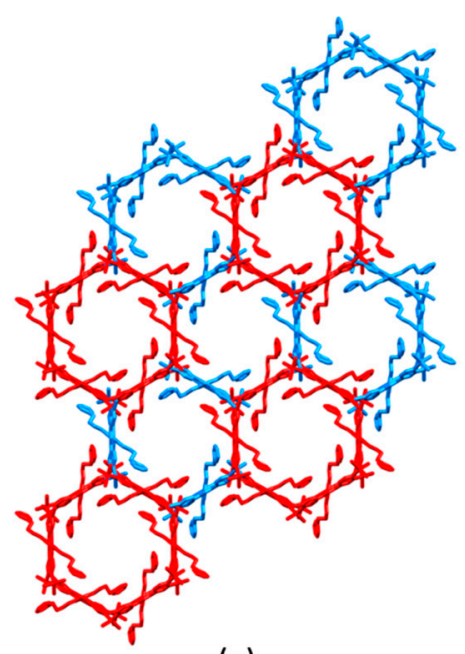

(e)

Figure 37. (a) Part of the $(4,4)$ network in $\left[\mathrm{Zn}_{2} \mathrm{Br}_{4}(53)\right]_{n} \cdot 2 n \mathrm{C}_{6} \mathrm{H}_{4} \mathrm{Cl}_{2}$; each ligand 53 is a 4-connecting node and one rhombus in the net is highlighted in red (CSD refcode ZUGVII). (b) A side-view of the 2D-net in $\left[\mathrm{Zn}_{2} \mathrm{Br}_{4}(53)\right]_{n} \cdot 2 n \mathrm{C}_{6} \mathrm{H}_{4} \mathrm{Cl}_{2}$. (c) In $\left[\mathrm{Zn}_{2} \mathrm{Cl}_{4}(55)\right]_{n} \cdot 4 n \mathrm{H}_{2} \mathrm{O}$ (refcode NOTPUI), the $n$-octyloxy chains lie in the plane of the network, and (d) the same representation of part of one sheet in $\left[\mathrm{Zn}_{2} \mathrm{Cl}_{4}(55)\right]_{n} \cdot 4 n \mathrm{H}_{2} \mathrm{O}$ showing the $2 \mathrm{D} \rightarrow 2 \mathrm{D}$ parallel interpenetrated nets (red and blue). (e) The 2-fold interpenetrating $n b o$ nets (red and blue) in $\left[\mathrm{Zn}_{2} \mathrm{Br}_{4}(57)\right]_{n} \cdot n \mathrm{H}_{2} \mathrm{O}$ (refcode DAQMAM).

Ligand 58 is related to 25 (Scheme 7) but offers two $4,2^{\prime}: 6^{\prime}, 4^{\prime \prime}$-tpy metal-binding domains. However, unlike ligands $53-57$, compound 58 exhibits rotational freedom about the ferrocenyl core that allows the ligand to adopt a cisoid conformation with the $4,2^{\prime}: 6^{\prime}, 4^{\prime \prime}$ tpy units lying over one another. This impacts on the assembly formed with 58 reacts with $\mathrm{ZnCl}_{2}$. In contrast to the networks described above and in Figure $37,\left[\mathrm{ZnCl}_{2}(\mathbf{5 8})\right]_{n} \cdot 3 n \mathrm{CHCl}_{3}$ is a 1D-coordination polymer (Figure 38a). This appears to be driven by face-to-face $\pi$-stacking between $4,2^{\prime}: 6^{\prime}, 4^{\prime \prime}$-tpy units of the same coordinated ligand (Figure 38b) [100]. 


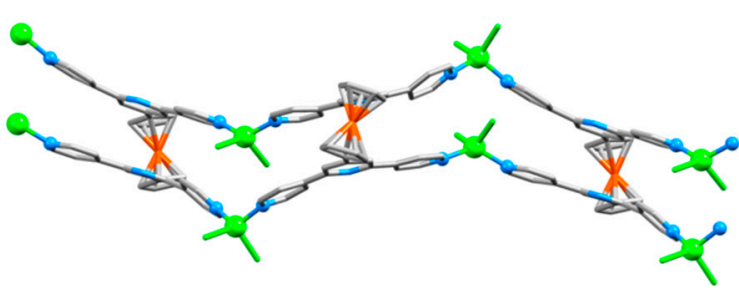

(a)

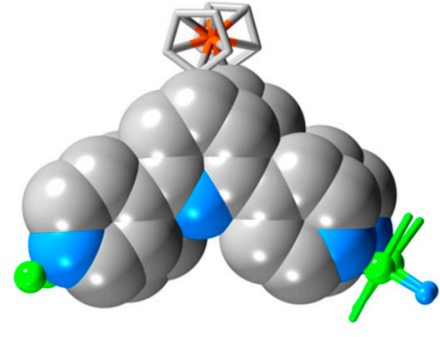

(b)

Figure 38. (a) Part of $1 \mathrm{D}$-coordination polymer in $\left[\mathrm{ZnCl}_{2}(58)\right]_{n} \cdot 3 n \mathrm{CHCl}_{3}$ and (b) $\pi$-stacking between $4,2^{\prime}: 6^{\prime}, 4^{\prime \prime}$-tpy units in the coordinated ligand 58 (CSD refcode UMUYUY).

\section{4. $3,2^{\prime}: 6^{\prime}, 3^{\prime \prime}$-terpyridine}

Compared to those involving $4,2^{\prime}: 6^{\prime}, 4^{\prime \prime}$-tpy domains, far fewer coordination assemblies have been reported in which the ligands bear $3,2^{\prime}: 6^{\prime}, 3^{\prime \prime}$-tpy metal binding domains. For those which incorporate zinc(II), we consider them in families of those with coordinatively innocent functionalities attached to the $3,2^{\prime}: 6^{\prime}, 3^{\prime \prime}$-tpy, and those with carboxylate or sulfonate groups which increase the connectivity of the ligand. No structurally characterized zinc(II)-containing assemblies with unfunctionalized $3,2^{\prime}: 6^{\prime}, 3^{\prime \prime}$-tpy or pyridinyl-substituted $3,2^{\prime}: 6^{\prime}, 3^{\prime \prime}$-tpy ligands had been reported in the CSD at the time of writing this review.

In this section, we provide schematic representations of the conformations of the coordinated $3,2^{\prime}: 6^{\prime}, 3^{\prime \prime}$-tpy units to emphasize its flexibility. Note, however, that in these diagrams, we use the three limiting, planar conformations.

\subsection{Assemblies Containing Zinc(II) and $4^{\prime}$-Functionalized $3,2^{\prime}: 6^{\prime}, 3^{\prime \prime}$-tpy Ligands with Coordinatively Innocent Substituents}

In Section 3.2, we described competition between the formation of polymeric and discrete molecular assemblies when zinc(II) salts reacted with $1-\left(4,2^{\prime}: 6^{\prime}, 4^{\prime \prime}\right.$-terpyridin- $4^{\prime}$ yl)ferrocene ( 25, Scheme 7$)$. Under conditions of crystal growth by layering, the isomer

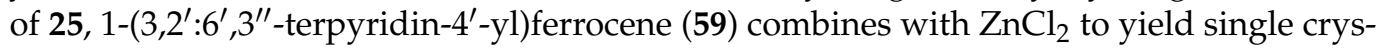
tals of the discrete metallosquare $\left[\mathrm{Zn}_{4} \mathrm{Cl}_{8}(59)_{4}\right] \cdot 3 \mathrm{CHCl}_{3} \cdot 3 \mathrm{MeOH}$ [57]. However, only a few crystals were obtained, and the bulk material was an amorphous powder for which PXRD data could not be obtained. Significantly, Xiao and Tian reported the formation of the 1D-polymer $\left[\mathrm{Zn}_{2} \mathrm{Cl}_{4}(59)_{2}\right]_{n} \cdot 3 n \mathrm{H}_{2} \mathrm{O}$ (Figure $39 \mathrm{a}$ ), but no synthetic details are available [102]. However, this observation provides support for possible competition between molecular and polymer assembly. $\left[\mathrm{Zn}_{2} \mathrm{Cl}_{4}(59)_{2}\right]_{n} \cdot 3 n \mathrm{H}_{2} \mathrm{O}$ crystallizes in the triclinic space group $P-1$ and the chain is built up by translation. The asymmetric unit contains two crystallographically independent ligands which differ in their conformations as shown in Figure 39b. This demonstrates the conformational flexibility of the $3,2^{\prime}: 6^{\prime}, 3^{\prime \prime}$-tpy unit (see Scheme 4), which sets it apart from the isomeric $4,2^{\prime}: 6^{\prime}, 4^{\prime \prime}$-tpy. We have also shown that the reaction of $\mathrm{ZnBr}_{2}$ and 59 yielded $\left[\mathrm{Zn}_{2} \mathrm{Br}_{4}(59)_{2}\right]_{n} \cdot 2 n \mathrm{MeOH}$ (CSD refcode TAYSIY) which has a very similar polymeric structure [57] to $\left[\mathrm{Zn}_{2} \mathrm{Cl}_{4}(59)_{2}\right]_{n} \cdot 3 n \mathrm{H}_{2} \mathrm{O}$. Xiao and Tian [103] have reported $\left[\mathrm{Zn}_{2} \mathrm{I}_{4}(59)_{2}\right]_{n}$ which is structurally analogous to the chlorido and bromido complexes. Changing to zinc(II) thiocyanate has the effect of switching the assembly with ligand 59 to a $2 \mathrm{D}$-network. The structure of $\left[\mathrm{Zn}_{3}(\mathrm{NCS})_{6}(59)_{6}\right] \cdot 6 n \mathrm{CHCl}_{3}$ is a communication to the CSD (refcode OGOYIU [104]). Each Zn center is bound by four pyridine rings from four different ligands $\mathbf{5 9}$, and the octahedral coordination sphere is completed by two thiocyanato ligands in a trans arrangement. The resulting $(4,4)$ net is shown in Figure 39c. The asymmetric unit contains three independent molecules of 59 but all the $3,2^{\prime}: 6^{\prime}, 3^{\prime \prime}$-tpy units have similar conformations (Figure 39c). 


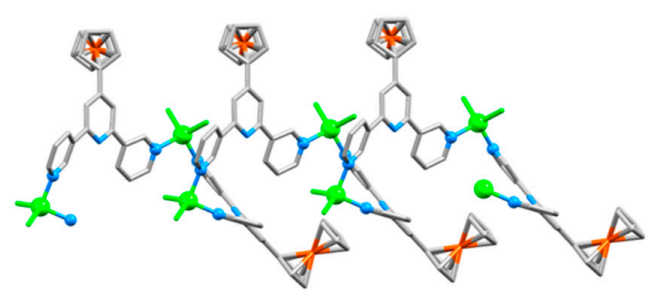

(a)

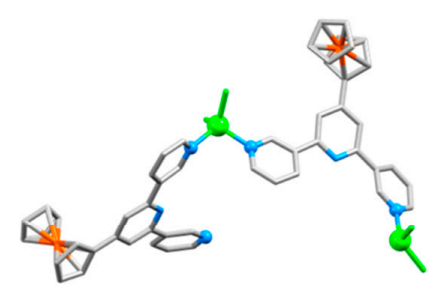

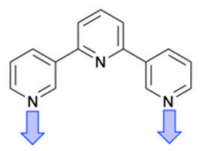

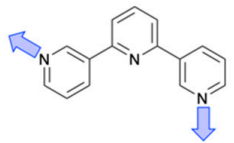

(b)
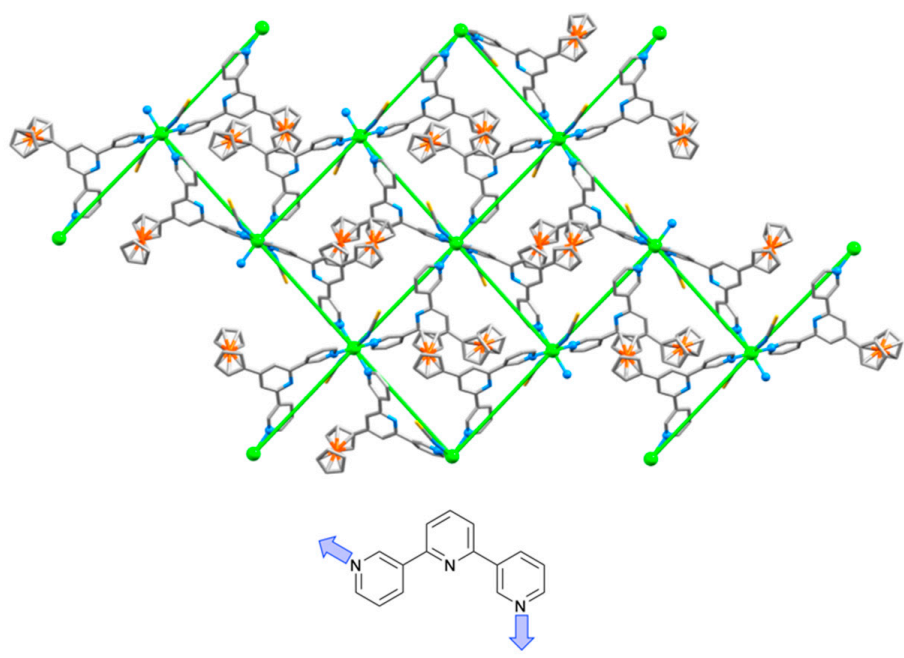

(c)

Figure 39. (a) Part of the 1D-polymer in $\left[\mathrm{Zn}_{2} \mathrm{Cl}_{4}(59)_{2}\right]_{n} \cdot 3 n \mathrm{H}_{2} \mathrm{O}(\mathrm{CSD}$ refcode VUKMOF) and (b) the asymmetric unit in $\left[\mathrm{Zn}_{2} \mathrm{Cl}_{4}(59)_{2}\right]_{n} \cdot 3 n \mathrm{H}_{2} \mathrm{O}$ and diagram showing the different conformations (in planar notation) of the crystallographically independent ligands 59. (c) Part of the $(4,4)$ net observed in $\left[\mathrm{Zn}_{3}(\mathrm{NCS})_{6}(59)_{6}\right] \cdot 6 n \mathrm{CHCl}_{3}$ (refcode OGOYIU). Each $\mathrm{Zn}$ is a 4-connecting node and the $\mathrm{Zn}_{4}$ rhombuses are highlighted; the conformation of the $3,2^{\prime}: 6^{\prime}, 3^{\prime \prime}$-tpy units is shown in planar notation.

\subsection{Assemblies Containing Zinc(II) and 3,2':6, $3^{\prime \prime}$-tpy Ligands Functionalized with Carboxylate or} Sulfonate Donors

The structures of the ligands relevant to this section are depicted in Scheme 14. As has already been discussed, the 3,2':6', $3^{\prime \prime}$-tpy metal-binding domain is conformationally flexible and only one planar conformation is shown for each ligand in Scheme 14. Crystals of zinc(II) complexes incorporating $\mathrm{H60}-\mathrm{H} 63, \mathrm{H}_{3} 64$, and $\mathrm{H}_{2} 65$ described in this section were grown under solvothermal conditions.<smiles>O=C(O)c1cc(-c2cccnc2)nc(-c2cccnc2)c1</smiles><smiles>O=C(O)c1ccc(-c2cc(-c3cccnc3)nc(-c3cccnc3)c2)cc1</smiles><smiles>O=C(O)c1cccc(-c2cc(-c3cccnc3)nc(-c3cccnc3)c2)c1</smiles><smiles>O=C(O)c1ccccc1-c1cc(-c2cccnc2)nc(-c2cccnc2)c1</smiles><smiles>CC(C)(C)c1cnccc1-c1cc(-c2cccnc2)cc(-c2c(C(=O)O)cc(C(=O)O)cc2C(=O)O)c1</smiles><smiles>O=S(=O)(O)c1ccc(-c2cc(-c3cccnc3)nc(-c3cccnc3)c2)c(S(=O)(=O)O)c1</smiles>

Scheme 14. Structures of $3,2^{\prime}: 6^{\prime}, 3^{\prime \prime}$-tpy ligands functionalized with carboxylic or sulfonic acid groups. 
$\mathrm{Hu}$ and coworkers have reported that a combination of $\mathrm{H} 60$ with $\mathrm{ZnCl}_{2}$ under hydrothermal conditions $\left(\mathrm{pH} 4.0,180^{\circ} \mathrm{C}\right.$ ) produced $\left[\mathrm{Zn}_{2} \mathrm{Cl}_{2}(60)_{2}\right]_{n}$ which is a 1D-coordination polymer in which each $\mathbf{6 0}^{-}$binds to three $\mathrm{Zn}$ (II) centers [105]. Note that the conformational flexibility of the $3,2^{\prime}: 6^{\prime}, 3^{\prime \prime}$-tpy unit facilitates this ladder-like assembly (Figure 40a) and should be contrasted with the V-shaped building block offered by the $4,2^{\prime}: 6^{\prime}, 4^{\prime \prime}$-tpy unit in $\mathrm{H} 31$ (an isomer of $\mathrm{H} 60$ ) and discussed in Section 3.4. In related work, $\mathrm{Hu}$ and coworkers used $\mathrm{H} 61$ in reactions with $\mathrm{ZnCl}_{2}$. Depending upon the $\mathrm{pH}$, either $\left[\mathrm{Zn}(61)_{2}(\mathrm{H} 61)_{2}\right] \cdot 2 n \mathrm{H}_{2} \mathrm{O}$ (at $\mathrm{pH} 4$, see below) or $[\mathrm{ZnCl}(\mathbf{6 1})]_{n}$ (at $\mathrm{pH}$ ) was produced under hydrothermal conditions in the presence of 1,10 -phenanthroline (phen) at $180^{\circ} \mathrm{C}$ [106]. It appears that phen plays a templating role; other examples in which template seemed to be required were described earlier, and we see a further example with ligand H62 (see below). The preparation and structure of $[\mathrm{ZnCl}(61)]_{n}$ has also been reported by Zhang et al. (CSD refcode FIJJIP01) [107]. As in $\left[\mathrm{Zn}_{2} \mathrm{Cl}_{2}(\mathbf{6 0})_{2}\right]_{n}$ (Figure 40a), a 1D-polymer is observed in $[\mathrm{ZnCl}(\mathbf{6 1})]_{n}$ and Figure $40 \mathrm{~b}$ illustrates that the $3,2^{\prime}: 6^{\prime}, 3^{\prime \prime}$-tpy unit adopts a common conformation in both polymers. In the investigation from $\mathrm{Hu}$ [106], the product $\left[\mathrm{Zn}(61)_{2}(\mathrm{H} 61)_{2}\right] \cdot 2 n \mathrm{H}_{2} \mathrm{O}$ formed at $\mathrm{pH} 4$ is a discrete molecular complex. The $\mathrm{Zn}$ (II) center is bound by two monodentate H61 ligands and two $61^{-}$coordinated through bidentate carboxylate groups (Figure $40 \mathrm{c}$ ). The conformation of the $3,2^{\prime}: 6^{\prime}, 3^{\prime \prime}$-tpy unit is the same as in the 1D-polymers in Figure 40a,b. Since $\mathrm{H} 61$ is an isomer of $\mathrm{H17}$ and both offer divergent $\mathrm{N}$-donor sets, it is instructive to compare their reactions with $\mathrm{ZnCl}_{2}$. As we detailed earlier, combinations of $\mathrm{ZnCl}_{2}$ and $\mathrm{H17}$ have led to $\left[\mathrm{Zn}_{2}(\mathrm{H17}) \mathrm{Cl}_{2}\right]_{n} \cdot 2 n \mathrm{EtOH} \cdot n \mathrm{H}_{2} \mathrm{O}$ (Figure 14) [48], and $\left[\mathrm{Zn}_{2}\left(\mathbf{1 7}_{2}\right)_{2} \mathrm{Cl}_{2}\right]_{n} \cdot 0.5 n \mathrm{H}_{2} \mathrm{O}$ (a 2-fold interpenetrated $6^{3}$ net) [70]. Carboxylic acids $\mathrm{H} 62$ and $\mathrm{H} 63$ are isomers of H61 (Scheme 14), and a comparison can be made between the reactions of $\mathrm{H} 61$ or $\mathrm{H} 62$ with $\mathrm{ZnCl}_{2}$ (all under solvothermal conditions). A combination of $\mathrm{ZnCl}_{2}$ and $\mathrm{H} 62\left(\mathrm{pH} 6,180^{\circ} \mathrm{C}\right)$ resulted in single crystals of $[\mathrm{ZnCl}(62)]_{n}$ which possesses a 2D-network with each $\mathrm{Zn}$ (II) center and each $62^{-}$ligand acting as a 3-connecting node [108]. Figure 41a shows a side-view of the 2D-network, and illustrates how the conformation of the ligand facilitates the assembly of the double-decker type architecture; the angles between the planes of pairs of connected pyridine rings are 19.3 and $37.7^{\circ}$. The building block in the network is shown in Figure $41 \mathrm{~b}$, with a schematic representation of the conformation of the $3,2^{\prime}: 6^{\prime}, 3^{\prime \prime}$-tpy unit. Hu and coworkers also carried out the reaction of $\mathrm{H} 62$ and $\mathrm{ZnCl}_{2}$ in the presence of malonic acid. The latter does not act as a co-ligand and the assembly is another example of a possible templating effect. Crystals of $\left[\mathrm{Zn}(62)_{2}\right]_{n} \cdot 2 n \mathrm{H}_{2} \mathrm{O}$ were obtained and structural characterization revealed a 1D-coordination polymer with a loop-like architecture (Figure 41c). Each pair of adjacent $\mathrm{Zn}$ (II) centers is bridged by two ligands $62^{-}$, each ligand coordinating through a bidentate $\mathrm{CO}_{2}^{-}$group and one pyridine $N$-donor. Although not discussed in the original work [108], inspection of the packing interactions in the structure (CSD refcode IKEXIH) indicates that hydrogen bonding from one non-coordinated $\mathrm{N}_{\mathrm{py}}$ atom to a water molecule may be responsible for the different conformations of the $3,2^{\prime}: 6^{\prime}, 3^{\prime \prime}$-tpy units (Figure 41d).

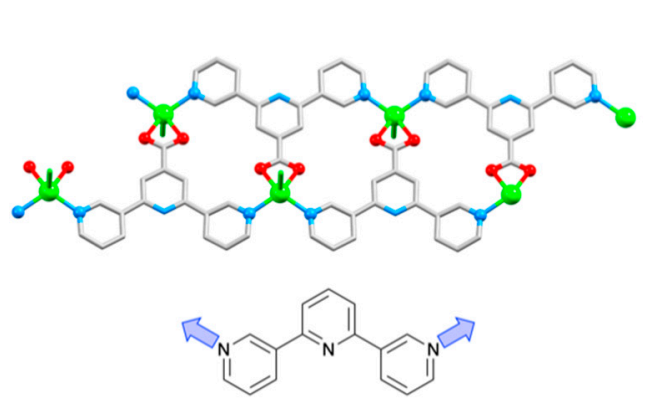

(a)

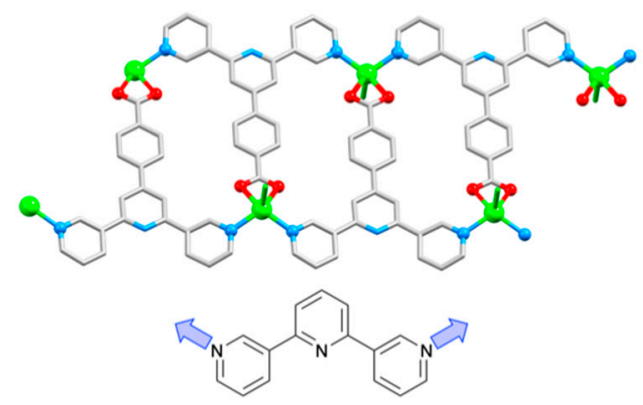

(b)

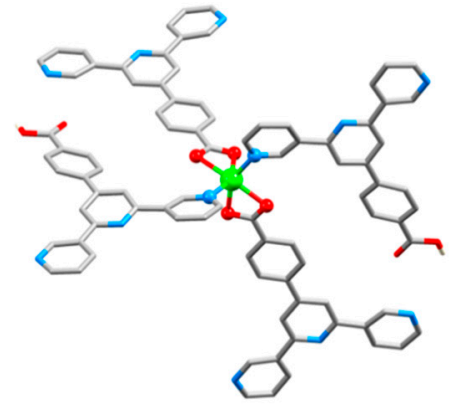

(c)

Figure 40. Part of the $1 \mathrm{D}$-polymer in (a) $\left.\mathrm{Zn}_{2} \mathrm{Cl}_{2}(\mathbf{6 0})_{2}\right]_{n}$ (CSD refcode XEWGUD), and (b) $[\mathrm{ZnCl}(\mathbf{6 1})]_{n}$ (CSD refcode FIJJIP); the conformation of the $3,2^{\prime}: 6^{\prime}, 3^{\prime \prime}$-tpy unit is shown in planar notation for both structures. (c) The structure of the mononuclear complex $\left[\mathrm{Zn}(\mathbf{6 1})_{2}(\mathrm{H} 61)_{2}\right]$ in the dihydrate (refcode FEJJEL); $\mathrm{H}$ atoms except for those in the $\mathrm{CO}_{2} \mathrm{H}$ groups are omitted. 


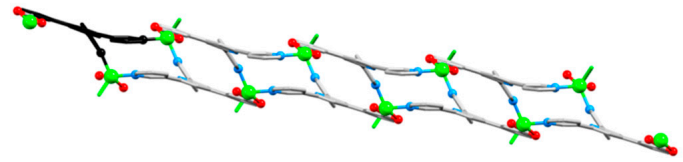

(a)

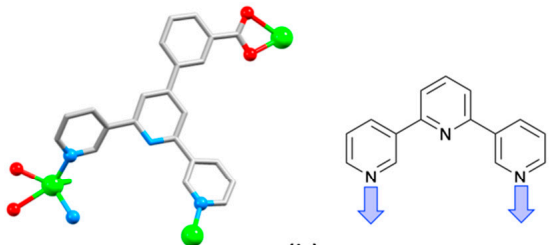

(b)

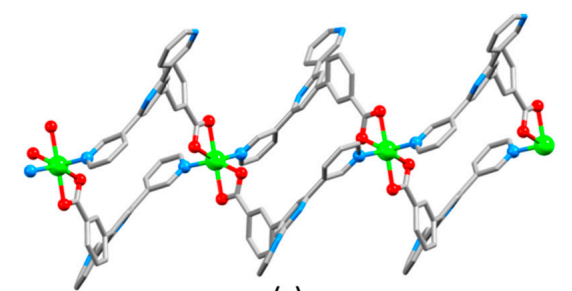

(c)

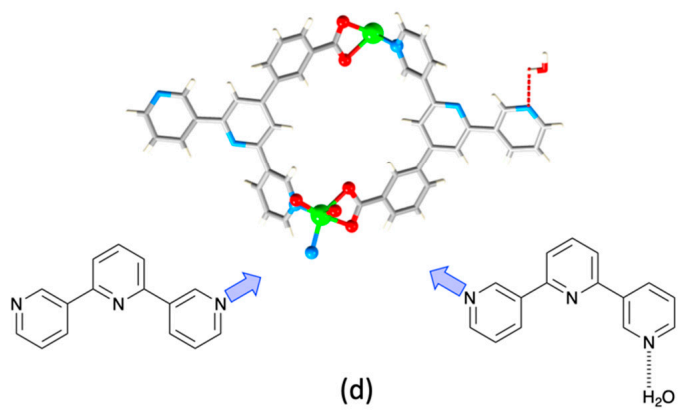

Figure 41. (a) Part of the 'double-decker' 2D-network in $[\mathrm{ZnCl}(62)]_{n}$ (CSD refcode IKEXED); one $\mathbf{6 2}^{-}$ligand is shown in black to emphasize the conformation of the ligand. (b) The building block in $[\mathrm{ZnCl}(62)]_{n}$ and the planar conformation of the $3,2^{\prime}: 6^{\prime}, 3^{\prime \prime}$-tpy unit. (c) Part of the loop-like 1D-polymer in [ $\left.\mathrm{Zn}(62)_{2}\right]_{n} \cdot 2 n \mathrm{H}_{2} \mathrm{O}$ (refcode IKEXIH), and (d) detail of one loop in the chain showing two different ligand conformations; one non-coordinated pyridine ring is involved in hydrogen bond formation.

On going from H61 and H62 to H63 (Scheme 14), there are no data available to directly compare reactions of $\mathrm{ZnCl}_{2}$ with the final isomer in the series. However, crystals of $[\mathrm{ZnCl}(63)]_{n} \cdot n \mathrm{H}_{2} \mathrm{O}$ were prepared in the hydrothermal reaction of $\mathrm{H} 63$ and $\mathrm{Zn}(\mathrm{OAc})_{2}$ with the addition of $\mathrm{EuCl}_{3} \cdot 6 \mathrm{H}_{2} \mathrm{O}$ and glutaric acid ( $\left.\mathrm{pH} 3.5,180{ }^{\circ} \mathrm{C}\right)$. The assembly in $[\mathrm{ZnCl}(\mathbf{6 3})]_{n} \cdot n \mathrm{H}_{2} \mathrm{O}$ is unlike either of those in $[\mathrm{ZnCl}(\mathbf{6 1})]_{n}[106,107]$ or $[\mathrm{ZnCl}(\mathbf{6 2})]_{n}[109]$. In $[\mathrm{ZnCl}(63)]_{n} \cdot n \mathrm{H}_{2} \mathrm{O}$, each $\mathrm{Zn}(\mathrm{II})$ is bound by two $\mathrm{N}$-donors of two different $63^{-}$ligands, a bidentate $\mathrm{CO}_{2}^{-}$from a third $63^{-}$ligand, and a chlorido ligand. Each $\mathrm{Zn}$ (II) and each $63^{-}$is a 3-connecting node and the assembly propagates into a 3D-network with a $u t p$ topology [11]. Note that the building block in $[\mathrm{ZnCl}(63)]_{n} \cdot n \mathrm{H}_{2} \mathrm{O}$ (Figure 42a) is similar to that in $[\mathrm{ZnCl}(\mathbf{6 2})]_{n}$ (Figure 41b) and adopts an analogous conformation of the $3,2^{\prime}: 6^{\prime}, 3^{\prime \prime}$-tpy unit. $\mathrm{Hu}$ and coworkers have also reported the single crystal structure of $\left[\mathrm{Zn}(63)_{2}\right]_{n}[11]$ and this exhibits a similar loop-like 1D-coordination polymer as observed in $\left[\mathrm{Zn}(62)_{2}\right]_{n} \cdot 2 n \mathrm{H}_{2} \mathrm{O}$ (see above). However, a comparison of Figure $42 \mathrm{~b}$ with Figure $41 \mathrm{~d}$ reveals a 'tighter' loop in $\left[\mathrm{Zn}(63)_{2}\right]_{n}$ than in $\left[\mathrm{Zn}(62)_{2}\right]_{n} \cdot 2 n \mathrm{H}_{2} \mathrm{O}$, as well as a change in the conformation of the $3,2^{\prime}: 6^{\prime}, 3^{\prime \prime}$-tpy unit.

The tricarboxylic acid $\mathrm{H}_{3} 64$ (Scheme 14) has been combined with $\mathrm{Zn}\left(\mathrm{NO}_{3}\right)_{2} \cdot 6 \mathrm{H}_{2} \mathrm{O}$ under hydrothermal conditions with phen added to the reaction mixture. As with many of the investigations reviewed in this section, the aim was to prepare a fluorescent material for sensing applications. Crystals of $[\mathrm{Zn}(\mathrm{H} 64)]_{n} \cdot 1.5 n \mathrm{H}_{2} \mathrm{O}$ (CSD refcode MUNDEH) were isolated, and contain $\mathrm{H}_{64}{ }^{2-}$ in which one outer pyridine ring bears the proton. The asymmetric unit with symmetry-generated atoms is shown in Figure 42c. Both $\mathrm{H}_{64}{ }^{2-}$ and $\mathrm{Zn}(\mathrm{II})$ are 4-connecting nodes, and a 2D (4,4)-net (Figure 42d) is assembled [109].

Finally in this section, we consider the assembly formed when $\mathrm{Zn}\left(\mathrm{NO}_{3}\right)_{2} \cdot 6 \mathrm{H}_{2} \mathrm{O}$ was treated with the disulfonic acid $\mathrm{H}_{2} 65$ (Scheme 14) under hydrothermal conditions ( $\mathrm{pH}$ $\left.7,120{ }^{\circ} \mathrm{C}\right)$. Crystals of $\left[\mathrm{Zn}(65)\left(\mathrm{OH}_{2}\right)_{2}\right]_{n} \cdot 2 n \mathrm{H}_{2} \mathrm{O}$ were isolated in $78 \%$ yield, and the coordination compound is isostructural with that of the cadmium(II) analog [110]. Ligand $65^{2-}$ is a 4-connecting node as shown in Figure 43a, and each $\mathrm{Zn}$ (II) center is octahedrally sited, bound by two pyridine $N$-donors in a trans-arrangement, two monodentate sulfonato groups (cis with respect to one another) from two different $65^{2-}$ ligands, and two aqua ligands. Like ligand $65^{2-}$, the $\mathrm{Zn}(\mathrm{II})$ center is a 4-connecting node, and a 3D-network with a sar topology is produced (Figure 43 b). 


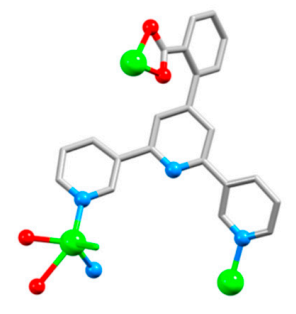

(a)

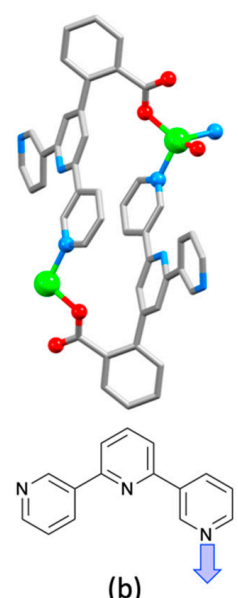

(b)

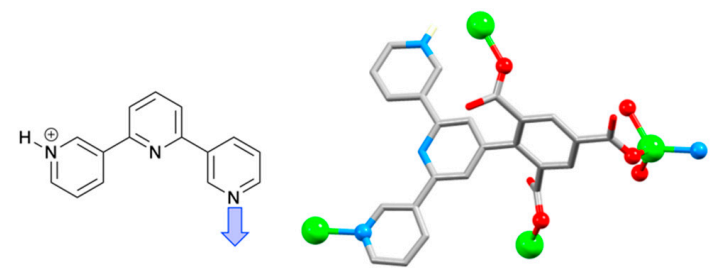

(c)

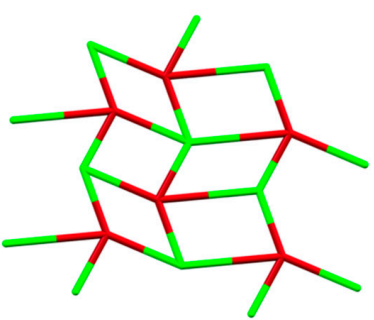

(d)

Figure 42. (a) The building block in $[\mathrm{ZnCl}(63)]_{n} \cdot n \mathrm{H}_{2} \mathrm{O}$ (CSD refcode MICTAW); compare this with Figure 41b. (b) Detail of one loop in the 1D-chain in $\left[\mathrm{Zn}(63)_{2}\right]_{n}$ (refcode MICTEA) and the ligand conformation; one terminal pyridine ring is non-coordinated; compare with Figure 41d. (c) The building block in [ $\mathrm{Zn}(\mathrm{H} 64)]_{n} \cdot 1.5 n \mathrm{H}_{2} \mathrm{O}$ (refcode MUNDEH) and ligand conformation. (d) Part of the $(4,4)$ net in $[\mathrm{Zn}(\mathrm{H} 64)]_{n} \cdot 1.5 n \mathrm{H}_{2} \mathrm{O}$ with 4 -connecting $\mathrm{Zn}$ nodes (green) and ligand nodes (red); the ligand node is defined as the centroid of the central pyridine ring.

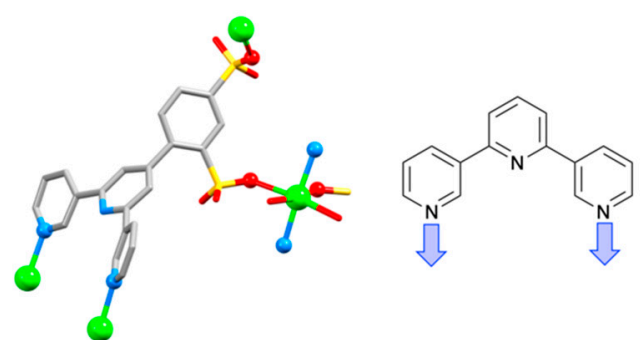

(a)

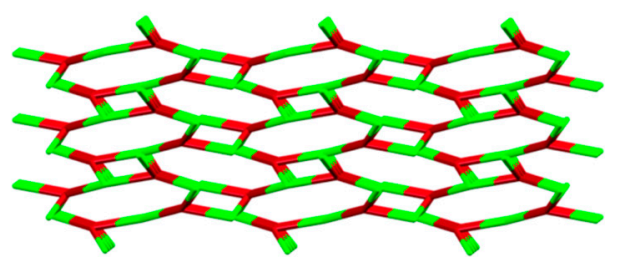

(b)

Figure 43. (a) The building block and representation of the conformation of the $3,2^{\prime}: 6^{\prime}, 3^{\prime \prime}$-tpy unit in $\left[\mathrm{Zn}(65)\left(\mathrm{OH}_{2}\right)_{2}\right]_{n} \cdot 2 n \mathrm{H}_{2} \mathrm{O}$ (CSD refcode DUWDUW), and (b) part of the $3 \mathrm{D}$ sar network in $\left[\mathrm{Zn}(65)\left(\mathrm{OH}_{2}\right)_{2}\right]_{n} \cdot 2 n \mathrm{H}_{2} \mathrm{O}$ with 4-connecting $\mathrm{Zn}$ nodes (green) and 4-connecting ligand nodes (red); the ligand node is defined as the centroid of the central pyridine ring.

\subsection{Assemblies Containing Cadmium(II) and $3,2^{\prime}: 6^{\prime}, 3^{\prime \prime}$-tpy Ligands}

Only a few examples of coordination polymers and networks comprising $\mathrm{Cd}(\mathrm{II})$ and $3,2^{\prime}: 6^{\prime}, 3^{\prime \prime}$-tpy ligands have been described. With one exception (CSD refcode HATFOA, see below), in all cases, the $3,2^{\prime}: 6^{\prime}, 3^{\prime \prime}$-tpy is functionalized in the $4^{\prime}$-position with either a carboxylic or sulfonic acid. The exception is the ligand $\left[3,2^{\prime}: 6^{\prime}, 3^{\prime \prime}\right.$-terpyridine] $N^{\prime}$-oxide (66) which was combined with $\mathrm{CdI}_{2}$ under conditions of crystal growth by layering. The interest in using an $\mathrm{N}$-oxide was to incorporate catalytically active species into solid coordination polymer frameworks [111]. Crystals of the $1 \mathrm{D}$-coordination polymer $\left[\mathrm{CdI}_{2}(66)\right]_{n}$ were isolated. The polymer chain (Figure $44 \mathrm{a}$ ) is built up by a 2 -fold rotation axis and equal numbers of left- and right-handed helical chains are present in the crystal lattice. The angle between the planes of the middle and terminal pyridine rings is $43.3^{\circ}$, and Figure $44 \mathrm{a}$ shows the most appropriate limiting planar conformation of the $3,2^{\prime}: 6^{\prime}, 3^{\prime \prime}$-tpy unit. Dong and coworkers also confirmed that $\left[\mathrm{HgI}_{2}(66)\right]_{n}$ is isostructural with $\left[\mathrm{CdI}_{2}(66)\right]_{n}$. These and related coordination polymers (see Section 5) were shown to be heterogeneous catalysts for Knoevenagel condensation reactions under ambient conditions [111]. 


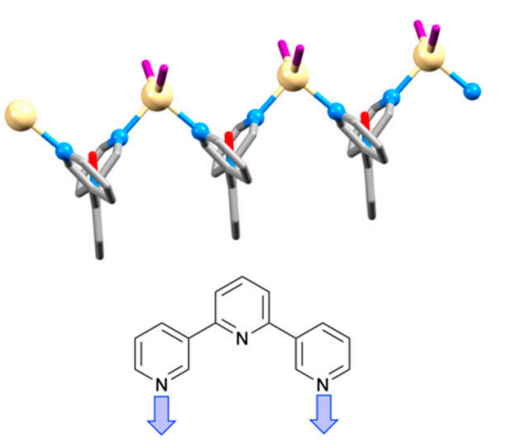

(a)

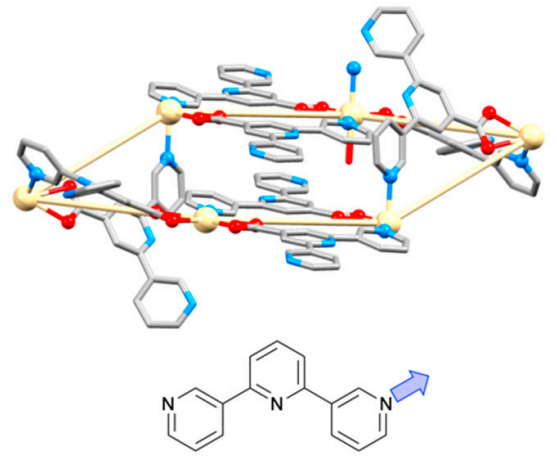

(b)

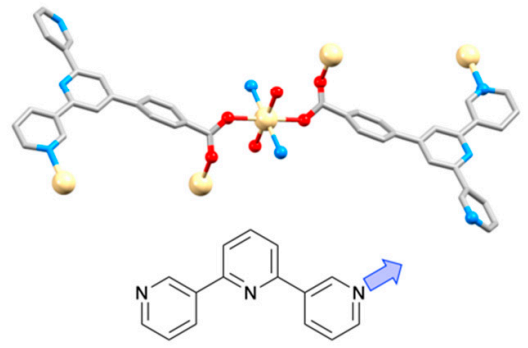

(d)

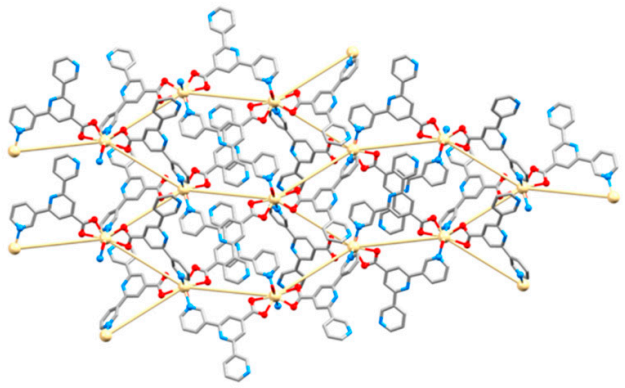

(c)

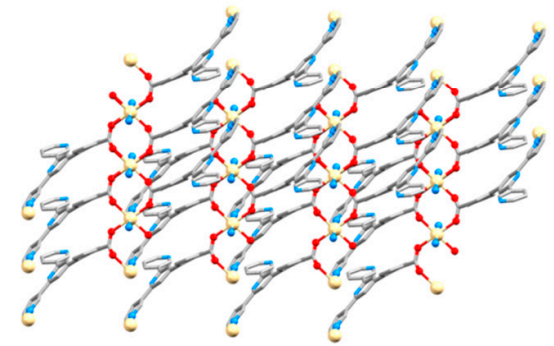

(e)

Figure 44. (a) Part of the 1D-polymer in $\left[\mathrm{CdI}_{2}(\mathbf{6 6})\right]_{n}$ (CSD refcode HATFOA), and the limiting planar conformation. (b) Part of one 6-membered circuit in the $(6,3)$ net in $\left[\mathrm{Cd}(60)_{2}\left(\mathrm{OH}_{2}\right)\right]_{n}$ (refcode XEWGEN); there are two crystallographically independent $\mathbf{6 0}^{-}$ligands but both can be described by the same limiting planar conformation. (c) Part of the $(6,3)$ net in $\left[\mathrm{Cd}(60)_{2}\left(\mathrm{OH}_{2}\right)\right]_{n}$. (d) The 6-connecting $\mathrm{Cd}(\mathrm{II})$ and 3-connecting ligand nodes in $\left[\mathrm{Cd}(\mathbf{6 1})_{2}\right]_{n}$ with a schematic diagram of the planar conformation of the $3,2^{\prime}: 6^{\prime}, 3^{\prime \prime}$-tpy, and (e) part of the 2D-network in $\left[\mathrm{Cd}(\mathbf{6 1})_{2}\right]_{n}$ (refcode DOGFEN) viewed down the $c$-axis.

Zinc(II) coordination polymers and networks involving carboxylic and sulfonic acid functionalized ligands H60, H61, H63 and $\mathrm{H}_{2} 65$ (Scheme 14) were discussed in Section 4.2. We now compare the effects of moving from $\mathrm{Zn}$ (II) to $\mathrm{Cd}(\mathrm{II})$. For H60, a direct comparison between $\mathrm{Zn}$ and $\mathrm{Cd}$ cannot be made since $\mathrm{H} 60$ has been combined with zinc(II) chloride (hydrothermal conditions, $\mathrm{pH} 4,180{ }^{\circ} \mathrm{C}$ ) as opposed to cadmium(II) nitrate (hydrothermal, $\left.\mathrm{pH} 5,180^{\circ} \mathrm{C}\right)$ [105]. In the latter reaction, crystals of $\left[\mathrm{Cd}(60)_{2}\left(\mathrm{OH}_{2}\right)\right]_{n}$ were obtained. The Cd(II) center is 7-coordinate, being bound by two bidentate carboxylates from two different ligands, by two terminal pyridine rings of two additional ligands, and by an aqua ligand. The remaining two $\mathrm{N}$-donors of each ligand are uncoordinated. The assembly of a 2D-network is thereby directed by the $\mathrm{Cd}(\mathrm{II})$ nodes, and each $60^{-}$ligand serves as a linker. In contrast to the $(4,4)$ net in $\left[\mathrm{Cd}_{2}(34)_{4}\right]_{n} \cdot n \mathrm{H}_{2} \mathrm{O}$ (see Figure 33 ) in which each $\mathrm{Cd}(\mathrm{II})$ is 4-connecting and each $\mathrm{Cd}$... Cd vector is bridged by one ligand, the assembly in $\left[\mathrm{Cd}(60)_{2}\left(\mathrm{OH}_{2}\right)\right]_{n}$ is a $(6,3)$ net in which $\mathrm{Cd}(\mathrm{II})$ is a 3-connecting node. Two of the six $\mathrm{Cd} \ldots$ $\mathrm{Cd}$ vectors in the 6-membered circuit are each bridged by two $60^{-}$ligands, and four $\mathrm{Cd}$... $\mathrm{Cd}$ vectors are each bridged by one ligand (Figure $44 \mathrm{~b}$ ). Part of the 2D-network is depicted in Figure 44c [105]. Going from H60 to $\mathrm{H61}$ introduces a phenylene spacer, and under solvothermal conditions $\left(\mathrm{MeCN} / \mathrm{H}_{2} \mathrm{O}, 160{ }^{\circ} \mathrm{C}\right)$, the reaction of $\mathrm{H} 61$ and $\mathrm{Cd}\left(\mathrm{NO}_{3}\right)_{2} \cdot 6 \mathrm{H}_{2} \mathrm{O}$ leads to crystals of $\left[\mathrm{Cd}(61)_{2}\right]_{n}$. The $\mathrm{Cd}(\mathrm{II})$ center lies on a center-of-symmetry and is 6-coordinate, and bound to six different ligands (Figure 44d). Given the availability of both pyridine and carboxylato donors, we again see the preference for $\mathrm{CO}_{2}{ }^{-}$coordination to $\mathrm{Cd}(\mathrm{II})$, and the $3,2^{\prime}: 6^{\prime}, 3^{\prime \prime}$-tpy domain retains two uncoordinated pyridine rings and adopts the conformation shown in Figure $44 \mathrm{~d}$. The combination of 6-connecting Cd(II) and 3-connecting $\mathbf{6 1}^{-}$ligand leads to the 2D-network shown in Figure 44e. A noteworthy feature of the 2D-sheet is the incorporation of infinite $\left\{\mathrm{Cd}_{2}\left(\mu-\mathrm{O}_{2} \mathrm{CR}\right)_{2}\right\}_{n}$ chains. $\left[\mathrm{Cd}(61)_{2}\right]_{n}$ is strongly luminescent and its application as a luminescence sensor for 2,4,6-trinitrophenol was demonstrated [112]. When $\mathrm{H} 63$ was combined with $\mathrm{CdCl}_{2} \cdot 2.5 \mathrm{H}_{2} \mathrm{O}$ under hydrothermal conditions ( $\mathrm{pH} 6,180^{\circ} \mathrm{C}$ ) and in the presence of benzene-1,2-dicarboxylic acid, crystals 
of $\left[\mathrm{Cd}(63)_{2}\left(\mathrm{OH}_{2}\right)_{2}\right]_{n}$ (CSD refcode MICTIE) were isolated. The structure is a loop-like 1D-polymer [11], similar to that found in $\left[\mathrm{Zn}(63)_{2}\right]_{n}$ (Figure 42b). The major difference is the incorporation of two aqua ligands per $\mathrm{Cd}(\mathrm{II})$, consistent with the preference for a higher coordination number for the larger metal ion. A change in the $\mathrm{pH}$ from 6.0 to 4.0 resulted in the assembly of $\left[\mathrm{Cd}(63)_{2}\left(\mathrm{OH}_{2}\right)\right]_{n}$ which is again a $1 \mathrm{D}$-polymer comprising loop-like building blocks [11]. The structure is rather unusual. $\left[\mathrm{Cd}(63)_{2}\left(\mathrm{OH}_{2}\right)\right]_{n}$ crystallizes in the monoclinic space group $P 2{ }_{1} / c$ and Figure 45 a shows the asymmetric unit with symmetry generated atoms. There are two independent $63^{-}$ligands, and the two different $3,2^{\prime}: 6^{\prime}, 3^{\prime \prime}$-tpy units adopt the same conformation. However, while one $3,2^{\prime}: 6^{\prime}, 3^{\prime \prime}$-tpy coordinates to two $\mathrm{Cd}$ (II) centers, the second is non-coordinated and simply decorates the periphery of the chain (Figure $45 \mathrm{~b}$ ). The assembly in $\left[\mathrm{Cd}(63)_{2}\left(\mathrm{OH}_{2}\right)\right]_{n}$ once again illustrates the dominance of the anionic carboxylato donor over coordination through the terpyridine domain. Finally, for the sulfonato-functionalized ligand $65^{2-},\left[\mathrm{Cd}(65)\left(\mathrm{OH}_{2}\right)_{2}\right]_{n} \cdot 2 n \mathrm{H}_{2} \mathrm{O}$ (CSD refcode DUWFAE) is isostructural with $\left[\mathrm{Zn}(65)\left(\mathrm{OH}_{2}\right)_{2}\right]_{n} \cdot 2 n \mathrm{H}_{2} \mathrm{O}$ (Figure 43) [110].

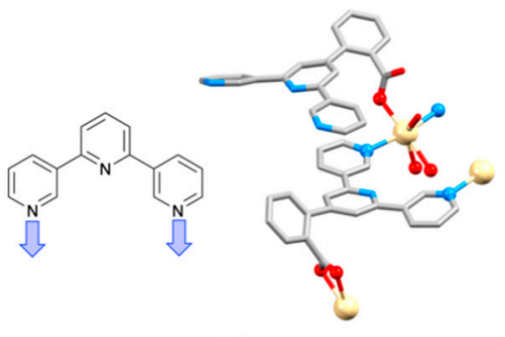

(a)

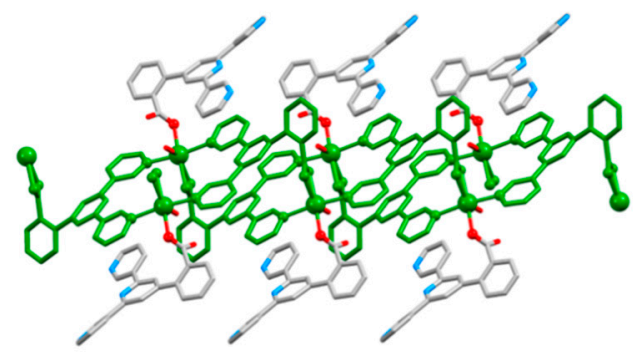

(b)

Figure 45. The structure of $\left[\mathrm{Cd}(63)_{2}\left(\mathrm{OH}_{2}\right)\right]_{n}$ (CSD refcode MICTOK). (a) The asymmetric unit with symmetry generated atoms, and the planar conformation of both independent $3,2^{\prime}: 6^{\prime}, 3^{\prime \prime}$-tpy units. (b) A representation of part of the 1D-polymer illustrating the different roles of the two independent $63^{-}$ligands; the ligands colored green comprise the polymer backbone, while the second ligands are peripheral to the assembly.

\section{5. $4,3^{\prime}: 5^{\prime}, 4^{\prime \prime}$-terpyridine}

Like $4,2^{\prime}: 6^{\prime}, 4^{\prime \prime}$-tpy, the isomer $4,3^{\prime}: 5^{\prime}, 4^{\prime \prime}$-tpy offers a V-shaped building block for coordination polymer assembly. However, this ligand has been little utilized, and coordination polymers involving $\mathrm{Zn}(\mathrm{II})$ and $\mathrm{Cd}(\mathrm{II})$ are limited to those directed by ligand 67 (Scheme 15), plus one example which also involves a co-ligand [113].<smiles>c1cc(-c2cncc(-c3ccncc3)c2)ccn1</smiles>

$4,3^{\prime}: 5^{\prime}, 4^{\prime \prime}$-tpy<smiles>[O-][n+]1cc(-c2ccncc2)cc(-c2ccncc2)c1</smiles>

67

Scheme 15. The structure of $4,3^{\prime}: 5^{\prime}, 4^{\prime \prime}$-terpyridine and of the $N$-oxide 67.

As discussed in Section 4.3, Dong and coworkers have been interested in incorporating catalytically active species in the form of terpyridine $\mathrm{N}$-oxides into coordination polymer frameworks [111]. In addition to using $\left[3,2^{\prime}: 6^{\prime}, 3^{\prime \prime}\right.$-terpyridine] $N^{\prime}$-oxide (66), they have reported the reactions of $\mathrm{ZnCl}_{2}$ and $\mathrm{ZnI}_{2}$ with [4, $3^{\prime}: 5^{\prime}, 4^{\prime \prime}$-terpyridine] $N^{\prime}$-oxide (67). Crystal growth was under ambient conditions, and the structurally similar 1D-coordination polymers $\left[\mathrm{ZnCl}_{2}(67)\right]_{n}$ and $\left[\mathrm{ZnI}_{2}(67)\right]_{n}$ were formed (CSD refcodes HATFAM and HATFEQ). Both contain helical chains which are built up by a screw axis. In contrast, the reaction of $\mathrm{CdI}_{2}$ with 67 (carried out under similar layering conditions to $\mathrm{ZnI}_{2}$ with 67) gave crystals of $\left[\mathrm{Cd}_{3} \mathrm{I}_{6}(67)_{2}\right]_{n}$ which crystallizes in the tetragonal space group $I 4_{1} / a$. Both the outer 
pyridine rings of 67 and the $N$-oxide bind to $\mathrm{Cd}(\mathrm{II})$. Trinuclear $\left\{\mathrm{Cd}_{3} \mathrm{I}_{4}(\mu-\mathrm{I})_{2}(\mu-\mathrm{O})_{2} \mathrm{~N}_{4}\right\}$ units assemble (Figure 46a). Ligand $\mathbf{6 7}$ acts as a 3-connecting node, and the central $\mathrm{Cd}(\mathrm{II})$ of the $\mathrm{Cd}_{3}$ cluster is a 4 -connecting node. The structure propagates into the 2 -fold interpenetrating 3D network shown in Figure 46b [111].

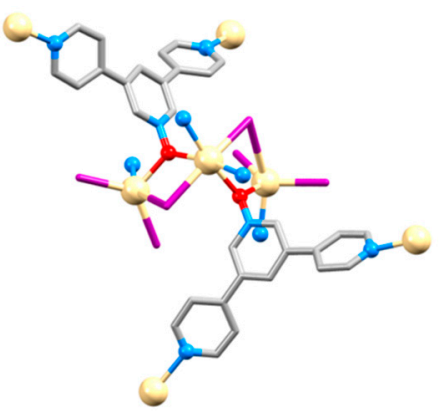

(a)

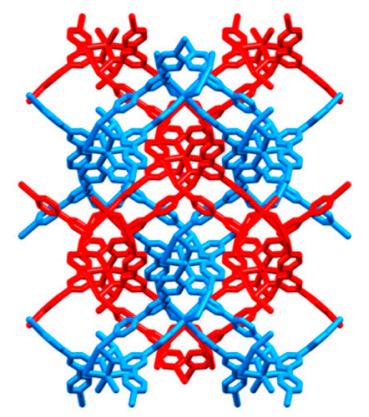

(b)

Figure 46. The structure of $\left[\mathrm{Cd}_{3} \mathrm{I}_{6}(67)_{2}\right]_{n}$ (CSD refcode HATFIU). (a) The building block in the $3 \mathrm{D}$-assembly showing the $\left\{\mathrm{Cd}_{3} \mathrm{I}_{4}(\mu-\mathrm{I})_{2}(\mu-\mathrm{O})_{2} \mathrm{~N}_{4}\right\}$ unit, and (b) part of the 2-fold interpenetrating 3D network view down the crystallographic $a$-axis (terminal I atoms are omitted).

Given the relative rigidity of $4,3^{\prime}: 5^{\prime}, 4^{\prime \prime}$-tpy, and the fact that there is precedent for all three pyridine rings to be involved in coordination [114,115], there is significant scope for further exploration of this ligand in coordination polymer assemblies.

\section{Conclusions}

In this review, we have presented a survey of coordination polymers and networks containing isomers of terpyridine combined with zinc(II) or cadmium(II). Although 48 isomers of terpyridine can be drawn, three dominate the coordination chemistry of $\mathrm{Zn}$ (II) and $\mathrm{Cd}$ (II) in infinite assemblies. These are $2,2^{\prime}: 6^{\prime}, 2^{\prime \prime}$-tpy, $4,2^{\prime}: 6^{\prime}, 4^{\prime \prime}$-tpy, and $3,2^{\prime}: 6^{\prime}, 3^{\prime \prime}$-tpy. A few examples utilizing $4,3^{\prime}: 5^{\prime}, 4^{\prime \prime}$-tpy or its $N^{\prime}$-oxide have also been described. For $2,2^{\prime}: 6^{\prime}, 2^{\prime \prime}$-tpy, the propensity for chelation means that extended assemblies rely on the introduction of substituents that incorporate additional coordination sites. All of the coordination polymers containing $\mathrm{Zn}(\mathrm{II})$ or $\mathrm{Cd}(\mathrm{II})$ with $2,2^{\prime}: 6^{\prime}, 2^{\prime \prime}$-tpy involve $\left\{\mathrm{M}\left(2,2^{\prime}: 6^{\prime}, 2^{\prime \prime}\right.\right.$-tpy $\left.) \mathrm{X}_{n}\right\}$ domains, and there are no examples containing $\left\{\mathrm{M}\left(2,2^{\prime}: 6^{\prime}, 2^{\prime \prime} \text {-tpy }\right)_{2}\right\}$ cores. Both $4,2^{\prime}: 6^{\prime}, 4^{\prime \prime}$-tpy, and $3,2^{\prime}: 6^{\prime}, 3^{\prime \prime}$-tpy can be classed as divergent ligands, and there is a wide range of extended structures incorporating these ligands bound to $\mathrm{Zn}$ (II) or $\mathrm{Cd}$ (II). The addition of functionalities such as carboxylic acid or pyridinyl units has led to a wealth of different networks, but predictive crystal engineering in these systems is difficult. What is clear, however, is that the presence of an anionic carboxylate donor in functionalized $4,2^{\prime}: 6^{\prime}, 4^{\prime \prime}$-tpy and $3,2^{\prime}: 6^{\prime}, 3^{\prime \prime}$-tpy ligands often leads to preferential coordination by the $\mathrm{CO}_{2}{ }^{-}$to $\mathrm{Zn}$ (II) or $\mathrm{Cd}$ (II), with the result that a significant number of assemblies exhibit pendant, non-coordinated pyridine units.

Our focus has been on structural data. Where possible, we have demonstrated the effects of going from $\mathrm{Zn}$ (II) to the larger Cd(II) while retaining the same ligand. However, in trying to make such comparisons, we have noted a significant lack of systematic investigations, and without such studies, it is difficult to even begin to understand why a particular assembly arises from a given combination of metal ion and terpyridine ligand.

We have also highlighted cases where there is structural evidence for the competitive assembly of different products, for example, competition between the formation of a 1Dpolymer and a metallomacrocycle. In these cases, in particular, the need for PXRD analysis of bulk materials is essential but is, often, lacking. Indeed, since coordination polymer chemistry typically involves the growth of single crystals, the selection of one crystal, and a structure determination, bulk sample characterization is essential if one is to be able to say anything about the significance of the singe crystal structure that is presented. 
Supplementary Materials: The following is available online: Figure S1: Structures of the 47 isomers of terpyridine other than $2,2^{\prime}: 6^{\prime}, 2^{\prime \prime}$-tpy.

Author Contributions: E.C.C. and C.E.H. contributed equally to writing of this review. All authors have read and agreed to the published version of the manuscript.

Funding: Research relevant to this review was partially funded by the Swiss National Science Foundation (grant numbers 200020_162631,200020_182000 and 200020_182559).

Data Availability Statement: There are no origibal data available for this review article.

Acknowledgments: We thank the University of Basel for continued support.

Conflicts of Interest: The authors declare no conflict of interest.

\section{References}

1. Constable, E.C. The Coordination Chemistry of $2,2^{\prime}: 6^{\prime}, 2^{\prime \prime}$-terpyridine and Higher Oligopyridines. Adv. Inorg. Chem. 1986, 30, 69-121. [CrossRef]

2. Constable, E.C. 2,2': $6^{\prime}, 2^{\prime \prime}$-terpyridines: From chemical obscurity to common supramolecular motifs. Chem. Soc. Rev. 2007, 36, 246-253. [CrossRef] [PubMed]

3. Schubert, U.S.; Hofmeier, H.; Newkome, G.R. Modern Terpyridine Chemistry; Wiley-VCH Verlag \& Co.: Weinheim, Germany, 2006.

4. Wei, C.; He, Y.; Shi, X.; Song, Z. Terpyridine-metal complexes: Applications in catalysis and supramolecular chemistry. Coord. Chem. Rev. 2019, 385, 1-19. [CrossRef] [PubMed]

5. Constable, E.C.; Housecroft, C.E. More Hydra than Janus-non-classical coordination modes in complexes of oligopyridine ligands. Coord. Chem. Rev. 2017, 350, 84-104. [CrossRef]

6. Kröhnke, F. The Specific Synthesis of Pyridines and Oligopyridines. Synthesis 1976, 1-24. [CrossRef]

7. Wang, J.; Hanan, G.S. A facile route to sterically hindered and non-hindered $4^{\prime}$-aryl-2,2' $: 6^{\prime}, 2^{\prime \prime}$ - terpyridines. Synlett 2005, 1251-1254. [CrossRef]

8. Rocco, D.; Housecroft, C.E.; Constable, E.C. Synthesis of Terpyridines: Simple Reactions-What Could Possibly Go Wrong? Molecules 2019, 24, 1799. [CrossRef]

9. Hannon, M.J.; Painting, C.L.; Errington, W. Self-assembly of supramolecular boxes. Chem. Commun. 1997, 307-308. [CrossRef]

10. Rocco, D.; Prescimone, A.; Constable, E.C.; Housecroft, C.E. Switching the conformation of $3,2^{\prime}: 6^{\prime}, 3^{\prime \prime}-$ tpy domains in $4^{\prime}-(4-n-$ alkyloxyphenyl)-3,2' $: 6^{\prime}, 3^{\prime \prime}$-terpyridines. Molecules 2020, 25, 3162. [CrossRef]

11. Wang, T.-T.; Zhang, J.-L.; Hua, H.-M.; Cheng, Y.; Xue, L.-L.; Wanga, X.; Wang, B.-Z. Syntheses, structures and luminescent properties of $\mathrm{Zn} / \mathrm{Cd}$ coordination polymers based on $4^{\prime}$-(2-carboxyphenyl)-3,2':6', $3^{\prime \prime}$-terpyridine. Polyhedron 2018, 151, 43-50. [CrossRef]

12. Rocco, D.; Prescimone, A.; Constable, E.C.; Housecroft, C.E. Directing 2D-coordination networks: Combined effects of a conformationally flexible $3,2^{\prime}: 6^{\prime}, 3^{\prime \prime}$-terpyridine and chain length variation in $4^{\prime}$-(4-n-alkyloxyphenyl) substituents. Molecules 2020, 25, 1663. [CrossRef] [PubMed]

13. Rocco, D.; Novak, S.; Prescimone, A.; Constable, E.C.; Housecroft, C.E. Manipulating the conformation of $3,2^{\prime}: 6^{\prime}, 3^{\prime \prime}$-terpyridine in $\left[\mathrm{Cu}_{2}(\mu-\mathrm{OAc})_{4}\left(3,2^{\prime}: 6^{\prime}, 3^{\prime \prime} \text {-tpy) }\right]_{n}\right.$ 1D-polymers. Chemistry 2021, 3, 15. [CrossRef]

14. Zhao, M.; Tan, J.; Su, J.; Zhang, J.; Zhang, S.; Wu, J.; Tian, J. Syntheses, crystal structures and third-order nonlinear optical properties of two series of $\mathrm{Zn}(\mathrm{II})$ complexes using the thiophene-based terpyridine ligands. Dyes Pigm. 2016, 130, $216-225$. [CrossRef]

15. Groom, C.R.; Bruno, I.J.; Lightfoot, M.P.; Ward, S.C. The Cambridge Structural Database. Acta Cryst. 2016, B72, 171-179. [CrossRef]

16. Bruno, I.J.; Cole, J.C.; Edgington, P.R.; Kessler, M.; Macrae, C.F.; McCabe, P.; Pearson, J.; Taylor, R. New software for searching the Cambridge Structural Database and visualizing crystal structures. Acta Cryst. 2002, B58, 389-397. [CrossRef]

17. Macrae, C.F.; Sovago, I.; Cottrell, S.J.; Galek, P.T.A.; McCabe, P.; Pidcock, E.; Platings, M.; Shields, G.P.; Stevens, J.S.; Towler, M.; et al. Mercury 4.0: From visualization to analysis, design and prediction. J. Appl. Cryst. 2020, 53, 226-235. [CrossRef]

18. Guo, L.; Li, D.-L. Synthesis, crystal structure and photoluminescence of a one-dimensional zinc(II) coordination polymer with substituted terpyridine. Chin. J. Struct. Chem. 2010, 29, 1098-1102.

19. Momeni, B.Z.; Heydari, S. Design of novel copper(II) and zinc(II) coordination polymers based on the $4^{\prime}$-functionalized terpyridines. Polyhedron 2015, 97, 94-102. [CrossRef]

20. Gou, L.; Wu, Q.-R.; Hu, H.-M.; Qin, T.; Xue, G.-L.; Yang, M.-L.; Tang, Z.-X. An investigation of the positional isomeric effect of terpyridine derivatives: Self-assembly of novel cadmium coordination architectures driven by N-donor covalence and $\pi \ldots \pi$ non-covalent interactions. Polyhedron 2008, 27, 1517-1526. [CrossRef]

21. Gou, L.; Zhang, B.; Hu, H.-M.; Chen, X.-L.; Wang, B.-C.; Wu, Q.-R.; Qin, T.; Tang, Z.-X. Syntheses and characterization of two novel cadmium(II) coordination polymers derived from pyridyl substituted terpyridine and diphenate mixed ligands. J. Mol. Struct. 2008, 889, 244-250. [CrossRef]

22. Wang, Z. CSD Communication 2019 (refcode QIVRAR). [CrossRef]

23. Wang, Z. CSD Communication 2019 (refcode QIVQUK). [CrossRef] 
24. Wang, Z. CSD Communication 2019 (refcode QIVREV). [CrossRef]

25. Wang, Z.; Zhu, C.-Y.; Wei, Z.-W.; Fan, Y.-N.; Pan, M. CSD Communication 2020 (refcode PUCBUN). [CrossRef]

26. Wang, Z.; Zhu, C.-Y.; Wei, Z.-W.; Fan, Y.-N.; Pan, M. Breathing-Ignited Long Persistent Luminescence in a Resilient Metal-Organic Framework. Chem. Mater. 2020, 32, 841-848. [CrossRef]

27. Li, R.; Wang, S.-H.; Liu, Z.-F.; Chen, X.-X.; Xiao, Y.; Zheng, F.-K.; Guo, G.-C. An Azole-Based Metal-Organic Framework toward Direct White-Light Emissions by the Synergism of Ligand-Centered Charge Transfer and Interligand $\pi-\pi$ Interactions. Cryst. Growth Des. 2016, 16, 3969-3975. [CrossRef]

28. Yang, J.; Hu, R.-X.; Zhang, M.-B. Construction of monomers and chains assembled by $3 \mathrm{~d} / 4 \mathrm{f}$ metals and $4^{\prime}$-(4-carboxyphenyl)$2,2^{\prime}: 6^{\prime}, 2^{\prime \prime}$-terpyridine. J. Solid State Chem. 2012, 196, 398-403. [CrossRef]

29. Li, H.-Z.; Wang, F. A zinc(II) coordination polymer based on carboxyphenyl-terpyridine ligand with novel hydrogen-bond topology. Inorg. Chim. Acta 2020, 502, 119351. [CrossRef]

30. Gai, Y.-L.; Jiang, F.-L.; Chen, L.; Bu, Y.; Wu, M.-Y.; Zhou, K.; Pan, J.; Hong, M.-C. A series of novel zinc(II) entangled coordination polymers based on carboxyphenyl-terpyridine ligands. Dalton Trans. 2013, 42, 9954-9965. [CrossRef]

31. Yuan, H. CSD Communication 2020 (refcode NUCBAR). [CrossRef]

32. Xie, J.; Wu, Q.-R.; Hu, H.-M.; Cheng, Y.; Yang, M.-L.; Dong, F.-X.; Xue, G.-L. Synthesis, crystal structure and luminescence of zinc(II) coordination polymers based on a flexible bifunctional terpyridyl carboxylic ligand. Polyhedron 2014, 83, 92-101. [CrossRef]

33. Liang, X.; Jia, Y.; Zhan, Z.; Hu, M. A highly selective multifunctional Zn-coordaintion polymer sensor for detection of Cr(III), Cr(VI) ion, and TNP molecule. Appl. Organometal. Chem. 2019, 33, e4988. [CrossRef]

34. Bai, N.N.; Hou, L.; Gao, R.-C.; Liang, J.-Y.; Yang, F.; Wang, Y.-Y. Five 1D to 3D Z(II)/Mn(II)-CPs based on dicarboxyphenylterpyridine ligand: Stepwise adsorptivity and magnetic properties. CrystEngComm 2017, 19, 4789-4796. [CrossRef]

35. Young, D.C.; Yang, H.; Telfer, S.G.; Kruger, P.E. An Isoreticular Series of Zinc(II) Metal-Organic Frameworks Derived from Terpyridylcarboxylate Ligands. Inorg. Chem. 2017, 56, 12224-12231. [CrossRef] [PubMed]

36. Zhang, J.; Yang, W.; Wu, X.-Y.; Zhang, L.; Lu, C.-Z. Synthesis, Photoluminescence, and Gas Adsorption Properties of a New Furan-Functionalized MOF and Direct Carbonization for Synthesis of Porous Carbon. Cryst. Growth Des. 2016, 16, 475-482. [CrossRef]

37. Wang, W.; Xiao, Z.; Lin, H.; Wang, R.; Zhang, L.; Sun, D. Synthesis, structure, and properties of a 3D porous Zn(II) MOF constructed from a terpyridine-based ligand. RSC Adv. 2016, 6, 16575-16580. [CrossRef]

38. Zhang, S.R.; Wang, W.; Xu, G.-J.; Yao, C.; Xu, Y.H.; Su, Z.-M. A fluorescent sensor for selective, sensitive, and recyclable detection of mercury(II) in aqueous solution based on a zinc(II) coordination polymer. Inorg. Chem. Comm. 2018, 89, 73-77. [CrossRef]

39. Bai, C.; Xu, B.; Hu, H.-M.; Yang, M.-L.; Xue, G. Cadmium(II) coordination polymers constructed from a bis-functionalized ligand $4^{\prime}$-(3-carboxyphenyl)-2,2':6', 2'

40. Tseng, T.-W.; Yang, M.-L.; Luo, T.-T. A key route to designing huge eight-fold interpenetrated coordination networks with ths-type topology: Synthesis, structures, and topological characteristics. J. Solid State Chem. 2015, 221, 345-350. [CrossRef]

41. Wu, Q.-R.; Wang, J.-J.; Hu, H.-M.; Wang, B.-C.; Wu, X.-L.; Fu, F.; Li, D.-S.; Yang, M.-L.; Xue, G.-L. Two novel cadmium(II) coordination polymers based on bis-functionalized ligand $4^{\prime}$-(4-carboxyphenyl)-2,2': $6^{\prime}, 2^{\prime \prime}$-terpyridine. Inorg. Chem.Comm. 2010, 13, 715-719. [CrossRef]

42. Du, Y.; Liu, J.; Shao, C.; Yang, L. Synthesis and characterization of luminescent metal-organic frameworks for the selective recognition of $\mathrm{Cu}^{2+}$ cation and Tryptophan. J. Alloys Compd. 2019, 781, 904-912. [CrossRef]

43. Wei, Y.; Li, Q.; Sa, R.; Wu, K. A white-light-emitting Ln MOF with color properties improved via Eu ${ }^{3+}$ doping: An alternative approach to a rational design for solid-state lighting. Chem. Commun. 2014, 50, 1820-1823. [CrossRef] [PubMed]

44. Barquin, M.; Cancela, J.; González Garmendia, M.J.; Quintanilla, J.; Amador, U. Coordination compounds of $4,2^{\prime}-6^{\prime}, 4^{\prime \prime}-$ terpyridine, $\left[\mathrm{MCl}_{2}\left(4,2^{\prime}-6^{\prime}, 4^{\prime \prime}\right.\right.$-terpyridine)], M = Mn(II), Co(II), Ni(II), Cu(II) or Zn(II). Crystal structure of catena-poly[(dichlorozinc)- $\mu$-(4,2' $6^{\prime}, 4^{\prime \prime}$-terpyridine)]. Polyhedron 1998, 17, 2373-2378. [CrossRef]

45. Housecroft, C.E. $4,2^{\prime}: 6^{\prime}, 4^{\prime \prime}$-Terpyridines: Diverging and diverse building blocks in coordination polymers and metallomacrocycles. Dalton Trans. 2014, 43, 6594-6604. [CrossRef] [PubMed]

46. Hou, L.; Li, D. A new ligand $4^{\prime}$-phenyl-4,2' $: 6^{\prime}, 4^{\prime \prime}$-terpyridine and its $1 \mathrm{D}$ helical zinc(II) coordination polymer: Syntheses, structures and photoluminescent properties. Inorg. Chem. Comm. 2005, 8, 190-193. [CrossRef]

47. Li, X.-Z.; Li, M.; Li, Z.; Hou, J.-Z.; Huang, X.-C.; Li, D. Concomitant and Controllable Chiral/Racemic Polymorphs: From Achirality to Isotactic, Syndiotactic, and Heterotactic Chirality. Angew. Chem. Int. Ed. 2008, 47, 6371-6374. [CrossRef]

48. Yang, P.; Wang, M.-S.; Shen, J.-J.; Li, M.-X.; Wang, Z.-X.; Shao, M.; He, X. Seven novel coordination polymers constructed by rigid 4-(4-carboxyphenyl)-terpyridine ligands: Synthesis, structural diversity, luminescence and magnetic properties. Dalton Trans. 2014, 43, 1460-1470. [CrossRef]

49. Yuan, F.; Wang, X.; Hu, H.-M.; Shen, S.-S.; An, R.; Xue, G.-L. Syntheses, structures and luminescent properties of two new zinc coordination polymers based on $4^{\prime}$-(4-aminephenyl)-4,2':6', $4^{\prime \prime}$-terpyridine. Inorg. Chem. Comm. 2014, 48, 26-29. [CrossRef]

50. Su, J.; Zhang, J.; Tian, X.; Zhao, M.; Song, T.; Yu, J.; Cui, Y.; Qian, G.; Zhong, H.; Luo, L.; et al. A series of multifunctional coordination polymers based on terpyridine and zinc halide: Second-harmonic generation and two-photon absorption properties and intracellular imaging. J. Mater. Chem. B 2017, 5, 5458-5463. [CrossRef] 
51. Cave, G.W.V.; Raston, C.L. Helical Polymeric Network of $\left[\mathrm{ZnCl}_{2}\left(4^{\prime} \text {-aryl-4,2': } 6^{\prime}, 4^{\prime \prime} \text {-terpyridine }\right)\right]_{n}$. J. Supramol. Chem. 2002, 2, 317-319. [CrossRef]

52. Constable, E.C.; Housecroft, C.E.; Prescimone, A.; Vujovic, S.; Zampese, J.A. Environmental control in the assembly of metallomacrocycles and one-dimensional polymers with $4,2^{\prime}: 6^{\prime}: 4^{\prime \prime}$-terpyridine linkers and zinc(II) nodes. CrystEngComm 2014, 16, 8691-8699. [CrossRef]

53. Beves, J.E.; Constable, E.C.; Housecroft, C.E.; Kepert, C.J.; Neuburger, M.; Price, D.J.; Schaffner, S. The conjugate acid of bis $\left\{4^{\prime}{ }^{-}\right.$ (4-pyridyl)-2,2': $6^{\prime}, 2^{\prime \prime}$-terpyridine\}iron(II) as a self-complementary hydrogen-bonded building block. CrystEngComm 2007, 9, 1073-1077. [CrossRef]

54. Constable, E.C.; Zhang, G.; Housecroft, C.E.; Neuburger, M.; Zampese, J.A. Assembling and dissembling zinc-containing coordination polymers of $4^{\prime}$-phenyl-4,2':6 $6^{\prime} 4^{\prime \prime}$-terpyridine. CrystEngComm 2010, 12, 2146-2152. [CrossRef]

55. Constable, E.C.; Housecroft, C.E.; Kopecky, P.; Neuburger, M.; Zampese, J.A.; Zhang, G. Coordination polymers with divergent $4^{\prime}$-tert-butyl-4,2':6',4"'-terpyridine linkers: From aryl-aryl to ball-and-socket packing. CrystEngComm 2012, 14, 446-452. [CrossRef]

56. Xiao, L.; Zhu, L.; Zeng, Q.; Liu, Q.; Zhang, J.; Li, S.; Zhou, H.; Zhang, S.; Wu, J.; Tian, Y. Novel metal-organic hybrid materials constructed by ferrocenyl terpyridine derivatives and $\mathrm{Zn}^{\mathrm{II}} \mathrm{X}_{2}\left(\mathrm{X}=\mathrm{Cl}^{-}, \mathrm{Br}^{-}, \mathrm{I}^{-}, \mathrm{SCN}^{-}\right.$and $\left.\mathrm{CH}_{3} \mathrm{COO}^{-}\right)$. J. Organomet. Chem. 2015, 789-790, 22-28. [CrossRef]

57. Klein, Y.M.; Prescimone, A.; Constable, E.C.; Housecroft, C.E. Coordination behaviour of 1-(4,2': $6^{\prime}, 4^{\prime \prime}$-terpyridin- $4^{\prime}$-yl)ferrocene and 1-(3,2': $6^{\prime}, 3^{\prime \prime}$-terpyridin- $4^{\prime}$-yl)ferrocene: Predictable and unpredictable assembly algorithms. Aust. J. Chem. 2017, 70, 468-477. [CrossRef]

58. Constable, E.C.; Housecroft, C.E.; Neuburger, M.; Schönle, J.; Vujovic, S.; Zampese, J.A. Coordination polymers with 4'-(4(anthracen-9-yl)phenyl)- and $4^{\prime}$-(4-(naphthalen-1-yl)phenyl)-4,2': $6^{\prime}, 4^{\prime \prime}$-terpyridines: Mono-, di and heptazinc(II) nodes. Polyhedron 2013, 62, 260-267. [CrossRef]

59. Constable, E.C.; Zhang, G.; Housecroft, C.E.; Zampese, J.A. Zinc(II) coordination polymers, metallohexacycles and metallocapsules-Do we understand self-assembly in metallosupramolecular chemistry: Algorithms or serendipity? CrystEngComm 2011, 13, 6864-6870. [CrossRef]

60. Constable, E.C.; Zhang, G.; Coronado, E.; Housecroft, C.E.; Neuburger, M. Not just size and shape: Spherically symmetrical d ${ }^{5}$ and $\mathrm{d}^{10}$ metal ions give different coordination nets with $4,2^{\prime}: 6^{\prime}, 4^{\prime \prime}$-terpyridines. CrystEngComm 2010, 12, 2139-2145. [CrossRef]

61. Zhang, G.; Jia, Y.-X.; Chen, W.; Lo, W.-F.; Brathwaite, N.; Golen, J.A.; Rheingold, A.L. Diverse zinc(II) coordination assemblies built on divergent $4,2^{\prime}: 6^{\prime}, 4^{\prime \prime}$-terpyridine derivatives: Syntheses, structures and catalytic properties. RSC Adv. 2015, 5, 15870-15879. [CrossRef]

62. Constable, E.C.; Housecroft, C.E.; Neuburger, M.; Schönle, J.; Vujovic, S.; Zampese, J.A. Molecular recognition between 4'-(4biphenylyl)-4, 2': 6', 4' -terpyridine domains in the assembly of $\mathrm{d} 9$ and $\mathrm{d} 10$ metal ion-containing one-dimensional coordination polymers. Polyhedron 2013, 60, 120-129. [CrossRef]

63. Klein, Y.M.; Constable, E.C.; Housecroft, C.E.; Zampese, J.A.; Crochet, A. Greasy tails switch 1D-coordination $\left[\mathrm{Zn}_{2}(\mathrm{OAc})_{4}\left(4^{\prime}-(4-\right.\right.$ $\left.\mathrm{ROC}_{6} \mathrm{H}_{4}\right)-4,2^{\prime}: 6^{\prime}, 4^{\prime \prime}$-tpy) $]_{n}$ polymers to discrete $\left[\mathrm{Zn}_{2}(\mathrm{OAc})_{4}\left(4^{\prime}-\left(4-\mathrm{ROC}_{6} \mathrm{H}_{4}\right)-4,2^{\prime}: 6^{\prime}, 4^{\prime \prime} \text {-tpy }\right)_{2}\right]$ complexes. CrystEngComm 2014, 16, 9915-9929. [CrossRef]

64. Constable, E.C.; Housecroft, C.E.; Vujovic, S.; Zampese, J.A.; Crochet, A.; Batten, S.R. Do perfluoroarene..arene and C-H ... F interactions make a difference to $4,2^{\prime}: 6^{\prime}, 4^{\prime \prime}$-terpyridine-based coordination polymers? CrystEngComm 2013, 15, 10068-10078. [CrossRef]

65. Köberl, M.; Cokoja, M.; Herrmann, W.A.; Kühn, F.E. From molecules to materials: Molecular paddle-wheel synthons of macromolecules, cage compounds and metal-organic frameworks. Dalton Trans. 2011, 40, 6834-6859. [CrossRef] [PubMed]

66. Yuan, F.; Yuan, C.-M.; Hu, H.-M.; Wang, T.-T.; Zhou, C.-S. Structural diversity of a series of terpyridyl carboxylate coordination polymers: Luminescent sensor and magnetic properties. J. Solid State Chem. 2018, 258, 588-601. [CrossRef]

67. Yuan, F.; Zhu, Q.-E.; Hu, H.-M.; Xie, J.; Xu, B.; Yuan, C.-M.; Yang, M.L.; Dong, F.-X.; Xue, G.-L. Three novel coordination polymers based on bifunctionalized ligand $4^{\prime}$-carboxy-4,2': $6^{\prime}, 4^{\prime \prime}$-terpyridine. Inorg. Chim. Acta 2013, 397, 117-123. [CrossRef]

68. Liu, H.-Y.; Gao, G.-M.; Liu, J.; Wang, H.-Y. Two metal-organic frameworks based on carboxyphenyl-terpyridine ligands: Synthesis, structure and highly luminescent sensing of nitrobenzene. Polyhedron 2018, 152, 11-16. [CrossRef]

69. Yuan, F.; Wang, T.-T.; Hu, H.-M.; Li, C.-T.; Zhou, C.-S.; Wang, X.; Xue, G. Two luminescent d ${ }^{10}$ metal coordination polymers assembled from a semirigid terpyridyl carboxylate ligand with high selective detecting of $\mathrm{Cu}^{2+}, \mathrm{Cr}_{2} \mathrm{O}_{7}{ }^{2-}$ and acetone. J. Solid State Chem. 2017, 251, 79-89. [CrossRef]

70. Yuan, F.; An, R.; Hu, H.-M.; Shen, S.-S.; Wang, X.; Yang, M.-L.; Xue, G. Syntheses, structures and luminescent properties of two new two-fold interpenetrating $2 \mathrm{D}$ coordination polymers based on $4^{\prime}$-(4-carboxyphenyl)-4,2': $6^{\prime}, 4^{\prime \prime}$-terpyridine. Inorg. Chem. Comm. 2015, 56, 1-4. [CrossRef]

71. Zhang, H.-N.; Yuan, F.; Hu, H.-M.; Shen, S.-S.; Xue, G.-L. A 3D Zn(II) coordination polymer with a new semi-rigid tripodal ligand tecton showing 4-connected three-fold interpenetrating diamond network and helical character. Inorg. Chem. Comm. 2013, 34, 51-54. [CrossRef]

72. Xiao, J.; Liu, J.; Gao, X.; Ji, G.; Wang, D.; Liu, Z. A multi-chemosensor based on Zn-MOF: Ratio-dependent color transition detection of $\mathrm{Hg}(\mathrm{II})$ and highly sensitive sensor of Cr(VI). Sens. Actuators B 2018, 269, 164-172. [CrossRef] 
73. Xu, B.; Xie, J.; Hu, H.-M.; Yang, X.-L.; Dong, F.-X.; Yang, M.-L.; Xue, G.-L. Synthesis, Crystal Structure, and Luminescence of Zn/Cd Coordination Polymers with a New Fuctionalized Terpyridyl Carboxylate Ligand. Cryst. Growth Des. 2014, 14, $1629-1641$. [CrossRef]

74. Sheng, L.; Li, Q.; Wang, H.; Feng, L. Two novel Mn(II) and Zn(II) complexes: Crystal structures and anti-prostatic cancer activity. Main Group Chem. 2018, 17, 229-234. [CrossRef]

75. Shi, Y.; Song, T.-Q.; Cao, C.-S.; Zhao, B. CSD Communication 2019 (refcode HOSMEK). [CrossRef]

76. Shi, Y. CSD Communication 2018 (refcode QIDQUS). [CrossRef]

77. Liu, B.; Hou, L.; Wu, W.-P.; Dou, A.-N.; Wang, Y.-Y. Highly selective luminescence sensing for $\mathrm{Cu}^{2+}$ ions and selective $\mathrm{CO}_{2}$ capture in a doubly interpenetrated MOF with Lewis basic pyridyl sites. Dalton Trans. 2015, 44, 4423-4427. [CrossRef] [PubMed]

78. Li, D.-S.; Wu, Y.-P.; Zhao, J.; Zhang, J.; Lu, J.Y. Metal-organic frameworks based upon non-zeotype 4-connected topology. Coord. Chem. Rev. 2014, 261, 1-27. [CrossRef]

79. Wu, Y.; Wu, J.; Luo, Z.; Wang, J.; Li, Y.; Han, Y.; Liu, J. Fluorescence detection of $\mathrm{Mn}^{2+}, \mathrm{Cr}_{2} \mathrm{O}_{7}{ }^{2-}$ and nitroexplosives and photocatalytic degradation of methyl violet and rhodamine B based on two stable metal-organic frameworks. RSC Adv. 2017, 7, 10415-10423. [CrossRef]

80. Wang, B.-C.; Wu, Q.-R.; Hu, H.-M.; Chen, X.-L.; Yang, Z.-H.; Shangguan, Y.-Q.; Yang, M.-L.; Xue, G.-L. Four novel Zn(II)/Cd(II) metal-organic frameworks constructed from $4^{\prime}$-(4-pyridyl)-4, $2^{\prime}: 6^{\prime}, 4^{\prime \prime}$-terpyridine: Hydrothermal synthesis, crystal structures, and luminescent properties. CrystEngComm 2010, 12, 485-492. [CrossRef]

81. Heine, J.; auf der Günne, J.S.; Dehnen, S. Formation of a Strandlike Polycatenane of Icosahedral Cages for Reversible OneDimensional Encapsulation of Guests. J. Am. Chem. Soc. 2011, 133, 10018-10021. [CrossRef]

82. Yang, X.-L.; Shangguan, Y.-Q.; Hun, H.-M.; Xu, B.; Wang, B.-C.; Xie, J.; Yuan, F.; Yang, M.-L.; Dong, F.-X.; Xue, G.-L. Synthesis, crystal structures and luminescent properties of zinc(II) metal-organic frameworks constructed from terpyridyl derivative ligand. J. Solid State Chem. 2014, 216, 13-22. [CrossRef]

83. Klein, Y.M.; Constable, E.C.; Housecroft, C.E.; Zampese, J.A. $4^{\prime}$-(Pyrimidin-5-yl)- and $4^{\prime}$-(2-methylpyrimidin-5-yl)- 4,2' $6^{\prime}, 4^{\prime \prime}$ terpyridines: Selective coordination to zinc(II) through the $4,2^{\prime}: 6^{\prime}, 4^{\prime \prime}$-terpyridine domain. Polyhedron 2014, 81, 98-104. [CrossRef]

84. Granifo, J.; Gavino, R.; Freire, E.; Baggio, R. A novel hybrid terpyridine-pyrimidine ligand and the supramolecular structures of two of its complexes with $\mathrm{Zn}(\mathrm{II})$ and acetylacetonato: The underlying role of non-covalent $\pi \ldots \pi$ contacts and $\mathrm{C}-\mathrm{H} \ldots \mathrm{X}(\mathrm{O}, \mathrm{N}$, $\pi$ ) hydrogen bonds. J. Mol. Struct. 2014, 1063, 102-108. [CrossRef]

85. Granifo, J.; Gavino, R.; Suárez, S.; Baggio, R. Structural characterization of a hybrid terpyridine-pyrazine ligand and its one-dimensional $\mathrm{Zn}$ II coordination polymer: A computational approach to conventional and nonconventional intermolecular interactions. Acta Crystallogr. 2019, 75C, 1299-1309. [CrossRef] [PubMed]

86. Yuan, H. CSD Communication 2020 (refcode NUBZUI). [CrossRef]

87. Constable, E.C.; Zhang, G.; Housecroft, C.E.; Neuburger, M.; Zampese, J.A. Adding the second dimension with cadmium: Two-dimensional sheets assembled from cadmium(II) and $4^{\prime}$-phenyl-4, $2^{\prime}: 6^{\prime}, 4^{\prime \prime}$-terpyridine and locked by $\pi$-stacked interactions CrystEngComm 2009, 11, 2279-2281. [CrossRef]

88. Singh, U.P.; Narang, S.; Pachfule, P.; Banerjee, R. Variation of $\mathrm{CO}_{2}$ adsorption in isostructural $\mathrm{Cd}(\mathrm{II}) / \mathrm{Co}(\mathrm{II})$ based $\mathrm{MOFs}$ by anion modulation. CrystEngComm 2014, 16, 5012-5020. [CrossRef]

89. Klein, Y.M.; Prescimone, A.; Constable, E.C.; Housecroft, C.E. Manipulating connecting nodes through remote alkoxy chain variation in coordination networks with $4^{\prime}$-alkoxy-4,2':6' $4^{\prime \prime}$-terpyridine linkers. CrystEngComm 2015, 17, 6483-6492. [CrossRef]

90. Klein, Y.M.; Constable, E.C.; Housecroft, C.E.; Prescimone, A. Assembling coordination ladders with $4^{\prime}$-(4-methoxyphenyl)$4,2^{\prime}: 6^{\prime}, 4^{\prime \prime}$-terpyridine as rails and rungs. Inorg. Chem. Commun. 2014, 49, 41-43. [CrossRef]

91. Constable, E.C.; Zhang, G.; Housecroft, C.E.; Neuburger, M.; Zampese, J.A. Sheet, ladder or chain? Small substituents in 4' phenyl-4,2': $6^{\prime}, 4^{\prime \prime}$-terpyridines control dimensionality in cadmium(II) coordination polymers. CrystEngComm 2010, 12, 3733-3739. [CrossRef]

92. Yuan, F.; Xie, J.; Hu, H.-M.; Yuan, C.-M.; Xu, B.; Yang, M.-L.; Dong, F.-X.; Xue, G.-L. Effect of pH/metal ion on the structure of metal-organic frameworks based on novel bifunctionalized ligand $4^{\prime}$-carboxy-4, $2^{\prime}: 6^{\prime}, 4^{\prime \prime}$-terpyridine. CrystEngComm 2013, 15, 1460-1467. [CrossRef]

93. Wen, L.; Ke, X.; Qiu, L.; Zou, Y.; Zhou, L.; Zhao, J.; Li, D. Assembly of Two Porous Cadmium(II) Frameworks: Selective Adsorption and Luminescent Property. Cryst. Growth Des. 2012, 12, 4083-4089. [CrossRef]

94. Xiao, J.; Liu, J.; Liu, M.; Ji, G.; Liu, Z. Fabrication of a Luminescence-Silent System Based on a Post- Synthetic Modification Cd-MOFs: A Highly Selective and Sensitive Turn-on Luminescent Probe for Ascorbic Acid Detection. Inorg. Chem. 2019, 58, 6167-6174. [CrossRef]

95. Zhang, L.; Zheng, J.-D.; Chen, Y.-T.; Zheng, S.-R.; Fan, J.; Zhang, W.-G. Syntheses, structures, and properties of nine $d^{10}$ or p-block coordination polymers based on a ligand containing both terpyridyl and sulfo groups. CrystEngComm 2015, 17, 5538-5550. [CrossRef]

96. Shen, S.-S.; Bai, C.; Hu, H.-M.; Yuan, F.; Wang, X.; Xue, G. Syntheses, Structures, and Luminescent Properties of Two Cadmium(II) Coordination Compounds based on a Sulfonate Functionalized Terpyridine Ligand. Z. Anorg. Allg. Chem. 2015, 641, 1772-1776. [CrossRef]

97. Zhang, S.-F.; Li, J. Effect of Anionic Ancillary Ligands on Terpyridine Based Coordination Polymers: Synthesis, Crystal Structure and Fluorescence Property. Chin. J. Struct. Chem. 2016, 35, 811-817. [CrossRef] 
98. Constable, E.C.; Housecroft, C.E.; Vujovic, S.; Zampese, J.A. 2D $\rightarrow 2$ D Parallel interpenetration of $(4,4)$ sheets constructed from a ditopic bis $\left(4,2^{\prime}: 6^{\prime}, 4^{\prime \prime}\right.$-terpyridine). CrystEngComm 2014, 16, 3494-3497. [CrossRef]

99. Vujovic, S.; Constable, E.C.; Housecroft, C.E.; Morris, C.D.; Neuburger, M.; Prescimone, A. Engineering 2D $\rightarrow 2 \mathrm{D}$ parallel interpenetration using long alkoxy-chain substituents. Polyhedron 2015, 92, 77-83. [CrossRef]

100. Klein, Y.M.; Prescimone, A.; Constable, E.C.; Housecroft, C.E. A double-stranded 1D-coordination polymer assembled using the tetravergent ligand 1,1'-bis $\left(4,2^{\prime}: 6^{\prime}, 4^{\prime \prime}\right.$-terpyridin-4'-yl)ferrocene. Inorg. Chem. Commun. 2016, 70, 118-120. [CrossRef]

101. Klein, Y.M.; Prescimone, A.; Neuburger, M.; Constable, E.C.; Housecroft, C.E. What a difference a tail makes: 2D $\rightarrow 2 \mathrm{D}$ parallel interpenetration of sheets to interpenetrated nbo networks using ditopic- $4,2^{\prime}: 6^{\prime}, 4^{\prime \prime}$-terpyridine ligands. CrystEngComm 2017, 19, 2894-2902. [CrossRef]

102. Xiao, L.; Tian, Y. CSD Communication 2015 (refcode VUKMOF). [CrossRef]

103. Tian, Y.; Xiao, L. CSD Communication 2015 (refcode CACXEM). [CrossRef]

104. Xiao, L.; Tian, Y. CSD Communication 2015 (refcode OGOYIU). [CrossRef]

105. Li, N.; Guo, H.-L.; Hu, H.-M.; Song, J.; Xu, B.; Yang, M.-L.; Dong, F.-X.; Xue, G.-L. Hydrothermalsyntheses, crystal structures and luminescence properties of zinc(II) and cadmium(II) coordination polymers based on bifunctional $3,2^{\prime}: 6^{\prime}, 3^{\prime \prime}$-terpyridine- $4^{\prime}$ carboxylic acid. J. Solid State Chem. 2013, 198, 416-423. [CrossRef]

106. Li, N.; Zhu, Q.-E.; Hu, H.-M.; Guo, H.-L.; Xie, J.; Yang, F.; Dong, F.-X.; Yang, M.-L.; Xue, G.-L. Hydrothermal syntheses, crystal structures and luminescence properties of zinc(II) coordination polymers constructed by bifunctional 4 '-(4-carboxyphenyl)$3,2^{\prime}: 6^{\prime}, 3^{\prime \prime}$-terpyridine. Polyhedron 2013, 49, 207-215. [CrossRef]

107. Zhang, J.; Xu, B.; Luo, F.; Tang, G.; Zhang, C. Two 4'-(4-carboxyphenyl)-3,2' $: 6^{\prime}, 3^{\prime \prime}$-terpyridine-based luminescent Zn(II) coordination polymers for detection of 2,4,6-trinitrophenol. Polyhedron 2019, 169, 51-57. [CrossRef]

108. Cheng, Y.; Yang, M.-L.; Hu, H.-M.; Xu, B.; Wang, X.; Xue, G. Syntheses, structures and luminescence for zinc coordination polymers based on a multifunctional $4^{\prime}$-(3-carboxyphenyl)-3, $2^{\prime}: 6^{\prime}, 3^{\prime \prime}$-terpyridine ligand. J. Solid State Chem. 2016, 239, 121-130. [CrossRef]

109. Wang, J.; Lu, L.; Ding, Q.; Zhang, S.-L.; Wang, J.; Singh, A.; Kumar, A.; Ma, A.J. Multi-responsive luminescent 2D Zn (II)-based coordination polymer for detection of trinitrophenol and $\mathrm{Fe}^{3+}$. J. Coord. Chem. 2020, 73, 307-316. [CrossRef]

110. Zhang, L.; Li, C.-J.; He, J.-E.; Chen, Y.-Y.; Zheng, S.-R.; Fan, J.; Zhang, W.-G. Construction of New Coordination Polymers from $4^{\prime}$-(2,4-disulfophenyl)-3,2' $: 6^{\prime}, 3^{\prime \prime}$-terpyridine: Polymorphism, $\mathrm{pH}$-dependent syntheses, structures, and properties. J. Solid State Chem. 2016, 233, 444-454. [CrossRef]

111. Cheng, J.-Y.; Ding, F.-W.; Wang, P.; Zhao, C.-W.; Dong, Y.-B. Synthesis, Structure, and Ligand-Centered Catalytic Properties of M ${ }^{\mathrm{II}}$ Coordination Polymers $\left(\mathrm{M}=\mathrm{Zn}^{\mathrm{II}}, \mathrm{Cd}^{\mathrm{II}}, \mathrm{Hg}^{\mathrm{II}}\right)$ with Open Pyridyl N-Oxide Sites. ChemPlusChem 2016, 81, 743-751. [CrossRef]

112. Xu, B.; Luo, F.; Tang, G.; Zhang, J. A $4^{\prime}$-(4-carboxyphenyl)-3, $2^{\prime}: 6^{\prime}, 3^{\prime \prime}$-terpyridine-based luminescent cadmium(II) coordination polymer for the detection of 2,4,6-trinitrophenol. Acta Crystallogr. 2019, C75, 508-513. [CrossRef] [PubMed]

113. Zhang, C.-L.; Xu, H.; Song, X.-W.; Meng, Y.; Chen, J.-J. Three $\mathrm{d}^{10}$ coordination polymers based on rigid ligands with flexible functional groups: Syntheses, structures and luminescence. Inorg. Chem. Commun. 2017, 84, 229-233. [CrossRef]

114. Thébault, F.; Barnett, S.A.; Blake, A.J.; Wilson, C.; Champness, N.R.; Schröder, M. Control of Copper(I) Iodide Architectures by Ligand Design: Angular versus Linear Bridging Ligands. Inorg. Chem. 2006, 45, 6179-6187. [CrossRef] [PubMed]

115. Kubota, Y.; Biradha, K.; Fujita, M.; Sakamoto, S.; Yamaguchi, K. A Chiral $\mathrm{M}_{6} \mathrm{~L}_{4}$ Cage Complex Assembled from a $D_{2 \mathrm{~h}}-\mathrm{Symmetric}$ Ligand: Self-Assembly, Structure, and Chirality Observation. Bull. Chem. Soc. Jpn. 2002, 75, 559-565. [CrossRef] 